\title{
Infant atopic manifestations : the role of alternative lifestyle choices
}

Citation for published version (APA):

Kummeling, I. (2007). Infant atopic manifestations : the role of alternative lifestyle choices. [Doctoral Thesis, Maastricht University]. Datawyse / Universitaire Pers Maastricht.

https://doi.org/10.26481/dis.20070308ik

Document status and date:

Published: 01/01/2007

DOI:

10.26481/dis.20070308ik

Document Version:

Publisher's PDF, also known as Version of record

\section{Please check the document version of this publication:}

- A submitted manuscript is the version of the article upon submission and before peer-review. There can be important differences between the submitted version and the official published version of record.

People interested in the research are advised to contact the author for the final version of the publication, or visit the DOI to the publisher's website.

- The final author version and the galley proof are versions of the publication after peer review.

- The final published version features the final layout of the paper including the volume, issue and page numbers.

Link to publication

\footnotetext{
General rights rights.

- You may freely distribute the URL identifying the publication in the public portal. please follow below link for the End User Agreement:

www.umlib.nl/taverne-license

Take down policy

If you believe that this document breaches copyright please contact us at:

repository@maastrichtuniversity.nl

providing details and we will investigate your claim.
}

Copyright and moral rights for the publications made accessible in the public portal are retained by the authors and/or other copyright owners and it is a condition of accessing publications that users recognise and abide by the legal requirements associated with these

- Users may download and print one copy of any publication from the public portal for the purpose of private study or research.

- You may not further distribute the material or use it for any profit-making activity or commercial gain

If the publication is distributed under the terms of Article $25 \mathrm{fa}$ of the Dutch Copyright Act, indicated by the "Taverne" license above, 


\section{INFANT ATOPIC MANIFESTATIONS:}

THE ROLE OF ALTERNATIVE LIFESTYLE CHOICES 


\section{INFANT ATOPIC MANIFESTATIONS: THE ROLE OF ALTERNATIVE LIFESTYLE CHOICES}

\section{Ischa Kummeling}

ISBN 10: $90-5278-602-X$

ISBN 13: $978-90-5278-602-5$

Universiteit Pers Maastricht

Lay-out: $\quad$ Yvonne Jaegers \& Ischa Kummeling

Cover illustration: Thamar Bovend'Eerdt \& Ischa Kummeling

Production:

Datawyse

(C) 2007, I. Kummeling

All rights reserved. No part of this thesis may be reproduced or transmitted in any form or by any means, electronic or mechanical, including photocopying, recording or any information storage or retrieval system, without permission in writing from the author, or, when appropriate from the publisher of the publications. 


\title{
INFANT ATOPIC MANIFESTATIONS:
}

\author{
THE ROLE OF ALTERNATIVE LIFESTYLE CHOICES
}

\section{PROEFSCHRIFT}

\author{
ter verkrijging van de graad van doctor \\ aan de Universiteit Maastricht, \\ op gezag van de Rector Magnificus, \\ Prof. mr. G.P.M.F. Mols, \\ volgens het besluit van het College van Decanen, \\ in het openbaar te verdedigen \\ op donderdag 8 maart 2007 om 14.00 uur
}

door

Ischa Kummeling

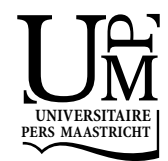


PROMOTOR

Prof. dr. ir. P.A. van den Brandt

CO-PROMOTORES

Dr. C.T.M.C.N. Thijs

Dr. ir. P.C. Dagnelie

\section{BEOORDELINGSCOMMISSIE}

Prof. dr. C.P. van Schayck (voorzitter)

Prof. dr. C.A. Bruggeman

Prof. dr. ir. B. Brunekreef (Universiteit Utrecht)

Prof. P.G.J. Burney (Imperial College London, United Kingdom)

Dr. E. Dompeling

This project was funded by grants from Iona Stichting, Profileringsfonds (azM/UM), Raphael Stichting, Stichting ter Bevordering van de Heilpedagogie, Stichting Phoenix, Stichting Triodos Foundation.

The studies presented in this thesis were conducted at the Department of Epidemiology (Maastricht University), and were embedded in the Care and Public Health Research Institute (CAPHRI) and Nutrition and Toxicology Research Institute Maastricht (NUTRIM). CAPHRI participates in the Netherlands School of Primary Care Research (CaRe). NUTRIM participates in the Graduate School VLAG (Food Technology, Agrobiotechnology, Nutrition and Health Sciences). CaRe and VLAG were accredited by the Royal Netherlands Acedemy of Arts and Sciences (KNAW).

Financial support for the printing of this thesis was kindly provided by Stichting Triodos Foundation and Stichting Phoenix. 
Wat nooit is betwijfeld, is nooit bewezen.

Denis Diderot 



\section{Contents}

CHAPTER 1 General introduction

CHAPTER 2 Etiology of atopy in infancy: the KOALA Birth Cohort Study

CHAPTER 3 Do parents with an atopic family history adopt a 'prudent' lifestyle for their infant?

CHAPTER 4 House dust endotoxin in the homes of families with an anthroposophic lifestyle

CHAPTER 5 DPPT-Hib vaccinations and risk of eczema and recurrent wheeze in the first year of life

CHAPTER 6 Early life exposure to antibiotics and the subsequent development of eczema, wheeze and atopic sensitisation in the first two years of life

CHAPTER 7 Consumption of organic foods and risk of atopic disease in the first two years of life

CHAPTER 8 General discussion

Summary

Samenvatting (Summary in Dutch)

Dankwoord (Acknowledgements in Dutch)

About the author (De auteur) 



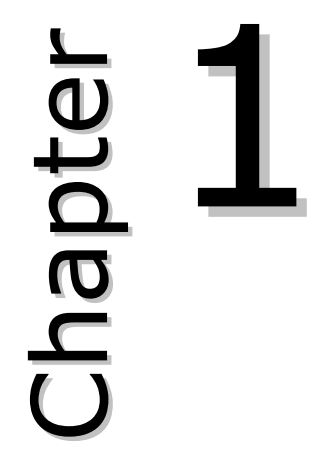

General introduction 


\section{Background}

Eczema, food allergy, hay fever (and other airway allergies) and asthma are collectively known as 'atopic diseases', disorders associated with dysfunction of the immune system and featured by chronic or intermittent inflammation in organs such as the skin, nose and lungs. A largely unexplained increase in the prevalence of these diseases was noted from the early 1970s, prominently in industrialised countries and especially in children (1). Recently, it seems that a plateau phase has been reached in some countries $(2,3)$. Currently, atopy is present in about $40 \%$ of the westernised world's population, constituting a large burden both from personal, health care and economic perspectives.

The present thesis describes results from the KOALA Birth Cohort Study, the Netherlands. This prospective study among 2834 families started in October 2000. A detailed description of the study design will be presented in Chapter 2 . The aim of the investigation described in this thesis is to identify factors that influence the clinical expression of atopic disease with a main focus on alternative lifestyle choices.

\section{NOMENCLATURE AND DISEASE DEFINITION}

The nomenclature of atopic diseases remains confusing. Atopy was first introduced as a term in the beginning of the previous century to describe respiratory hyper-responsiveness, and a few decades later eczema was added to the group of atopic disorders. Nomenclature has been a source of debate ever since. For example, terms like 'atopic dermatitis', '(intrinsic/extrinsic) atopic eczema', 'allergic eczema/dermatitis syndrome (AEDS)' or 'eczema' are being used more or less interchangeably. To address this important topic and to ensure clear communication between health professionals, the World Allergy Organisation (WAO) recommends the adoption of a global nomenclature. 'Atopy' is defined as 'a personal and/or familial tendency, usually in childhood or adolescence, to become sensitised and produce Immunoglobulin $\mathrm{E}$ (IgE) antibodies in response to ordinary exposures to allergens, usually proteins' (4). The Committee suggested that the term atopy should be reserved as a clinical definition to describe the genetic predisposition to become sensitised to allergens.

In the present thesis, three outcomes will be addressed: eczema (a chronic inflammatory pruritic skin disease), wheeze (whistling sound produced in the respiratory airways during breathing) and atopic sensitisation (increased specific IgE) to common environmental allergens), which will be referred to as atopic manifestations, an umbrella term for the wide variety of symptoms that are associated with atopy. Eczema and wheeze were measured in infants during the first two years of life, an age group in which skin and respiratory manifestations are difficult to diagnose. Therefore we used a symptom (manifestation)-based approach. In accordance with the World Allergy Organisation's proposed terminology, we refer to 'eczema' or 'wheeze' (without 'atopic') independent of atopic sensitisation. Eczema, wheeze and atopic sensitisation are all widely prevalent $(>10 \%)$ and often coincide without being causally related. We acknowledge that the term 'eczema' is imprecise and may include types such as seborrheic dermatitis or contact dermatitis, as recently pointed out by Simpson and Hanifin (5). Also wheeze, a main symptom of asthma (a chronic inflammatory 
disorder of the airways characterised by an obstruction of airflow) can be associated with other causes of airway obstruction, especially at young age. Of note, when we cite other authors in this thesis, we will use the terminology chosen in their paper even if this deviates from ours.

\section{OUTCOMES USED IN THE PRESENT THESIS}

\section{Eczema}

Eczema is a chronic inflammatory pruritic skin disease and is the most common atopic manifestation in infancy. The timeframe of onset of atopic disease in affected individuals is as follows: in $45 \%$ the onset of eczema has occurred during the first 6 months of life, in $60 \%$ during the first year of life, and in at least $85 \%$ before the age of 5 years (6), however the disease disappears around age 3 years in a large proportion of children (7). Longitudinal studies reveal that eczema is a risk factor for the future development of asthma or allergic rhinitis (hay fever) (7-9). Eczema has been viewed as the entry point of the 'atopic march': the natural course of atopic disease that gradually evolves from eczema with or without food allergy in the first 3-4 years of life, to asthma ( $>6$ years) and allergic rhinitis (>15 years) (10). This concept, however, has recently been challenged by findings indicating that early wheeze was a significant predictor for wheezing at school age, irrespective of early eczema (7). Early eczema without this cofactor did not confer any increased risk of subsequent asthma. These findings are interesting, but need to be confirmed in other studies.

The proportion of infants with atopic sensitisation at age 2 years and parental reported eczema and recurrent wheeze during the first 2 years of life in the KOALA Birth Cohort Study is shown in Figure 1. Although the disease phenotype called eczema has been thought of as principally an atopic disease since its association with atopic sensitisation, this figure shows that far from all children with parental reported eczema have raised specific IgE-levels. It is wellknown that a subgroup of patients suffers from a skin disease with features that clinically resemble the skin lesions and distribution pattern of atopic eczema without being sensitised $(11,12)$. This has led to a continuing controversy as to whether atopic sensitisation is a causative factor of childhood eczema $(11,13)$. Several theories have been proposed to explain why not all infants with eczema are sensitised. First, there may exist two different variants of eczema, a nonatopic form and an atopic form (14). Second, atopic sensitisation may as well be a predictor (or even an epiphenomenon) of disease activity, since sensitised infants more often have severe eczema compared to non-sensitised infants (11). Also, sensitisation may be a consequence of eczema rather than a cause, since the dry skin and damaged skin barrier may act as an important route of antigen sensitisation $(5,12)$. It should, however, also be noted that the number of allergens tested for, and also how often and at what age(s) measurements are performed, will have a direct effect on the proportion of infants with eczema which are considered as being sensitised. This is especially important with regard to sensitisation to food allergens, which in contrast to aero-allergens is often transient (11). In the present thesis, eczema and atopic sensitisation will addressed as two separate outcomes. 


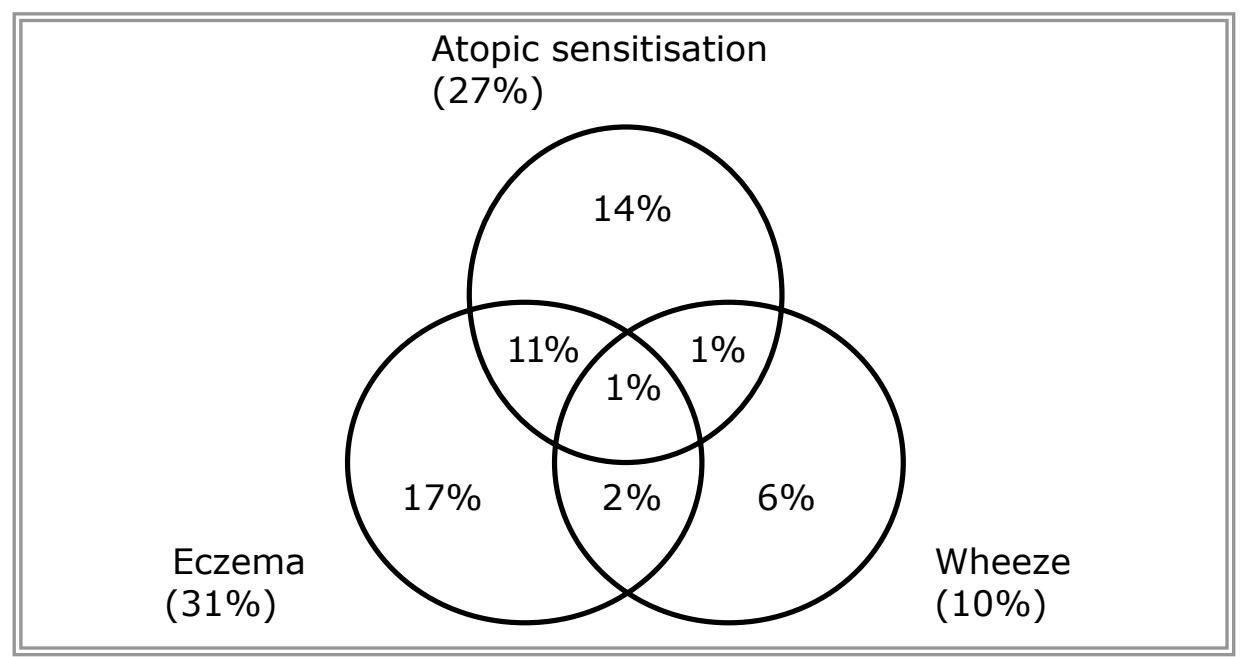

Figure I

Venn diagram showing the proportion of infants with atopic sensitisation at age $\mathbf{2}$ years (specific serum IgE to hen's egg, cow's milk, peanut, birch, grass pollen, cat, dog and/or house dust mite), parental reported eczema or wheeze during the first 2 years of life or any combination of the three conditions in the KOALA study. Subset areas presented above are not proportional to the actual relative subset size.

\section{Early wheeze}

A wheeze is a continuous, coarse, whistling sound produced in the respiratory airways during breathing. Since hay fever and asthma usually occur in later childhood, early wheeze is often used as an indicator of atopic airway disease in young infants $(15,16)$. Wheezing is a relatively common symptom in infancy and affects $25-60 \%$ of infants in the first few years of life. However, not all wheezing bronchitis is or will become asthma and wheezing illness in young children represents a heterogeneous group of conditions (17). Despite the heterogeneity in the definition of wheezing, follow-up studies indicate that wheezing in infancy is an important risk factor for asthma later in life. Of children who wheezed in the first 3 years of life $40 \%$ also wheezed at age 6 , compared to $22 \%$ of the children who did not wheeze (18). Infants with wheezing lower respiratory disease in infancy are four to five times more likely to have recurrent wheezing at age 11 (19). The causal relationship of atopy to wheezing in infancy is unclear at present (20) and Figure I shows that far from all children with parental reported wheeze have raised specific IgE-levels. Recently, infant wheeze was suggested to be less useful as an indicator of the atopic phenotype since only a weak association was found between wheeze and atopic eczema and a different etiology was suggested for wheeze and atopic dermatitis (21). These findings need to be confirmed by other studies. In the present thesis, wheeze and atopic sensitisation will be addressed as two separate outcomes. 


\section{Atopic sensitisation}

Atopic sensitisation in children below the age of 4 occurs predominantly against foods. By the age of 2 to 4 years, most children outgrow common food allergies such as to cow's milk and hen's egg (22). After 6 years of age atopic sensitisation to inhalant allergens such as house dust mite and pollen is more frequently diagnosed than food sensitisation (23). Sensitisation was reported to be strongly associated with eczema, rhinitis and asthma at age four years as well as with adult asthma $(22,24)$.

\section{PATHOGENESIS AND ETIOLOGY OF ATOPIC DISEASE}

Atopy is characterised by 'exaggerated' immune responses to low doses of harmless antigens, usually innocuous proteins. The adaptive immune responses responsible for clinical symptoms are driven by pro-inflammatory cytokines produced by T-lymphocytes. The immune system at birth is strongly T-helper cell2 (Th2) polarised and relatively immature compared to that of adults. Early life environmental influences act on the innate immune system, which has the ability to integrate information and provide a response that is important for normal postnatal maturation of adaptive immune functions. By the age of 5-6 years, the majority of foetally primed Th2-responses against food and inhalant allergens are supplanted by emerging Th1-like responses (25). Allergy is believed to be caused by failure of proper development of natural mechanisms that counterbalance overactive Th2 cells. Broadly stated, this failure is currently thought to be caused by the imbalance of a strong anti-inflammatory regulatory network including regulatory $T$ (Treg) cells (26). Over-expression of Th2 cytokines induces $B$ lymphocytes to produce IgE-antibodies. This leads to IgE-mediated mast cell degranulation and eosinophil-dominated inflammation, resulting in chronic inflammation with tissue damage.

The underlying mechanisms and causes of atopic disease are thought to be manifold. Although genetic predisposition is a fundamental factor in the susceptibility to the disease, the rate of change in its prevalence has been too rapid to be explained by genetic factors, thus environmental and lifestyle changes are considered responsible. Several hypotheses have been put forward to explain the underlying mechanism of the increasing prevalence of atopic diseases. The first, so-called 'hygiene hypothesis' postulates that atopic diseases have increased as a result of reduction in exposure to bacterial and viral pathogens during early childhood. As a consequence, an insufficient stimulation of the infant immune system results in a poorly developed tolerance against potential allergens. The hygiene hypothesis has originated from the epidemiological observation that the risk of hay fever and atopic sensitisation decreases with an increasing number of siblings (27) and with daycare attendance early in life (28, 29). This led to extensive investigations of the relationship between prevalence of atopic disease and measures of infection and microbial exposure (Box I, reviewed by Bloomfield et al. (30)). Second, the 'microflora hypothesis' proposes that perturbations in the gastrointestinal microflora due to increased antibiotic use and dietary differences in 'industrialised' countries have disrupted the normal microbiota-mediated mechanisms of immunological tolerance in the mucosa (31). 


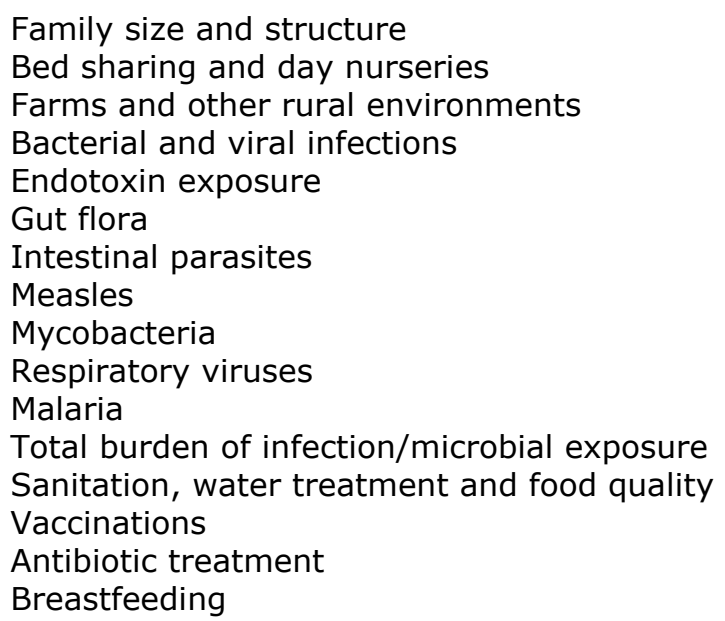

\section{Box I}

Factors potentially related to the development of atopic disease, recently reviewed by Bloomfield et al. (30).

A third explanation for the increase in the prevalence of atopy is given by the 'dietary hypothesis'. Differences between industrialised vs. developing countries have been noted as well as changes in diet, such as increased intake of omega- 6 poly-unsaturated fatty acids (such as linoleid acid from vegetable margarines) and decreased intake of omega-3 fatty acids (such as alpha-linolenic acid from green vegetables and fish oils from fatty fish) (32).

\section{ALTERNATIVE LIFESTYLE CHOICES}

In 1999, Alm et al. published a paper describing that an anthroposophic lifestyle protected against atopic disease in 7-8 year old children (33). Anthroposophy is a human oriented spiritual philosophy grounded by Rudolf Steiner with specific theories and practices on health, education, art, architecture, and 'bio-dynamic' agriculture. Due to the cross-sectional design of the study, specific protective factors could not be identified. Potentially beneficial factors of an anthroposophic lifestyle in relation to atopic disease are reduced antibiotic use and vaccinations, and consumption of organically produced food (food or agricultural production certified as 'organic' is a system that excludes the use of synthetic inputs, such as synthetic fertilizers and pesticides, preventive veterinary drugs, genetically modified seeds and breeds, most preservatives, additives and irradiation). An anthroposophic lifestyle pattern partly reflects the traditional lifestyle of western societies several decades ago when the prevalence of atopy was lower than today, but main characteristics may differ between countries. The study of Alm et al. was one important reason for prospectively investigating the role of alternative lifestyle choices in the development of atopic disease. 


\section{A family history of atopic manifestatations}

Atopic parents may adopt lifestyle characteristics that allegedly protect against atopic disease. If this is true, infants from atopic parents will be characterised by low-risk behaviour. Consequently, etiologic studies on lifestyle factors and atopic disease in childhood may be biased by confounding-byindication. We explored whether parents with a family history of atopic manifestations adopt a 'prudent' lifestyle relative to parents of non-atopic families. We specifically addressed the issue of differential effects of atopic complaints in parents vs. siblings on lifestyle practices, which to our knowledge has not been reported in atopy studies to date (Chapter 3 ).

\section{House dust}

Children growing up on a farm were reported to be at decreased risk of developing atopic disease (34-40). This might be explained by the higher microbial exposure, especially to bacterial endotoxin (commonly present in normal indoor environments as a constituent of house dust) (38). It has been shown that environmental exposure to endotoxin during infancy protects against development of atopy $(41,42)$. Little is known about the endotoxin exposure in the homes of anthroposophic families. During the home visits conducted in our study, we got the impression that the homes of many anthroposophic families were less clean that the homes of conventional families. Therefore, we decided to investigate whether we could confirm this subjective observation by objective, quantitative data by determining whether dust and thus endotoxin levels in the homes of both types of families were different (Chapter 4).

\section{Vaccinations}

Two mechanisms have been proposed by which vaccinations could affect the development of atopic disease: they may either have direct allergy-inducing immune effects, or prevent possible protective effects of natural infections (43, 44). Epidemiological evidence for an association between vaccinations and atopy development is inconsistent (44-66) at present. In the Netherlands, a minority of parents opts for deviating from the standard vaccination schedule. We investigated if infants without vaccinations or with incomplete vaccination schedules differed in eczema risk compared to infants that were standard vaccinated (Chapter 5).

\section{Antibiotics}

The increased prevalence of atopy in developed countries closely followed time trends in increased use of antibiotics among young children. Antibiotics particularly interfere with the bacterial commensal flora and disturb the intestinal microbiota composition (67-69). Consequently, antibiotic exposure in early life may be associated with atopic disease development either by interfering with bacterial commensal flora or by modifying the course of bacterial infections. Indeed positive associations between antibiotic use and childhood allergy and asthma has been reported (70-77). The majority of these results came from cross-sectional studies and in many $(70,71,73-75,77)$, the question of 'reverse causation' remained unresolved: Did antibiotic intake precede symptoms or were antibiotics prescribed in response to symptoms of wheezy bronchitis (an obstructive pulmonary disorder characterised by inflammation of the bronchi of 
the lungs)? In the present study we investigated whether infants with and without antibiotic use in the first six months differed in risk of atopic manifestations in the first 2 years of life. Likewise, we investigated whether infants of mothers with and without antibiotic use during lactation differed in risk of atopic manifestations in the first 2 years of life (Chapter 6).

\section{Organic food}

A rapidly growing group of consumers in our society prefers to buy organically grown and processed products, which are perceived as healthier and safer (78-80). However, there are few studies that have evaluated effects of organic vs. conventionally grown foods on human health (81). We investigated whether early life organic food consumption is protective against the development of atopic manifestations in the first two years of life (Chapter 7).

\section{AIM OF THE THESIS}

The aim of this thesis is to evaluate the role of alternative lifestyle choices in the development of infant atopic manifestations. This was performed in a prospective manner in the KOALA Birth Cohort Study. The rationale for focusing on risk factors and atopic manifestations in early life in the KOALA study was based on the fact that the immature immune system in young children is widely viewed as a 'window of opportunity', a period during the first years of life in which an enhanced risk of atopic sensitisation exists, leading to the development of atopic disease in childhood (82). The importance of studying these questions in a prospective cohort study relates to 'reverse causation': to determine whether an association is causal, one of the prerequisites it that the time relationship between cause and effect are clear. 


\section{References}

1. Magnus $\mathrm{P}$, Jaakkola JJ. Secular trend in the occurrence of asthma among children and young adults: critical appraisal of repeated cross sectional surveys. BMJ. 1997;314:1795-1799.

2. Ronchetti R, Villa MP, Barreto $M$, et al. Is the increase in childhood asthma coming to an end? Findings from three surveys of schoolchildren in Rome, Italy. Eur Respir J. 2001;17:881-6.

3. Zollner IK, Weiland SK, Piechotowski I, et al. No increase in the prevalence of asthma, allergies, and atopic sensitisation among children in Germany: 1992-2001. Thorax. 2005;60:545-8.

4. Johansson SGO, Bieber T, Dahl R, et al. Revised nomenclature for allergy for global use: report of the nomenclature review committee of the World Allergy Organization, October 2003. J Allergy Clin Immunol. 2004;113:832-6.

5. $\quad$ Simpson EL, Hanifin JM. Atopic dermatitis. Med Clin N Am. 2006;90:149-167.

6. Kay J, Gawkrodger DJ, Mortimer MJ, et al. The prevalence of childhood atopic eczema in a general population. J Am Acad Dermatol. 1994;30:35-9.

7. Illi S, von Mutius $E$, Lau S, et al. The natural course of atopic dermatitis from birth to age 7 years and the association with asthma. J Allergy Clin Immunol. 2004;113: 925-31.

8. Bergmann RL, Edenharter G, Bergmann KE, et al. Atopic dermatitis in early infancy perdicts allergic airway disease at 5 years. Clin Exp Allergy. 1998;28:965-70.

9. Gustafsson D, Sjoberg O, Foucard T. Development of allergies and asthma in infants and young children with atopic dermatitis-a prospective follow-up to 7 years of age. Allergy. 2000;55:240-5.

10. Wahn U. What drives the atopic march? Allergy. 2000;55: 591-9.

11. Flohr C, Johansson SGO, Wahlgren CF, et al. How atopic is atopic dermatitis? J Allergy Clin Immunol. 2004;114:150-8.

12. Schmid Gendelmeier, Simon D, Simon HU, et al. Epidemiology, clinical features, and immunology of the "intrinsic" (non-IgE-mediated) type of atopic dermatitis (constitutional dermatitis). Allergy. 2001;56:841-9.

13. Williams $\mathrm{H}$, Flohr $\mathrm{C}$. How epidemiology has challenged 3 prevailing concepts about atopic dermatitis. J Allergy Clin Immunol. 2006;118: 209-13.

14. Kusel MM, Holt PG, de Klerk N, et al. Support for 2 variants of eczema. J Allergy Clin Immunol. 2005;116:1067-72.

15. Koopman LP, Brunekreef B, de Jongste JC. Definition of respiratory symptoms and disease in early childhood in large prospective birth cohort studies that predict the development of asthma. Pediatr Allergy Immunol. 2001;12:118-124.

16. Hagendorens $\mathrm{MM}$, Bridts $\mathrm{CH}$, Lauwers $\mathrm{K}$, et al. Perinatal risk factors for sensitisation, atopic dermatitis and wheezing during the first year of life (PIPO study). Clin Exp Allergy. 2005;35:733-40.

17. Henderson J, North K, Griffiths M, et al. Pertussis vaccination and wheezing illnesses in young children: prospective cohort study. The Longitudinal Study of Pregnancy and Childhood Team. BMJ. 1999;318:1173-6.

18. Martinez FD, Wright AL, Taussig LM, et al. Asthma and wheezing in the first six years of life. N Engl J Med. 1995;332:133-8.

19. Martinez FD. Recognizing early asthma [in process citation]. Allergy. 1999;54:24-8.

20. Sicherer SH, Leung DYM. Advances in allergic skin disease, anaphylaxis, and hypersensitivity reactions to foods, drugs, and insects. J Allergy Clin Immunol. 2005; 116:153-63.

21. Linneberg A, Simonsen JB, Petersen J, et al. Differential effects of risk factors on infant wheeze and atopic dermatitis emphasize a different etiology. J Allergy Clin Immunol. 2006;117:184-9. 
22. Arshad AH, Tariq SM, Matthews S, et al. Sensitisation to common allergens and its association with allergic disorders at age 4 years: a whole population birth cohort study. Pediatrics. 2001;108:33-40.

23. Sigurs N, Hattevig G, Kjellman B, et al. Appearance of atopic disease in relation to serum IgE antibodies in children followed up from birth for 4 to 15 years. $J$ Allergy Clin Immunol. 1994; $94: 757-63$.

24. Rodes HL, Thomas $\mathrm{P}$, Sporik R, et al. Early life risk factors for adult asthma: a birth cohort study of subjects at risk. J Allergy Clin Immunol. 2001;108:720-5.

25. Holt PG. Key factors in the development of asthma: atopy. Am J Respir Crit Care Med. 2000;616: S172-5.

26. Yazdanbakhsh M, Kremsner PG, van Ree R. Allergy, parasites, and the hygiene hypothesis. Science. 2002;296: 490-4.

27. Strachan DP, Harkins LS, Golding J. Sibship size and self-reported inhalant allergy among adult women. ALSPAC Study Team. Clin Exp Allergy. 1997;27:151-5.

28. Kramer $U$, Heinrich J, Wjst M, et al. Age of entry to day nursery and allergy in later childhood. Lancet. 1999;353: 450-4.

29. Ball TM, Castro-Rodriguez JA, Griffith KA, et al. Siblings, Day-Care Attendance, and the Risk of Asthma and Wheezing during Childhood. New Engl J Med. 2000; 343:538-43.

30. Bloomfield SF, Stanwell-Smith R, Crevel RWR, et al. Too clean, or not too clean: the hygiene hypothesis and home hygiene. Clin Exp Allergy. 2006;36:402-25.

31. Noverr MC, Huffnagle GB. The 'microflora hypothesis' of allergic diseases. Clin Exp Allergy. 2005;35:1511-20.

32. Black PN, Sharpe S. Dietary fat and asthma: is there a connection? Eur Respir J. 1997;10:6-12.

33. Alm JS, Swartz J, Lilja G, et al. Atopy in children of families with an anthroposophic lifestyle. Lancet. 1999;353:1485-8.

34. Braun Fahrlander C, Gassner M, Grize L, et al. Prevalence of hay fever and allergic sensitisation in farmer's children and their peers living in the same rural community. SCARPOL team. Swiss Study on Childhood Allergy and Respiratory Symptoms with Respect to Air Pollution. Clin Exp Allergy. 1999;29:28-34.

35. Klintberg B, Berglund N, Lilja G, et al. Fewer allergic respiratory disorders among farmers' children in a closed birth cohort from Sweden. Eur Respir J. 2001;17:1151-7.

36. Alfven T, Braun-Fahrlander C, Brunekreef B, et al. Allergic diseases and atopic sensitisation in children related to farming and anthroposophic lifestyle - the PARSIFAL study. Allergy. 2006;61:414-21.

37. Ernst $\mathrm{P}$, Cormier $\mathrm{Y}$. Relative scarcity of asthma and atopy among rural adolescents raised on a farm. Am J Respir Crit Care Med. 2000;161:1563-6.

38. Riedler J, Braun Fahrlander C, Eder W, et al. Exposure to farming in early life and development of asthma and allergy: a cross-sectional survey. Lancet. 2001:358; 1129-33.

39. Von Ehrenstein OS, von Mutius E, Illi S, et al. Reduced risk of hay fever and asthma among children of farmers. Clin Exp Allergy. 2000;30:187-93.

40. Portegen L, Sigsgaard T, Omland O, et al. Low prevalence of atopy in young Danish farmers and farming students born and raised on a farm. Clin Exp Allergy. 2002;32:247-53.

41. Gehring U, Bischof W, Fahlbusch B, et al. House dust endotoxin and allergic sensitisation in children. Am J Respir Crit Care Med. 2002;166:939-44.

42. Gereda JE, Leung DY, Thatayatikom A, et al. Relation between house-dust endotoxin exposure, type $1 \mathrm{~T}$-cell development, and allergen sensitisation in infants at high risk of asthma. Lancet. 2000;355:1680-83.

43. Aaby $\mathrm{P}$, Shaheen SO, Heyes CB, et al. Early BCG vaccination and reduction in atopy in Guinea-Bissau. Clin Exp Allergy. 2000;30:644-50. 
44. Anderson HR, Poloniecki JD, Strachan DP, et al. Immunization and symptoms of atopic disease in children: results from the International Study of Asthma and Allergies in Childhood. Am J Public Health. 2001;91:1126-9.

45. Floistrup $\mathrm{H}$, Swartz J, Bergstrom A, et al. Allergic disease and sensitisation in Steiner school children. J Allergy Clin Immunol. 2006;117:59-66.

46. Odent M, Culpin E. Effect of immunisation status on asthma prevalence. Lancet. 2003;361:434.

47. Odent MR, Culpin EE, Kimmel T. Pertussis vaccination and asthma: is there a link? JAMA. $1994 ; 272: 592-3$.

48. Kemp $\mathrm{T}$, Pearce $\mathrm{N}$, Fitzharris $\mathrm{P}$, et al. Is infant immunization a risk factor for childhood asthma or allergy? Epidemiology. 1997;8:678-80.

49. Farooqi IS, Hopkin JM. Early childhood infection and atopic disorder. Thorax. 1998;53:927-32.

50. Nilsson L, Kjellman NI, Bjorksten B. A randomized controlled trial of the effect of pertussis vaccines on atopic disease. Arch Pediatr Adolesc Med. 1998;152:734-8.

51. Nilsson L, Kjellman NI, Bjorksten B. Allergic disease at the age of 7 years after pertussis vaccination in infancy: results from the follow-up of a randomized controlled trial of 3 vaccines. Arch Pediatr Adolesc Med. 2003;157:1184-9.

52. Henderson J, North K, Griffiths M, et al. Pertussis vaccination and wheezing illnesses in young children: prospective cohort study. BMJ. 1999;318:1173-6.

53. Hurwitz EL, Morgenstern H. Effects of diphtheria-tetanus-pertussis or tetanus vaccination on allergies and allergy-related respiratory symptoms among children and adolescents in the United States. J Manipulative Physiol Ther. 2000;23:81-90.

54. DeStefano F, Gu D, Kramarz P, et al. Childhood vaccinations and risk of asthma. Pediatr Infect Dis J. 2002;21:498-504.

55. Enriquez R, Addington W, Davis F, et al. The relationship between vaccine refusal and self-report of atopic disease in children. J Allergy Clin Immunol. 2005;115:73744.

56. McKeever TM, Lewis SA, Smith C, et al. Vaccination and allergic disease: a birth cohort study. Am J Public Health. 2004;94:985-9.

57. Bernsen RM, de Jongste JC, van der Wouden JC. Lower risk of atopic disorders in whole cell pertussis-vaccinated children. Eur Respir J. 2003;22:962-4.

58. Gruber C, Nilsson L, Bjorksten B. Do early childhood immunizations influence the development of atopy and do they cause allergic reactions? Pediatr Allergy Immunol. 2001;12:296-311.

59. Koppen S, De Groot R, Neijens HJ, et al. No epidemiological evidence for infant vaccinations to cause allergic disease. Vaccine. 2004;22:3375-85.

60. Rottem M, Shoenfeld Y. Vaccination and allergy. Curr Opin Otolaryngol Head Neck Surg. 2004;12:223-31.

61. Maher JE, Mullooly JP, Drew L, et al. Infant vaccinations and childhood asthma among full-term infants. Pharmacoepidemiol Drug Safety. 2004;13:1-9.

62. Mullooly JP, Pearson J, Drew L, et al. Wheezing lower respiratory disease and vaccination of full-term infants. Pharmacoepidemiol Drug Safety. 2002;11:21-30.

63. Gruber C, Illi S, Lau S, et al. Transient suppression of atopy in early childhood is associated with high vaccination coverage. Pediatrics. 2003;111:282-8.

64. Maitra A, Sherriff A, Griffiths $M$, et al. Pertussis vaccination in infancy and asthma or allergy in later childhood: birth cohort study. BMJ. 2004;328:925-6.

65. Bremner SA, Carey IM, DeWilde S, et al. Timing of routine immunisations and subsequent hay fever risk. Arch Dis Child. 2005;90:567-73

66. Mommers M, Weishoff Houben M, Swaen GM, et al. Infant immunization and the occurrence of atopic disease in Dutch and German children: a nested case-control study. Pediatr Pulmonol. 2004;38:329-34.

67. Levy $J$. The effects of antibiotic use on gastrointestinal function. $A m \quad J$ Gastroenterol. 2000;95:S8-10. 
68. Brismar B, Edlund C, Nord CE. Impact of cefpodoxime proxetil and amoxicillin on the normal oral and intestinal microflora. Eur $J$ Clin Microbiol Infect Dis. $1993 ; 12: 714-9$.

69. Bjorksten B, Naaber P, Sepp E, et al. The intestinal microflora in allergic Estonian and Swedish 2-year-old children. Clin Exp Allergy. 1999;29:342-6.

70. Floistrup $\mathrm{H}$, Swartz J, Bergstrom A, et al. Allergic disease and sensitisation in Steiner school children. J Allergy Clin Immunol. 2006;117:59-66.

71. Wjst M, Hoelscher B, Frye C, et al. Early antibiotic treatment and later asthma. Eur J Med Res. 2001;6:263-71.

72. Droste $\mathrm{JH}$, Wieringa $\mathrm{MH}$, Weyler $\mathrm{JJ}$, et al. Does the use of antibiotics in early childhood increase the risk of asthma and allergic disease? Clin Exp Allergy. 2000;30:1547-53.

73. von Mutius E, Illi S, Hirsch T, et al. Frequency of infections and risk of asthma, atopy and airway hyperresponsiveness in children. Eur Respir J. 1999;14:4-11.

74. Wickens $\mathrm{K}$, Pearce N, Crane J, et al. Antibiotic use in early childhood and the development of asthma. Clin Exp Allergy. 1999;29:766-71.

75. Alm JS, Swartz J, Lilja G, et al. Atopy in children of families with an anthroposophic lifestyle. Lancet. 1999;353:1485-8.

76. Farooqi IS, Hopkin JM. Early childhood infection and atopic disorder. Thorax. 1998; 53:927-32.

77. Cohet C, Cheng S, MacDonald C, et al. Infections, medication use, and the prevalence of symptoms of asthma, rhinitis, and eczema in childhood. J Epidemiol Community Health. 2004;58:852-7.

78. Magnusson MK, Arvola A, Hursti UK, et al. Choice of organic foods is related to perceived consequences for human health and to environmentally friendly behaviour. Appetite. 2003; 40:109-17.

79. Lockie S, Lyons K, Lawrence $\mathrm{G}$, et al. Choosing organics: a path analysis of factors underlying the selection of organic food among Australian consumers. Appetite. 2004;43:1346.

80. Williams PR, Hammitt JK. Perceived risks of conventional and organic produce: pesticides, pathogens, and natural toxins. Risk Anal. 2001;21:319-30.

81. Williams CM. Nutritional quality of organic food: shades of grey or shades of green? Proc Nutr Soc. 2002;61:19-24.

82. Holt PG, Macaubas C. Development of long-term tolerance versus sensitisation to environmental allergens during the perinatal period. Curr Opin Immunol. 1997; 9:782-87. 


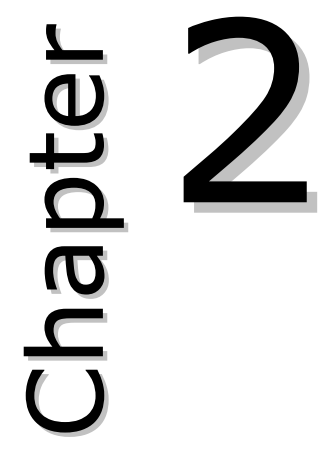

\section{Etiology of atopy in infancy: the KOALA Birth Cohort Study}

Kummeling I, Thijs C, Penders J, Snijders BEP, Stelma F, Reimerink J, Koopmans M, Dagnelie PC, Huber M, Jansen MCJF, de Bie $R$, van den Brandt PA

PEDIATRIC ALLERGY AND IMMUNOLOGY 2005; 16: 679-684 


\section{Abstract}

The aim of the KOALA Birth Cohort Study in the Netherlands is to identify factors that influence the clinical expression of atopic disease with a main focus on lifestyle (e.g. anthroposophy, vaccinations, antibiotics, dietary habits, breastfeeding and breast milk composition, intestinal microflora composition, infections during the first year of life and gene-environment interaction). The recruitment of pregnant women started in October 2000. First, healthy participants with 'conventional lifestyles' $(n=2343)$ were retrieved from an ongoing prospective cohort study $(n=7020)$ on pregnancy-related pelvic girdle pain. In addition, pregnant women $(n=491)$ with 'alternative lifestyles' with regard to child rearing practices, dietary habits (organic, vegetarian), vaccination schemes and/or use of antibiotics, were recruited through organic food shops, anthroposophic doctors and midwifes, Steiner Schools, and dedicated magazines. All participants were enrolled between 14-18 weeks of gestation and completed an intake questionnaire on family history of atopy and infant care intentions. Documentation of other relevant variables started in the pregnant mother and covered the first and third trimester as well as early childhood by repeated questionnaires at 14-18, 30 and 34 weeks of gestation and 3, 7, 12 and 24 months postpartum. A subgroup of participants, including both conventional and alternative lifestyles, was asked to consent to maternal blood sampling, breast milk and a faecal sample of the infant at 1 month postpartum, capillary blood at age 1 year, venous blood, and buccal swabs for DNA isolation from child-parent trios. From the start, ethical approval and informed consent procedures included gene-environmental interaction studies. Follow-up at 3 and 7 months postpartum was completed with high response rates (respectively $90 \%$ and $88 \%$ in the conventional group, and $97 \%$ and $97 \%$ in the alternative group). The home visits at 2 years of age will be completed in 2005.

Results show that we have succeeded in recruiting a large population with various lifestyle choices, with a fairly large contrast with regard to dietary habits (including organic foods, vegetarian diet), vaccination schemes and/or use of antibiotics. A large proportion of the participants have consented with genetic studies. An outline of the focus and design of the KOALA Birth Cohort Study is presented. 


\section{Introduction}

The prevalence of atopic diseases such as eczema, food allergy, hay fever (and other airway allergies) and asthma has increased over the past decades and currently one-third of the children in western societies show atopic symptoms (1). Atopic disease is thus an important public health problem, and preventive measures would be beneficiary. Despite years of research, little is yet understood concerning the etiological pathways leading to these diseases. Atopic disorders typically run in families and therefore genetic factors are supposed to be important (2). However, it is not likely that the frequency of polymorphisms in genes associated with the development of atopic diseases like eczema and asthma would have changed within the same two generations experiencing the increasing prevalence of atopy. Due to a change in environmental exposures, the population fraction exposed to important environmental influences may have changed, leading to an increased incidence of the expression of the atopic phenotype in previously unaffected but genetically susceptible individuals (2). An already existing genetic susceptible proportion of the population may have either become increasingly exposed to certain environmental risk factors which have become increasingly prevalent (3) or have become less exposed to various protective factors (4).

Initially, in epidemiological studies concerning atopy risk factors deserved most attention (e.g. dust mites, ambient air pollution). More recently, however, the influence of various potentially protective factors (early microbial exposure, infections, pets, various immunological and dietary factors in breast milk) has been emphasised. The role of a protective lifestyle was highlighted by several studies, for example a study reporting that growing up in anthroposophic families was protective against developing atopic disease (5). An anthroposophic lifestyle differs in many respects from living a conventional lifestyle, such as different dietary habits (for example a higher intake of fermented vegetables, consumption of mainly organic or biodynamically produced food, and a vegetarian diet) and restricted use of antibiotics and vaccinations. This lifestyle pattern reflects in part the traditional lifestyle of western societies several decades ago when the prevalence of atopy was lower than today but main characteristics may differ between countries.

This paper describes the design of the KOALA Birth Cohort Study, the Netherlands. KOALA is (in Dutch) an acronym for: Child, Parent and health: Lifestyle and Genetic constitution. The aim of the KOALA study is to identify factors that influence the clinical expression of atopic disease with a main focus on lifestyle.

\section{LIFESTYLE FACTORS AND DEVELOPMENT OF ATOPY}

Studies performed in different geographical areas have shown that a western lifestyle predisposes to atopic disease (1). We aim to investigate the role of vaccinations, antibiotics, different dietary habits (breastfeeding, organic foods) and alternative child rearing practices (anthroposophy) in early life in the subsequent development of atopy.

Although several studies have suggested that breastfeeding is protective, results of the available studies so far are inconsistent $(6,7)$. Breast milk contains 
immunological factors (e.g. cytokines, chemokines, immunoglobulin A antibodies) and dietary factors such as fatty acids that can be beneficial for the recipient infant (8-11). We aim to investigate whether immunological factors and fatty acid patterns in breast milk depend on the mother's atopic constitution. In addition, the role of essential fatty acids and immunological factors on atopic outcomes in breastfed children is studied.

The composition of the intestinal microflora in early life is strongly influenced by dietary, environmental and lifestyle characteristics. Alm and colleagues (12) showed that lifestyle factors associated with an anthroposophic way of life correlated with differences in infant gut flora. These studies indicate that the composition of gut flora might influence the development and priming of the immune system, which in turn could affect the risk of atopy $(13,14)$. In the KOALA study we determine gut flora composition in infants at the age of one month. Also the relation with the development of atopy later in life will be investigated. To determine this microbial flora we are currently developing several species and genus specific real-time PCR assays. This culture-independent technique can be used on both fresh and frozen samples and overcomes many of the problems associated with traditional bacteriological culturing, such as the low sensitivity and reproducibility and the inability to detect nonculturable bacteria.

Another aim in the KOALA study is to address the role of infections and vaccinations in early life in the subsequent development of atopic manifestations, the so-called hygiene hypothesis. We look at the role of gastrointestinal infections in relation to development of atopic dermatitis and food allergy in the first year of life and focus on infections that occur at young age and that have been related in some way to the development of atopic diseases (rotavirus, norovirus, Bordetella pertussis and parasites Toxocara and Ascaris). Infection will be assessed through the determination of specific antibodies in capillary blood samples collected at one year of age. By combining the sampling dates with data from routine surveillance on seasonal occurrence of the diseases under study, the most probable period of infection will be mapped to 6-month intervals.

Familial predisposition has historically been identified as an important risk factor in asthma and atopic diseases (15). However, it is difficult to discriminate between the effect of genes and the effect of environmental factors, since both cluster in families. Therefore, in order to understand the familial aggregation of atopic diseases, genes and environmental factors should be studied in combination. The KOALA study aims at selecting genes important to the regulation of the innate immune system. Examples of candidate genes are polymorphisms in CD14, Toll-like receptors, MYD88, INF-gamma, IL-12, IL-10, IL4 and IL-13 genes. Buccal swabs from parent-child trios are collected for DNA isolation. Adequate power for gene-environment interaction is assured by combining data from the KOALA study with two other cohorts in the Netherlands.

\section{Design}

The KOALA study is a prospective birth cohort study. Pregnant women have been recruited from an ongoing prospective cohort study $(n=7020)$ on Pregnancy-related Pelvic Girdle Pain (PPGP study) among pregnant women in the Netherlands (16). Enrolment started in October 2000 and aimed at women at 14- 
16 weeks of gestation (the pregnant women were therefore not selected on the basis of pelvic pain symptoms). At 34 weeks of gestation, PPGP subjects were asked to participate in the KOALA study ('conventional participants'). Additionally, recruitment of pregnant women with alternative lifestyles ('alternative participants') started through several alternative recruitment channels, i.e. posters in organic food shops, anthroposophic doctors and midwifes, anthroposophic under-five clinics, Steiner Schools and magazines for special interest groups (e.g. homeopathy, anthroposophy, anti-vaccine). Like for the PPGP cohort, in this alternative population pregnant women were enrolled at 1418 weeks of gestation. In order to evaluate selective participation of PPGP participants in the KOALA study, we took a short recruitment questionnaire on family history of atopic manifestations and on infant care intentions (use of medication or vaccinations; dietary habits (regular, organic, vegetarian) and intention to breastfeed) at the time of enrolment.

Perinatal determinants and exposure data on determinants of atopy (hygiene, infections, nutritional data, child rearing and other lifestyle characteristics) were collected for all members of the cohort by repeated questionnaires at $14-18,30$ and 34 weeks of gestation and during the first 2 years of the infant's life at 3, 7, 12 and 24 months postpartum. Follow-up at 3 and 7 months postpartum was completed with high response rates (respectively $90 \%$ and $88 \%$ for conventional participants, and $97 \%$ and $97 \%$ for alternative participants).

Participants recruited from January 2002 onwards (conventional and alternative) were asked to consent to maternal blood sampling $(n=1355)$ around 36 weeks of gestation (for determination of Immunoglobulin E (IgE)) (subcohort named KOALA-SUB). KOALA-SUB participants were also asked to consent to sampling infant's faeces at 1 month postpartum (for determination of gut flora composition; $\mathrm{n}=1176$ ) and breast milk at 1 month postpartum (for measurement of immunological markers and fatty acids; $n=317$ ). Furthermore, they were asked to consent to collecting of capillary blood at the age of one year $(n=956)$ and venous blood at the age of two years (collected at the time of writing) for the determination of infection serology and the measurement of total and specific IgE-levels. Buccal swabs from trios (the child and both parents) as source of DNA for genetic analysis were collected at the time of writing. All biosamples are stored frozen in a biobank to which access is granted to the participating research groups following a review of protocols by the KOALA steering committee.

When the child is 2 years, the main atopic outcomes are eczema, wheeze and total and specific IgE. Questionnaires sent to all participants around the child's age of 7, 12 and 24 months include questions adapted from the International Study of Asthma and Allergies in Childhood (ISAAC) questionnaires (17).

All participants had signed informed consent. Ethical approval was obtained from the medical ethics committee of the Maastricht University/University Hospital of Maastricht. Genetic testing was also included in the medical ethical committee and informed consent procedures. 


\section{DEFINITIONS}

In the recruitment questionnaire, the questions on a family history of atopic manifestations were phrased as follows: 'Did you ever have allergic complaints such as eczema, hay fever, house dust mite allergy and/or food allergy?', and: 'Did you ever have asthma or asthmatic bronchitis?', for both parents separately. Both questions could be answered by 'yes', 'no' or 'unknown'. We defined a family history of atopic manifestations as present ('yes') in one or both parents. Questions on infant care intentions were phrased as: 'Do you adhere to a certain life philosophy for which you, for your child,: 1) consciously restrict use of medication (for example antibiotics) (yes, no, unknown); 2) consciously opt for lower vaccination uptake (yes, no, unknown); 3) consciously choose an organic, vegetarian or macrobiotic diet (yes, no, unknown) in comparison to most other Dutch people?' and 'How do you intent to feed your baby? (breastfeeding, formulae, both, don't know)'.

In the 7 months postpartum questionnaire we asked parents whether they had their child vaccinated by the standard Dutch National Vaccination Scheme, vaccinated according to an alternative scheme, or not vaccinated at all. An 'alternative vaccination scheme' was defined as: delayed vaccination scheme or alternative vaccine composition (for example, omitting the pertussis component from the diphtheria-pertussis-tetanus-polio vaccine). We asked parents if their child had ever used antibiotics (yes/no); whether the child had been exposed to environmental tobacco smoke (ETS) for more than one hour per week (yes/no) and if they had furred pets in the house at any time (yes/no). Breastfeeding during the first 4 months was categorized as 'exclusive', 'nonexclusive' and 'never'. We defined 'exclusive' as breastfeeding without any artificial feeding and/or supplemental feeding. Consumption of organic bananas (fresh) (yes/no) and organic fruit in jars (yes/no) were used as indicator variables for choice for organic foods when starting supplemental feeding, because these were the foods most used in the first 7 months of life.

\section{Results}

In total, 2834 pregnant women were included in the KOALA study, of whom 491 through alternative recruitment channels. The recruitment questionnaire was filled in by 3723 PPGP (candidate population) participants who do not participate and by 2329 out of 2343 PPGP participants that actually participate in the KOALA study; the same information was present for all 491 alternative participants. As shown in Table I, the percentage of parents with a history of atopic manifestations is higher in the participants compared to non-participants: $66 \%$ of the newborns recruited from the PPGP study and $74 \%$ of alternative participants have at least one parent with atopy, whereas in the non-participants (PPGP participants not willing to participate in the KOALA study) this is $60 \%$. A similar finding was apparent for parental asthma: $29 \%$ of the newborns recruited from the PPGP study and $26 \%$ in the alternative group have at least one parent with asthmatic history, whereas in the non-participants this is $23 \%$. KOALA participants and nonparticipants are of equal age (31.7 and 31.4 years); alternative mothers are slightly older (33.7 years). 


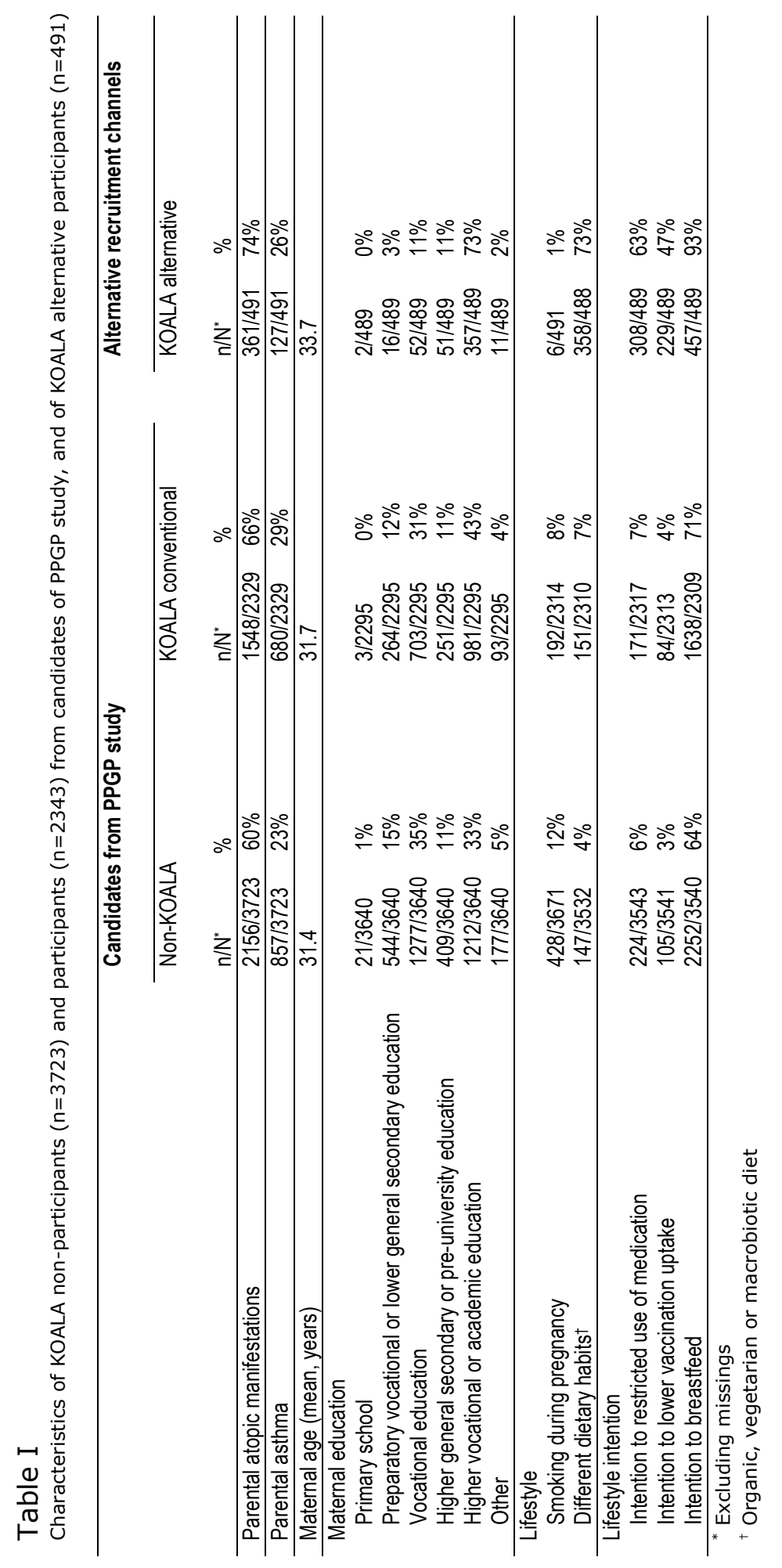


The KOALA participants more often had higher education compared to nonparticipants: $43 \%$ vs. $33 \%$; in the alternative participants a higher education is far more common (73\%). The KOALA participants have slightly different lifestyles compared with non-participants, notably with respect to the intention to breastfeed ( $71 \%$ vs. $64 \%$ ); in the alternative group the intention to breastfeed is far higher (93\%). Smoking during pregnancy also seems to differ considerably between the three groups, with the lowest prevalence in the alternative group $(1 \%)$.

\section{Table II}

Child characteristics of the conventional $(\mathrm{N}=2343)$ and alternative subcohort $(\mathrm{N}=491)$ in the KOALA Birth Cohort Study during the first 6 months after birth

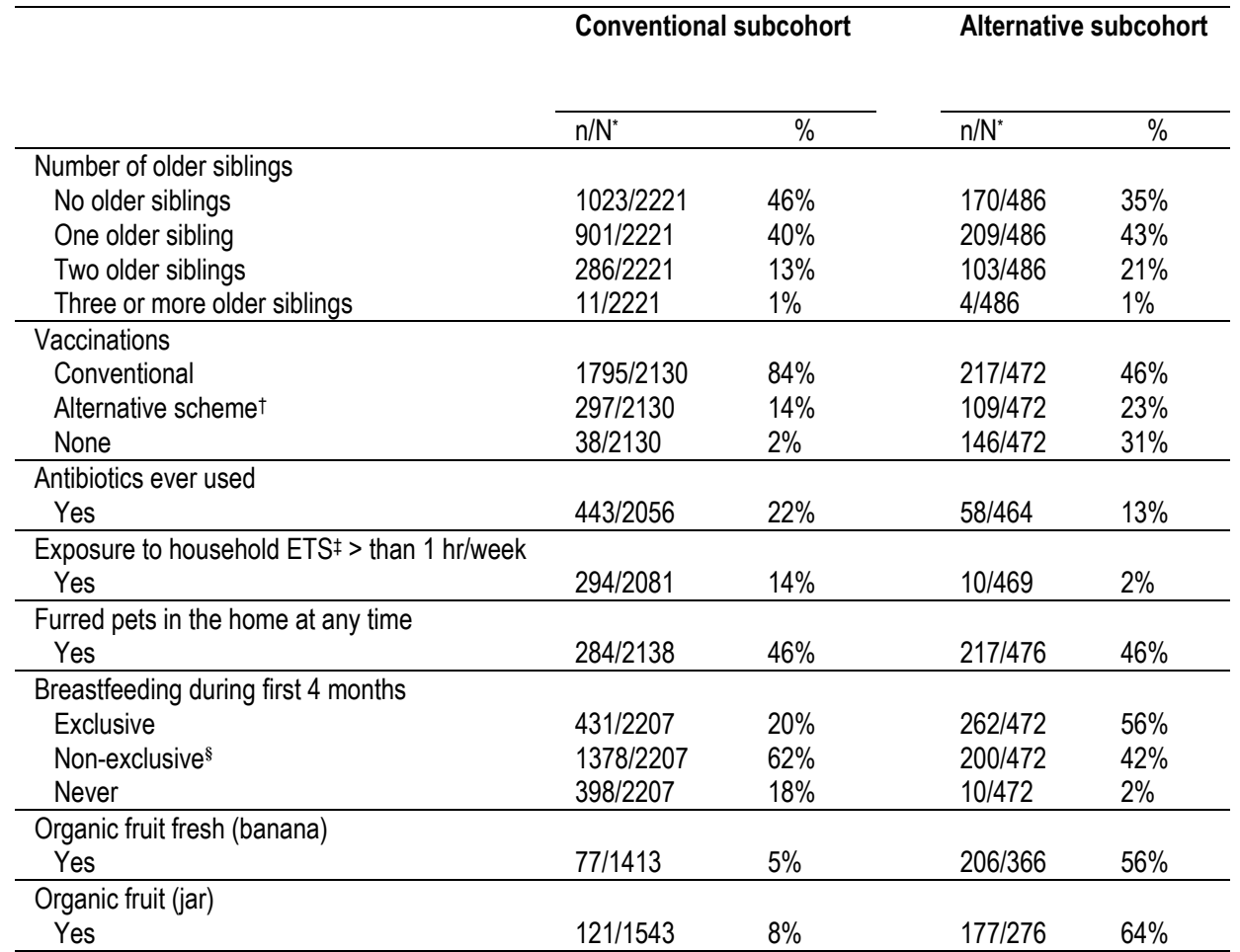

*Excluding missings

† Delayed schedule or alternative composition of vaccine

$\ddagger$ Environmental Tobacco Smoke

$\S$ Breastfeeding with supplemental liquids or solid foods 
Child characteristics of the conventional and alternative KOALA participants during the first 6 months of life are presented in Table II. A smaller proportion of alternative families had no older siblings compared to conventional families ( $35 \%$ vs. $46 \%)$. In alternative families, conventional vaccinations schemes and antibiotic use were less frequent ( $46 \%$ vs. $84 \%$, and $13 \%$ vs. $22 \%$, respectively) and fewer children had been exposed to environmental tobacco smoke (ETS) ( $2 \%$ vs. $14 \%$ ). Almost half of participants in both subcohorts had at least one furred pet in the home. Exclusive breastfeeding during thefirst 4 months was given in a considerably larger proportion of the alternative subcohort ( $56 \%$ vs. $20 \%$ ). Of children that had consumed bananas and fruit in jars, these food products had an organic origin in $56 \%$ and $64 \%$ respectively of the alternative subcohort, but only $5 \%$ and $8 \%$ respectively of the conventional participants.

\section{Discussion}

The KOALA Birth Cohort Study has succeeded in recruiting a large population of participants $(n=2834)$ with various lifestyle choices. Therefore, we have a fairly large contrast in exposure to dietary habits (including breastfeeding, organic foods, vegetarian diet), vaccination schemes and/or antibiotic use in a period when exposure to these exposures may influence the development of the immune system.

Another strength of this study is the large number of infants of which faecal samples $(n=1176)$ have been collected since previous studies on intestinal gut flora and atopy were all based upon much smaller populations (13, 18-20). Finally, other unique features of our study are the large number of children with capillary blood samples at age 1 year and large proportion of participants that have consented with genetic studies.

It is well known that families with atopic complaints tend to be overrepresented in studies on the etiology of atopy. The difference between the participants and non-participants may be explained by self-selection, since people with a positive family history of atopic manifestations will tend to be more interested in participating in a study on health-related topics. Also, the healthconscious lifestyle in the alternative group may be associated with greater willingness to report diseases in general, and consequently with over-reporting of atopic complaints. Yet another possible explanation for the higher prevalence of atopic family history in the alternative group is that people choose their alternative lifestyle partly for the reason of their atopic disease. The latter notion stresses the need for adjusting/testing for interaction for an atopic family history in the statistical analysis, to avoid confounding/effect modification between family history and lifestyle in our study as well as in other cohort studies. 


\section{References}

1. Anonymous. Worldwide variation in prevalence of symptoms of asthma, allergic rhinoconjunctivitis, and atopic eczema: ISAAC. The International Study of Asthma and Allergies in Childhood (ISAAC) Steering Committee. Lancet 1998: 351: 1225-32.

2. Bleecker ER, Postma DS, Meyers DA. Genetic susceptibility to asthma in a changing environment. Ciba Found Symp 1997: 206: 90-9.

3. McNally NJ, Phillips DR, Williams HC. The problem of atopic eczema: aetiological clues from the environment and lifestyles. Soc Sci Med 1998: 46: 729-41.

4. Pershagen G. Can immunization affect the development of allergy? Pediatr Allergy Immunol 2000: 11: 26-8.

5. Alm JS, Swartz J, Lilja G, Scheynius A, Pershagen G. Atopy in children of families with an anthroposophic lifestyle. Lancet 1999: 353: 1485-8.

6. Kramer M, Kakuma R. Maternal dietary antigen avoidance during pregnancy and/or lactation for preventing or treating atopic disease in the child. Cochrane Database Syst Rev 2003: 4: CD000133.

7. Wright AL, Holberg $\mathrm{CJ}$, Taussig LM, Martinez F. Material asthma status alters relation of infant feeding to asthma childhood. Adv Exp Med Biol 2000: 478: 131-7.

8. Hanson LA, Korotkova M, Haversen L, Mattsby-Baltzer I, Hahn-Zoric M, Silfverdal SA, et al. Breast-feeding, a complex support system for the offspring. Pediatr Int 2002: 44: 347-52.

9. Wright $\mathrm{S}$, Bolton $\mathrm{C}$. Breast milk fatty acids in mothers of children with atopic eczema. $\mathrm{Br}$ J Nutr 1989: 62: 693-7.

10. van Gool CJ, Thijs C, Henquet CJ, van Houwelingen AC, Dagnelie PC, Schrander J, et al. Gamma-linolenic acid supplementation for prophylaxis of atopic dermatitis--a randomized controlled trial in infants at high familial risk. Am J Clin Nutr 2003: 77: 943-51.

11. Thijs C, Houwelingen A, Poorterman I, Mordant A, van den Brandt P. Essential fatty acids in breast milk of atopic mothers: comparison with non-atopic mothers, and effect of borage oil supplementation. Eur J Clin Nutr 2000: 54: 234-8.

12. Alm JS, Swartz J, Bjorksten B, Engstrand L, Engstrom J, Kuhn I, et al. An anthroposophic lifestyle and intestinal microflora in infancy. Pediatr Allergy Immunol 2002: 13: 402-11.

13. Bjorksten B, Sepp E, Julge K, Voor T, Mikelsaar M. Allergy development and the intestinal microflora during the first year of life. J Allergy Clin Immunol 2001: 108: 516-20.

14. Bjorksten B. Effects of intestinal microflora and the environment on the development of asthma and allergy. Springer Semin Immunpathol 2004: 25: 257-70.

15. Duffy DL. Genetic epidemiology of asthma. Epidemiol Rev 1997: 19: 129-43.

16. Bastiaanssen JM, de Bie RA, Bastiaenen $\mathrm{CH}$, Heuts A, Kroese ME, Essed GG, van den Brandt PA. Etiology and prognosis of pregnancy-related pelvic girdle pain; design of a longitudinal study. BMC public health 2005: 5: 1.

17. Asher MI, Keil U, Anderson HR, Beasley R, Crane J, Martinez F, et al. International Study of Asthma and Allergies in Childhood (ISAAC): rationale and methods. Eur Respir J 1995: 8: 483-91.

18. Bjorksten B, Naaber P, Sepp E, Mikelsaar M. The intestinal microflora in allergic Estonian and Swedish 2-year-old children. Clin Exp Allergy 1999: 29: 342-6. 
19. Kalliomaki M, Kirjavainen P, Eerola E, Kero P, Salminen S, Isolauri E. Distinct patterns of neonatal gut microflora in infants in whom atopy was and was not developing. $J$ Allergy Clin Immunol 2001:107: 129-34.

20. Kirjavainen PV, Arvola T, Salminen SJ, Isolauri E. Aberrant composition of gut microbiota of allergic infants: a target of bifidobacterial therapy at weaning? Gut 2002: 51: 51-5. 


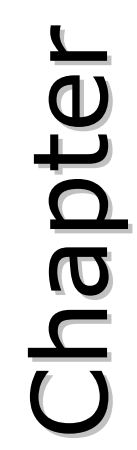

Do parents with an atopic family history adopt a 'prudent' lifestyle for their infant?

Kummeling I, Thijs C, Stelma F, Huber M, van den Brandt PA, Dagnelie PC

CLINICAL AND EXPERIMENTAL ALLERGY 2006; 36: 489-494 


\section{Abstract}

\section{BACKGROUND}

Atopic parents may adopt lifestyle characteristics that allegedly protect against atopic disease. If this is true, infants from atopic parents will be characterised by low-risk behaviour. Consequently, etiologic studies on lifestyle factors and atopic disease in childhood may be biased by confounding-by-indication.

\section{OBJECTIVE}

We explored whether the prevalence of 'prudent' lifestyle characteristics differs between atopic and non-atopic families.

\section{METHODS}

Information about a family history of atopic manifestations and lifestyle characteristics was collected by repeated questionnaires in the KOALA Birth Cohort Study, the Netherlands, in 2469 infants from families with divergent lifestyle practices (conventional vs. alternative).

\section{RESULTS}

In conventional lifestyle families, infants were less often exposed to environmental tobacco smoke when parents were atopic than when they were non-atopic ( $10 \%$ vs. $15 \%, P=0.001$ ). In alternative lifestyle families, exposure to smoking was very rare in both groups ( $2 \%$ vs. $3 \%, P=0.487)$. Furred pets were less often present in families with than without parental atopy (43\% vs. $48 \%$, $P=0.014$ for conventional lifestyle families; $39 \%$ vs. $51 \%, P=0.008$ for alternative lifestyle families). Infants with atopic older siblings had less often been vaccinated according to the standard scheme than infants with non-atopic older siblings in conventional lifestyle families $(77 \%$ vs. $86 \%, P<0.001)$. In alternative lifestyle families, the difference was in the same direction but not statistically significant ( $44 \%$ vs. $28 \%, P=0.011$ ). Antibiotic use, breastfeeding and consumption of organic foods were unrelated to a family history of atopic manifestations.

\section{CONCLUSION}

Some 'prudent' lifestyle characteristics differed between atopic and non-atopic families, depending on whether atopic manifestations were present in parents or older siblings. This has important consequences for the validity in epidemiological studies on the etiology of atopic manifestations in children. Confounding-byindication due to a family history of atopic manifestations can best be controlled for by considering atopy in parents and siblings as separate confounders. 


\section{Introduction}

These days in modern societies uncountable Internet websites, magazines and newspaper articles are devoted to atopic manifestations in childhood. This public concern tags along with scientific evidence that the prevalence of atopic diseases such as eczema, food allergy, hay fever (and other airway allergies) and asthma has increased over the past decades $(1,2)$. Currently one-third of the children in westernised societies show atopic symptoms (3).

A positive family history for atopy has proved to be an important risk factor for the development of atopic disease in offspring (4). Several findings have led to the notion that certain lifestyle practices may also be associated with atopy. First, studies performed in different geographical areas indicated that a western lifestyle predisposed to atopic disease $(3,5,6)$. Moreover, important regional differences in disease prevalence were revealed in genetically similar populations, indicating that rapid changes in genetic background cannot explain the epidemic (7). A Swedish study suggested that an anthroposophic lifestyle may lessen the risk of atopy in childhood (8); growing up on a farm has also been reported to be protective (9-11).

In order to determine which specific lifestyle factors are important, research on the etiology of atopy has focused on changes in lifestyle over the past decades. The introduction of vaccinations and antibiotics, smaller family sizes and better hygiene are all associated with atopy. The common denominator to those factors is decreased microbial stimulation $(8,12-17)$. Also altered patterns of food consumption $(18,19)$ and increased exposure and sensitisation to indoor allergens (20-23), are considered important cofactors for the development of atopic disease in westernised societies.

Since information on childhood atopic manifestations on the Internet or in magazines is easily accessible, modern parents have become more aware of the potential role that their lifestyle plays in relation to atopy. Consequently, they may seek to adapt their behaviour in an attempt to prevent atopic manifestations in their child, perhaps in particular in families with a history of atopic manifestations. This causes differences in exposure to important risk or protective factors in early life between children of atopic and non-atopic families (24). Consequently, the validity of epidemiological research concerning the role of lifestyle factors in relation to atopic disease is affected: if atopic families adopt a 'prudent' lifestyle, i.e. a lifestyle which allegedly protects against atopic disease, the effect of lifestyle on the development of atopy will be confounded by a family history of atopy (confounding-by-indication) (Figure I). A protective lifestyle factor may then appear as a risk factor because the exposed subjects are at the highest risk.

The aim of this paper is to explore whether parents with a family history of atopic manifestations adopt a 'prudent' lifestyle relative to parents of nonatopic families, using families with divergent lifestyle practices selected from the KOALA Birth Cohort Study, the Netherlands. We specifically addressed the issue of differential effects of atopy in parents vs. siblings on lifestyle practices, which to our knowledge has not been reported in atopy studies to date. 


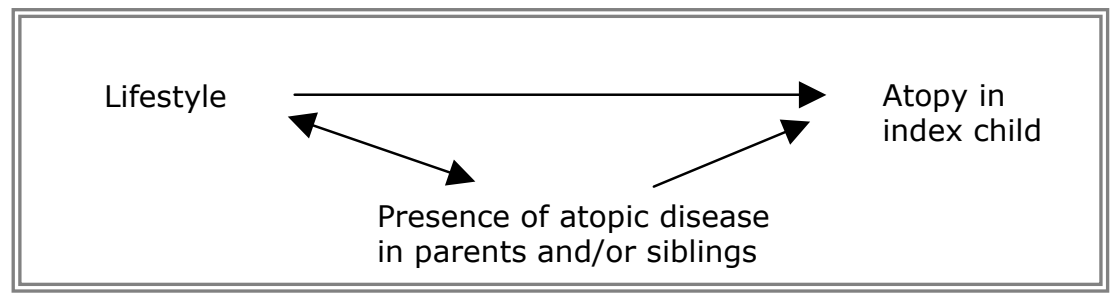

Figure I

Schematic presentation of confounding-by-indication: a family history of atopic disease confounds the observed association between the exposure to a certain lifestyle factor and the presence of atopy

\section{Subjects and methods}

\section{STUDY POPULATION}

A detailed description of the design of our cohort has been published previously (25). In summary, the KOALA Birth Cohort Study started in October 2000. Participants were recruited from two sources. First, healthy pregnant women were recruited from an ongoing prospective cohort study on Pregnancyrelated Pelvic Girdle pain (PPGP study) (26). Participants of the PPGP study were recruited via midwife clinics at 14-16 weeks of gestation. At 34 weeks of gestation PPGP subjects were asked to participate in the KOALA study ('conventional subcohort'). Second, to increase the number of participants with lifestyle choices that have a low prevalence in the general population, pregnant women with socalled 'alternative' lifestyles were recruited through several specific recruitment channels, i.e. anthroposophic doctors and midwifes, anthroposophic under-five clinics, Steiner Schools, posters and flyers in organic food shops and magazines for special interest groups (e.g. homeopathy, anthroposophy, anti-vaccine) ('alternative subcohort'). These women were also enrolled at 14-18 weeks of gestation. A total of 2834 participants were included in the KOALA study, of whom 2343 through the PPGP study and 491 through the specific recruitment channels. All participants signed informed consent and completed the first (pregnancy) questionnaire at 34 week of gestation. Parents in both subcohorts were sent detailed questionnaires when the infants were 3 and 7 months of age. Age 7 months was selected to have complete information on the first six months of life of infants.

In the present chapter we report on lifestyle characteristics in the first 6 months of life. Data on a family history of atopic manifestations and sibship size were collected by questionnaires with closed answer options at 34 weeks of gestation. Questionnaires at 34 weeks of gestation, 3 and 7 months postpartum were used to collect information about lifestyle characteristics. Out of 2343 conventional and 491 alternative subcohort participants, 2003 (85\%) and 466 (95\%), respectively, completed the 'family history of atopic manifestations' questionnaire as well as the 3 and 7 months postpartum questionnaires. Ethical approval was obtained from the medical ethics committee of the Maastricht University/University Hospital of Maastricht. 


\section{DEFINITIONS}

Positive family history of atopic manifestations included self-reported doctor's diagnosed asthma, pet or house dust mite allergy, hay fever and/or eczema for parents (none vs. one or both) and older siblings (none vs. one or more), separately. Food allergy was included in the definition of atopy for older siblings. At 7 months postpartum, we asked parents whether their child had been vaccinated according to the standard scheme, an 'alternative vaccination scheme' or not at all. In the Netherlands during the time of the study, infants in their first six months were standard vaccinated against diphtheria, tetanus, pertussis (with whole cell pertussis vaccine), poliomyelitis and Haemophilus influenzae type B vaccine ( $\mathrm{Hib}$ ) at 2, 3, and 4 months of age. An 'alternative vaccination scheme' was defined as: delayed vaccinations or alternative vaccine composition (for example, omitting the pertussis component from the diphtheria-pertussis-tetanuspolio vaccine). We asked parents if their child had ever used antibiotics (yes/no); whether the child had been exposed to environmental tobacco smoke (ETS) for more than one hour per week (yes/no) and if they had furred pets in the house at any time (yes/no). We defined 'exclusive breastfeeding' as breastfeeding without any artificial and/or supplemental feeding in the first four months of life. Consumption of organic bananas (fresh) (yes/no) and organic fruit (jar) (yes/no) were used as indicator variables for choice for organic foods when starting supplemental feeding, because these were the foods most used in the first 6 months.

\section{STATISTICAL ANALYSES}

We evaluated associations between lifestyle choices and the presence of a family history of atopic manifestations by Pearson's $x^{2}$ test. The evaluation of associations between lifestyle choices and sibling history of atopic manifestations was restricted to families in which the index child had one or more older siblings. Determination of whether choice for organic vs. conventional fruit (fresh, jar) was related to family history of atopic diseases was restricted to infants who had actually consumed these foods. P-values below 0.05 indicated statistical significance.

\section{Results}

About half of the families in both subcohorts had a parental history of atopic manifestations (Table I). About 35\% of index children in the alternative and $47 \%$ in the conventional subcohort had no older siblings. The percentage of families with a positive sibling's history of atopic manifestations was around $20 \%$ in the alternative and $15 \%$ in the conventional subcohort. The percentage of infants vaccinated according to the standard scheme was lower in the alternative lifestyle families than in conventional families (46\% vs. $84 \%$ ), and the same was true for antibiotic use ( $13 \%$ vs. $23 \%$ ). Exposure of infants to environmental tobacco smoke (ETS) was rare in the alternative subcohort (2\%) and more frequent in the conventional subcohort (12\%). Almost half of the families in both subcohorts had furred pets. The percentage of infants being exclusively breastfed during the first four months was $56 \%$ in the alternative and $21 \%$ in the 
conventional subcohort. Percentage of organic origin of foods consumed by infants was for banana's $56 \%$ in the alternative and $5 \%$ of the conventional subcohort; and for fruit from jars $64 \%$ in the alternative and $8 \%$ in the conventional subcohort.

Overall, the differences in lifestyle characteristics between families with and without parental atopic manifestations were small in both subcohorts (Table II). In the conventional subcohort, infants were less often exposed to ETS when parents were atopic than when they were non-atopic ( $10 \%$ vs. $15 \%, P=0.001)$. In the alternative subcohort, exposure to smoking was very low in both groups ( $2 \%$ vs. $3 \%, P=0.487)$. Furred pets were less often present in families with than without parental atopy ( $39 \%$ vs. $51 \%, P=0.008$ for the alternative subcohort; $43 \%$ vs. $48 \%, P=0.014$ for the conventional subcohort). Vaccinations scheme, antibiotic use, breastfeeding and consumption of organic fruit did not differ between parents with and without atopic manifestations in both subcohorts.

Differences in lifestyle characteristics between families with atopic manifestations in older siblings in both subcohorts were also small (Table III). Infants with atopic siblings had less often been vaccinated according to the standard scheme than infants with non-atopic siblings in the conventional subcohort $(77 \%$ vs. $86 \%, P<0.001)$. In the alternative subcohort, the difference was in the same direction but not statistically significant ( $41 \%$ vs. $51 \%$, $P=0.171$ ). Antibiotic use, exposure to ETS, furred pets and breastfeeding and consumption of organic foods (except for consuming bananas from organic origin in the alternative subcohort) did not differ between families with and without a history of atopic manifestations in siblings in both subcohorts.

We found similar results when we restricted our definition of atopic manifestations to a (self-reported) doctor's diagnosis of asthma; pet or house dust mite allergy; hay fever; or eczema separately: differences in lifestyle characteristics between atopic and non-atopic families were of same size and were only found for less smoking (when parents had a history of pet or house dust mite allergy or hay fever), fewer pets (when parents had a history of pet or house dust mite allergy or eczema) and lower frequencies of standard vaccination schemes (when siblings had a history of asthma or eczema) and not for antibiotic use, breastfeeding and consumption of organic foods.

We further evaluated maternal smoking or exposure to ETS during pregnancy, having furred pets during pregnancy, as well as parents' intention to have their infant vaccinated according to the standard scheme (asked during pregnancy). In the conventional subcohort, atopic pregnant women smoked less or were less often exposed to ETS than non-atopic pregnant women but the difference was not statistically significant ( $8 \%$ vs. $10 \%, P=0.101)$. In the alternative subcohort, maternal smoking or exposure to environmental tobacco smoking was very low in both groups ( $0 \%$ vs. $1 \%)$. In the conventional subcohort, during pregnancy, atopic parents had furred pets less often than nonatopic parents $(50 \%$ vs. $55 \%, P=0.021)$. In the alternative subcohort, the difference was in the same direction ( $42 \%$ vs. $50 \%, P=0.082)$. 


\section{Table I}

Characteristics of a conventional $(N=2003)$ and alternative subcohort $(N=466)$ in the KOALA Birth Cohort Study during the first 6 months after birth

\begin{tabular}{|c|c|c|c|c|c|}
\hline \multirow{3}{*}{\multicolumn{2}{|c|}{$\begin{array}{l}\text { Parental history of atopic manifestations } \\
\text { One or both parents }\end{array}$}} & \multicolumn{2}{|c|}{$\begin{array}{l}\text { Conventional } \\
\text { subcohort } \\
\mathrm{n} / \mathrm{N}\end{array}$} & $\begin{array}{l}\text { Alternative } \\
\text { subcohort } \\
\mathrm{n} / \mathrm{N}\end{array}$ & $\%$ \\
\hline & & & & & \\
\hline & & $1046 / 2003$ & $52 \%$ & $237 / 466$ & $51 \%$ \\
\hline \multicolumn{6}{|c|}{ Sibling history of atopic manifestations } \\
\hline & No older siblings & $935 / 2003$ & $47 \%$ & $162 / 466$ & $35 \%$ \\
\hline & $\geq 1$ older sibling(s), all without atopy & $773 / 2003$ & $38 \%$ & $211 / 466$ & $45 \%$ \\
\hline & $\geq 1$ older sibling(s), at least one with atopy & $295 / 2003$ & $15 \%$ & $93 / 466$ & $20 \%$ \\
\hline \multicolumn{6}{|c|}{ Vaccination scheme } \\
\hline & Standard & $1683 / 1998$ & $84 \%$ & $214 / 462$ & $46 \%$ \\
\hline & Alternative $^{*}$ & 280/1998 & $14 \%$ & $105 / 462$ & $23 \%$ \\
\hline & No vaccinations & $35 / 1998$ & $2 \%$ & $143 / 462$ & $31 \%$ \\
\hline \multicolumn{6}{|c|}{ Antibiotics ever used } \\
\hline & Yes & $452 / 1977$ & $23 \%$ & $61 / 457$ & $13 \%$ \\
\hline \multicolumn{6}{|c|}{ Exposure to household ETS ${ }^{\dagger}>$ than $1 \mathrm{hr} / \mathrm{wk}$} \\
\hline & Yes & $246 / 1998$ & $12 \%$ & $10 / 464$ & $2 \%$ \\
\hline \multicolumn{6}{|c|}{ Furred pets in the home at any time } \\
\hline & Yes & $914 / 1999$ & $46 \%$ & $209 / 461$ & $45 \%$ \\
\hline \multicolumn{6}{|c|}{ Breastfeeding during first 4 months } \\
\hline & Exclusive & $414 / 2003$ & $21 \%$ & $259 / 466$ & $56 \%$ \\
\hline & Non-exclusive $\ddagger$ & $1227 / 2003$ & $61 \%$ & $196 / 466$ & $42 \%$ \\
\hline & Never & $362 / 2003$ & $18 \%$ & $11 / 466$ & $2 \%$ \\
\hline \multicolumn{6}{|c|}{ Organic fruit fresh (banana)§ } \\
\hline & Yes & $72 / 1330$ & $5 \%$ & $203 / 360$ & $56 \%$ \\
\hline \multicolumn{6}{|c|}{ Organic fruit (jar)\| } \\
\hline & Yes & $118 / 1451$ & $8 \%$ & $174 / 271$ & $64 \%$ \\
\hline & \multicolumn{5}{|c|}{ Delayed or alternative composition of vaccinations } \\
\hline \multicolumn{6}{|c|}{ Environmental Tobacco Smoke } \\
\hline \multicolumn{6}{|c|}{ Breastfeeding with supplemental liquids or solid foods } \\
\hline \multicolumn{6}{|c|}{$\begin{array}{l}\mathrm{N}=1330 \text { (conventional subcohort) and } \mathrm{N}=360 \text { (alternative subcohort) due to unknown } \\
\text { origin or no consumption of the foods }\end{array}$} \\
\hline \multicolumn{6}{|c|}{$\begin{array}{l}N=1451 \text { (conventional subcohort) and } N=271 \text { (alternative subcohort) due to unknown } \\
\text { origin or no consumption of the foods }\end{array}$} \\
\hline
\end{tabular}

In the conventional subcohort, during pregnancy, parents of atopic siblings less often indented their child-to-come to be vaccinated according to the standard scheme than parents of non-atopic siblings ( $91 \%$ vs. $96 \%, P=0.001$ ). In the alternative subcohort, the difference was in the same direction but not statistically significant $(53 \%$ vs. $60 \%, P=0.143)$. Finally, results from multiple logistic regression analyses showed that parental and sibling's history were independently associated to the lifestyle practices mentioned above (smoking, furred pets, and vaccination scheme) and these associations were not statistically different between the conventional and alternative subcohort (test-of-interaction; results not shown). 


\section{Table II}

Relation between lifestyle and parental history of atopy in the conventional and alternative lifestyle subcohorts of the KOALA Birth Cohort Study during the first 6 months after birth

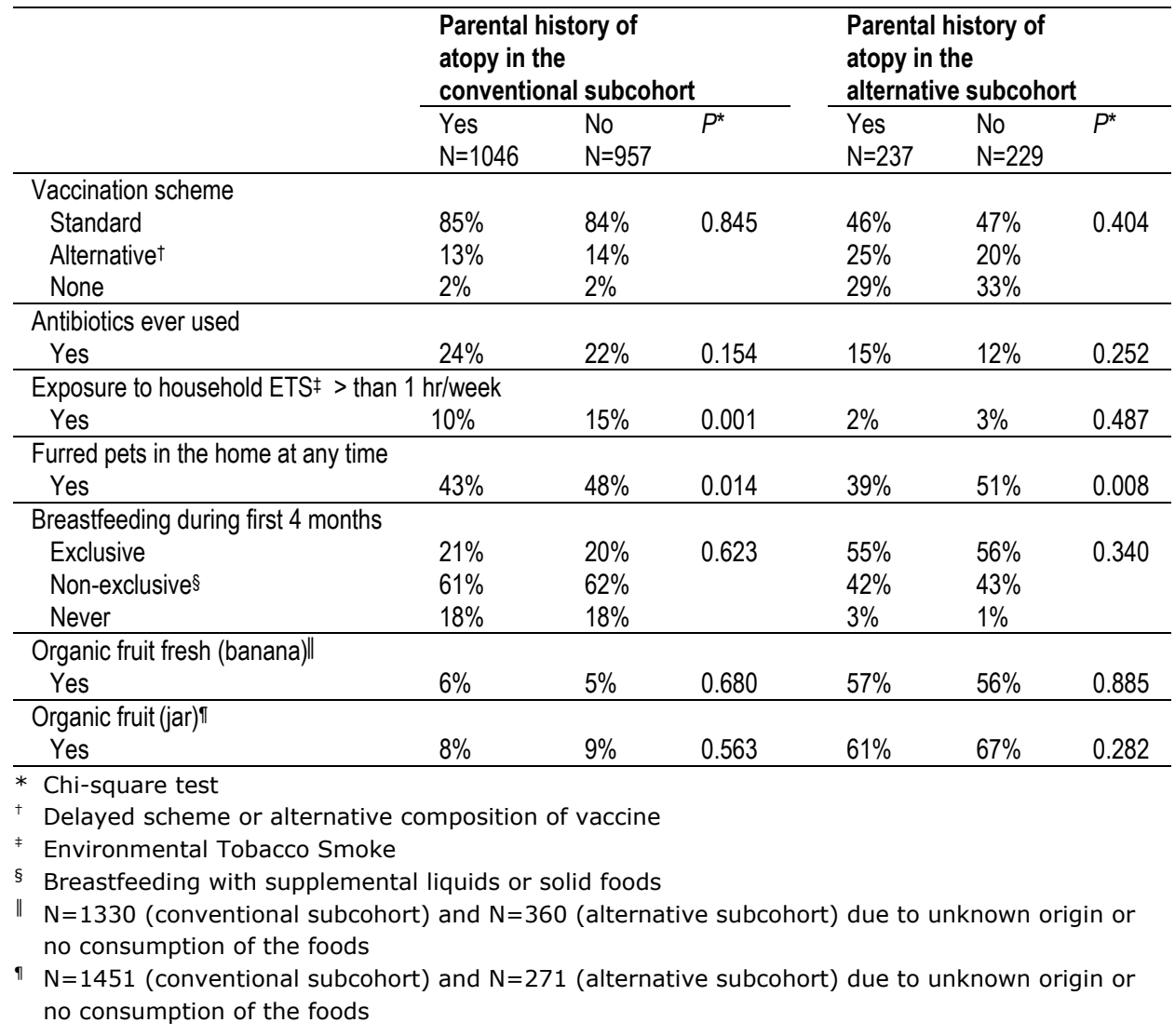

\section{Discussion}

Some 'prudent' lifestyle characteristics differed between atopic and nonatopic families, depending on whether atopic manifestations were present in parents or older siblings. A home environment with fewer furred pets and less exposure to environmental tobacco smoke (ETS) was related to a parental but not to a sibling history of atopic manifestations. Newborns were less often vaccinated according to the standard scheme when older siblings but not parents had a history of atopic manifestations. These findings were observed in our study with a relatively large group of families with alternative lifestyles. Due to the small intervals between the follow-up questionnaires, recall bias was kept to a minimum. This is particularly important since parents with alternative lifestyle choices may recall health-related lifestyle choices more accurately than a general population sample. 


\section{Table III}

Relation between lifestyle and sibling history of atopy in families with older siblings in the conventional and alternative lifestyle subcohorts of the KOALA Birth Cohort Study during the first 6 months after birth

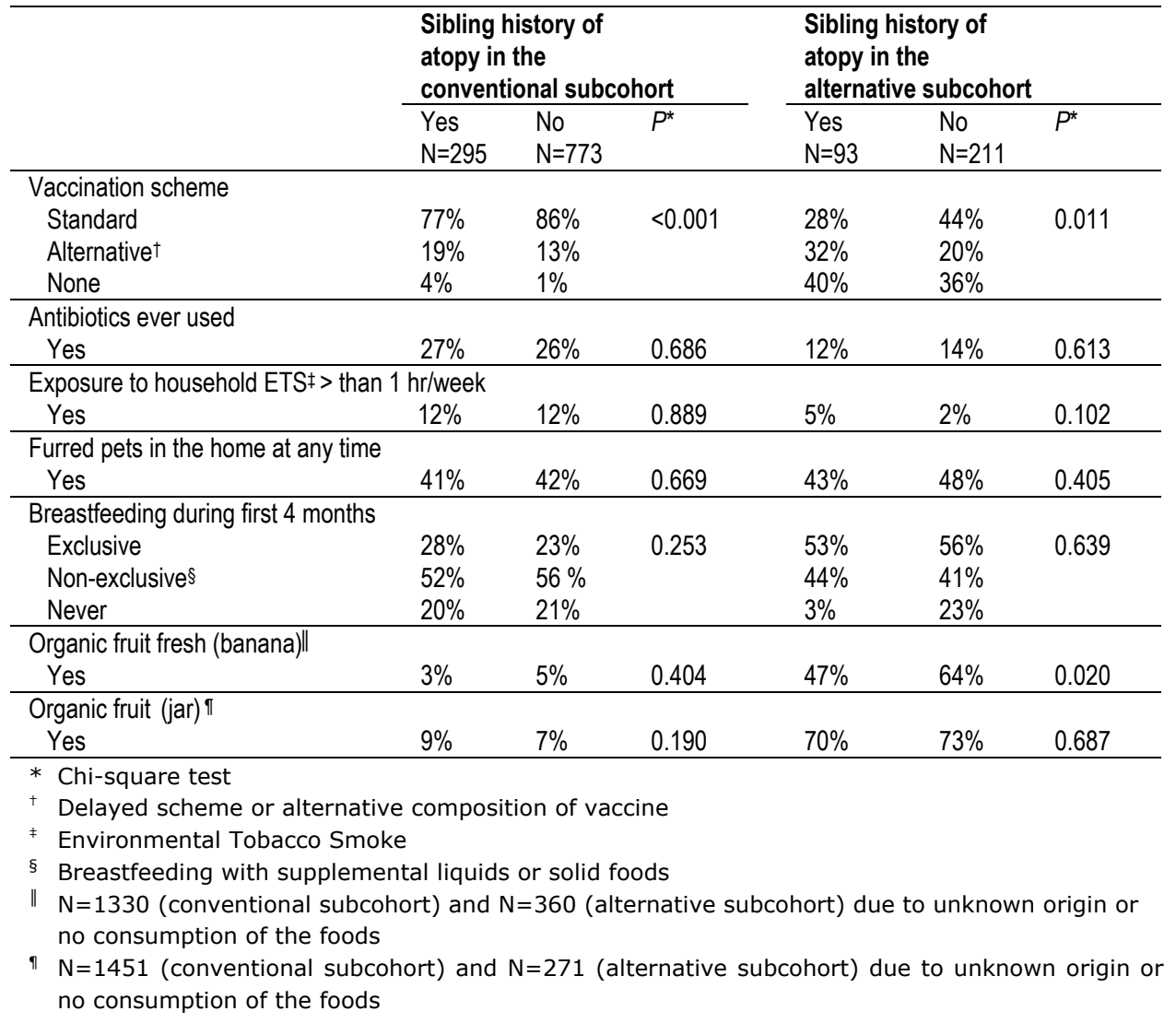

One may argue that a definition of atopic manifestations including asthma, pet or house dust mite allergy, hay fever as well as eczema has a low specificity. We therefore evaluated differences in lifestyle characteristics for these atopic manifestations separately. Differences in lifestyle characteristics between atopic and non-atopic families were of same size and were only found for the same lifestyle characteristics (furred pets, exposure to ETS and vaccinations), which might indicate that our definition of atopy was specific enough to evaluate our research question.

Several points merit consideration. First, parents who have 'prudent' lifestyle characteristics may also have a different way of labelling atopic complaints. Second, differences in reporting atopic symptoms may have occurred between the conventional and alternative subcohort due to diagnostic differences. Therefore, a direct comparison of prevalence rates between both subcohorts has to be made with caution, which was why we have presented our results for these two subcohorts separately. Finally, the differences in lifestyle practices between 
atopic and non-atopic families in our study were small and cannot have a strong confounding effect, suggesting that confounding-by-indication will presumably be limited in our study. This may be different in other birth cohort studies due to differences in study population characteristics and study design. Like every other study, our study deals with self-selection of participants (25). In this population with a probably high interest in health, one could have expected substantial differences between atopic and non-atopic families with regard to 'prudent' lifestyle choices. However, we report only small differences and expect differences to be even smaller in a general population.

An earlier Dutch study on differences in lifestyle and between allergic and non-allergic parents among 3147 infants aged 2-3 months revealed, like our study, a relationship between lifestyle factors related to furred pets or smoking and allergic disease in parents (27). Infants of allergic parents were more likely than other infants to be born in a home free of cats and cigarette smoking. The infants of allergic parents in this study were later exposed to newly introduced foods. In our study however, we did not find differences between families with and without a parental history of atopic manifestations with regard to exclusive breastfeeding for at least 4 months, which can be regarded as an indicator for postponing the introduction of artificial and/or supplemental feeding in this period. The study mentioned did not address the issue of atopy in siblings. There are few examples of studies that look into the separate effect of parental and sibling atopic manifestations.

Fewer furred pets and less exposure to ETS were significantly related to parental but not to sibling history of atopic manifestations. A potential explanation is the notion that atopic parents may experience effects of smoking or furred pets on their own health, and therefore take precautions since they anticipate the susceptibility of their child. In case of sibling but not parental atopic manifestations, there was a significant positive relation with alternative vaccination schemes. It is possible that side effects of vaccinations in the child or its older sibling made parents decide to alter their vaccination policy for their present child. These observations suggest a self-inflicted prudent lifestyle adopted by parents with a family history of atopic manifestations in order to protect their child against atopic disease development (confounding-by-indication).

We considered 'reverse causation' as possible explanation for our findings. Reverse causation in our study would mean that atopy in the index child had changed the lifestyle of parents. We evaluated associations between a parental history of atopy and having furred pets and exposure to ETS as measured before the index child was born (during pregnancy). We did the same for a sibling's history of atopy and intention to have the index child vaccinated according to the standard scheme. Less exposure to ETS might have been influenced by atopy in the index child, since the difference between atopic and non-atopic mothers that smoked or were exposed to ETS during pregnancy was not statistically significant.

In summary, some 'prudent' lifestyle characteristics differed between atopic and non-atopic families, depending on whether atopic manifestations were present in parents or older siblings. This has important consequences for the validity in epidemiological studies on the etiology of atopic manifestations in children. Confounding-by-indication due to a family history of atopic 
manifestations can best be controlled for by considering atopy in parents and siblings as separate confounders.

\section{Acknowledgement}

We thank Dr. Edmond Schoorel for giving valuable advice, and also like to thank all parents and infants who participated in this study. 


\section{References}

1. von Mutius E. The rising trends in asthma and allergic disease. Clin Exp Allergy 1998;5:45-9.

2. Sears MR. Epidemiology of childhood asthma. Lancet 1997;350:1015-20.

3. Worldwide variation in prevalence of symptoms of asthma, allergic rhinoconjunctivitis, and atopic eczema: ISAAC. Lancet 1998;351:1225-32.

4. Duffy DL. Genetic epidemiology of asthma. Epidemiol Rev 1997;19:129-43.

5. von Mutius E, Fritzsch C, Weiland SK, Roll G, Magnussen H. Prevalence of asthma and allergic disorders among children in united Germany: a descriptive comparison. BMJ 1992;305:1395-9.

6. von Mutius E, Martinez FD, Fritzsch C, Nicolai T, Roell G, Thiemann HH. Prevalence of asthma and atopy in two areas of West and East Germany. Am J Respir Crit Care Med 1994;149:358-64.

7. Cookson W. The alliance of genes and environment in asthma and allergy. Nature 1999; 402:B5-11.

8. Alm JS, Swartz J, Lilja G, Scheynius A, Pershagen G. Atopy in children of families with an anthroposophic lifestyle. Lancet 1999;353:1485-8.

9. Von Ehrenstein OS, Von Mutius E, Illi S, Baumann L, Bohm O, von Kries R. Reduced risk of hay fever and asthma among children of farmers. Clin Exp Allergy 2000;30:187-93.

10. Braun Fahrlander C, Gassner M, Grize L, Neu U, Sennhauser FH, Varonier HS, et al. Prevalence of hay fever and allergic sensitisation in farmer's children and their peers living in the same rural community. Clin Exp Allergy 1999;29:28-34.

11. Riedler J, Braun Fahrlander C, Eder W, Schreuer M, Waser M, Maisch S, et al. Exposure to farming in early life and development of asthma and allergy: a crosssectional survey. Lancet 2001;358:1129-33.

12. Wickens KL, Crane J, Kemp TJ, Lewis SJ, D'Souza WJ, Sawyer GM, et al. Family size, infections, and asthma prevalence in New Zealand children. Epidemiology 1999;10:699-705.

13. Bodner C, Godden D, Seaton A. Family size, childhood infections and atopic diseases. Thorax 1998;53:28-32.

14. Jarvis D, Chinn S, Luczynska C, Burney P. The association of family size with atopy and atopic disease. Clin Exp Allergy 1997;27:240-5.

15. Steerenberg PA, Van Amsterdam JG, Vandebriel RJ, Vos JG, Van Bree L, Van Loveren $\mathrm{H}$. Environmental and lifestyle factors may act in concert to increase the prevalence of respiratory allergy including asthma. Clin Exp Allergy 1999;29:1303-8.

16. Ceuppens J. Western lifestyle, local defenses and the rising incidence of allergic rhinitis. Acta Otorhinolaryngol Belg 2000;54:391-5.

17. Wickens K, Pearce N, Crane J, Beasley R. Antibiotic use in early childhood and the development of asthma. Clin Exp Allergy 1999;29:766-71.

18. Seaton A, Godden DJ, Brown K. Increase in asthma: a more toxic environment or a more susceptible population? Thorax 1994;49:171-4.

19. Black PN, Sharpe S. Dietary fat and asthma: is there a connection? Eur Respir J 1997;10:6-12.

20. Lau S, Illi S, Sommerfeld C, Niggemann B, Bergmann R, von Mutius E, et al. Early exposure to house-dust mite and cat allergens and development of childhood asthma: a cohort study. Lancet 2000;356:1392-7. 
21. Custovic A, Simpson BM, Simpson A, Hallam CL, Marolia H, Walsh D, et al. Current mite, cat, and dog allergen exposure, pet ownership, and sensitisation to inhalant allergens in adults. J Allergy Clin Immunol 2003;111:402-7.

22. Wahn U, Lau S, Bergmann R, Kulig M, Forster J, Bergmann K, et al. Indoor allergen exposure is a risk factor for sensitisation during the first three years of life. J Allergy Clin Immunol 1997;99:763-9.

23. Sporik R, Holgate ST, Platts Mills TA, Cogswell J]. Exposure to house-dust mite allergen (Der p I) and the development of asthma in childhood. A prospective study. $\mathrm{N}$ Engl J Med 1990;323:502-7.

24. Schayck CP, Knottnerus JA. Can the 'hygiene hypothesis' be explained by confounding by behaviour? J Clin Epidemiol 2004;57:435-37

25. Kummeling I, Thijs C, Penders J, Snijders BEP, Stelma F, Reimerink J, et al. Etiology of atopy in infancy: the KOALA Birth Cohort Study. Pediatr Allergy Immunol 2005;16:679-84.

26. Bastiaanssen JM, de Bie RA, Bastiaenen CH, Heuts A, Kroese ME, Essed GG, et al. Etiology and prognosis of pregnancy-related pelvic girdle pain; design of a longitudinal study. BMC public health 2005;5.

27. Wijga A, Smit HA, Brunekreef B, Gerritsen J, Kerkhof M, Koopman LP, et al. Are children at high familial risk of developing allergy born into a low risk environment? The PIAMA Birth Cohort Study. Clin Exp Allergy 2001;31:576-81. 


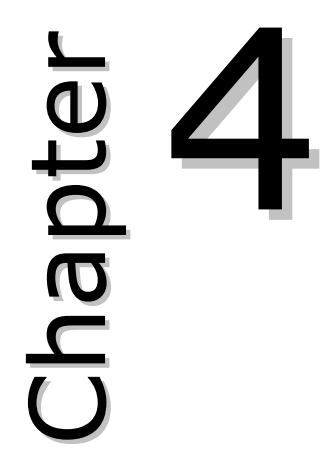

House dust endotoxin in the homes of families with an anthroposophic lifestyle

Kummeling I, de Bont C, Thijs C, Huber M, Brunekreef B, van den Brandt PA, Stelma F

SUBMITTED FOR PUBLICATION 


\section{Abstract}

Early life exposure to microbial endotoxin may protect against atopic disease. It was recently shown that children of anthroposophic families had a lower risk of atopy. Little is known about the microbial exposure in the homes of these families. We sampled dust from floors and children's mattresses in 26 anthroposophic and 24 families with a conventional lifestyle selected from the Dutch KOALA Birth Cohort Study. Total dust weights on floors were higher in anthroposophic families (geometric mean [GM] 0.71 vs. $0.09 \mathrm{~g} / \mathrm{m}^{2}, P<0.001$ ). Endotoxin quantity per $\mathrm{m}^{2}$ was higher in anthroposophic families (floors: geometric mean [GM] 17,442 vs. $1,937 \mathrm{EU} / \mathrm{m}^{2}, P<0.001$; mattresses: GM 2,654 vs. $\left.863 \mathrm{EU} / \mathrm{m}^{2}, P=0.008\right)$. Der $p 1$ quantity per $\mathrm{m}^{2}$ was also higher in anthroposophic families (floors: geometric mean [GM] $158.8 \mathrm{vs} .39 .0 \mathrm{ng} / \mathrm{m}^{2}, P=$ 0.049 ; mattresses: GM 174.3 vs. $51.8 \mathrm{ng} / \mathrm{m}^{2}, P=0.001$ ). Endotoxin and Der $p 1$ content per $\mathrm{m}^{2}$ were mainly explained by the higher total dust weights. In conclusion, an anthroposophic lifestyle seems to expose to more dust on living room floors and therefore more endotoxin and Der $p 1$ per $\mathrm{m}^{2}$ compared to conventional lifestyle families. 


\section{Introduction}

Domestic environment exposures are investigated intensively in attempts to understand the rise in atopy seen over the last decades, predominantly in children (1). Children who grew up on a farm were at decreased risk of developing allergic disease $(2,3)$. This may be explained by the higher microbial exposure, especially to bacterial endotoxin, that was found in farming environments (3). Endotoxin is a cell wall component of Gram-negative bacteria and is commonly present in normal indoor environments as a constituent of house dust. Children of anthroposophic families were also found to have a lower risk of allergy (4), but little is known about the endotoxin exposure in the homes of these families.

In the KOALA Birth Cohort Study, the Netherlands, participating families have divergent lifestyle practices (conventional vs. alternative, the latter including anthroposophy) (5). From 2002 onwards, participants were visited at home for sampling of biomaterials. Our staff anecdotally and unanimously recorded houses of alternative lifestyle participants to appear 'less clean' (more dust, more lumber, more use of dusty natural materials like sheepskin for decorating the house).

On this basis, we questioned whether house dust components like endotoxin are among the factors that are related to an anthroposophic lifestyle like they are for farming. The hypothesis was tested that endotoxin levels in house dust samples obtained from the indoor environment of anthroposophic lifestyle families were higher than in conventional lifestyle families. Simultaneously, we also measured a second component of house dust, namely house dust mite allergen Der $p 1$.

\section{Subjects and methods}

\section{SUBJECTS}

In June 2003 samples of settled house dust were collected in the homes of 50 families selected from the KOALA Birth Cohort Study when index infants were in their $5^{\text {th }}$ or $6^{\text {th }}$ month of age. Starting in October 2000, pregnant women had been recruited from 1 . an ongoing prospective cohort study on Pregnancyrelated Pelvic Girdle Pain (PPGP study) (6), and 2. through several 'alternative' recruitment channels, i.e. anthroposophic doctors and midwifes, anthroposophic under-five clinics, Steiner Schools, posters and flyers in organic food shops and magazines for special interest groups (e.g. homeopathy, anthroposophy, antivaccine) (5). A total of 2834 participants were included, 2343 through the PPGP study and 491 through the alternative recruitment channels. We randomly selected 30 anthroposophic and 30 conventional families with infants being in their $5^{\text {th }}$ or $6^{\text {th }}$ month of age in the month of planned dust sampling (June 2003), of whom 26 and 24 families agreed to participate, respectively. An 'anthroposophic family' fulfilled the following criteria. First, the family had to be enrolled via the alternative recruitment channels. Second, it had to meet the following anthroposophic childrearing practices: intention to refuse the uptake of (some) standard vaccinations, intention to restrict the use of antibiotics and intention to practice an organic foods or vegetarian diet as measured in the (pregnancy) questionnaire at 34 weeks of gestation. Data on housing characteristics were collected by questionnaires during the home visits. 


\section{HOUSE DUST SAMPLES}

House dust samples were collected by one researcher ( $\mathrm{CdB})$ from the living room floor (seating area) and children's mattresses with the dust collected in a nylon sock inserted into the upper part of the suction pipe of the family's vacuum cleaner (the part which is attached to the flexible tube), according to a standardized protocol. Briefly, samples from the floors were taken according to the following directions:

- completely (= wall-to-wall) carpeted or smooth floors: $1 \mathrm{~m}^{2}$ for 2 minutes;

- smooth floor with a rug of at least $2 \mathrm{~m}^{2}: 1 \mathrm{~m}^{2}$ of the rug for 2 minutes

The whole area of the child's mattress was sampled for a period of 2 minutes. Prior to sampling, duvets, blankets or sheets (that the child sleeps under) were removed but under sheets or mattress covers remained on the bed. Dust samples were stored at $-20^{\circ} \mathrm{C}$ until extraction was performed.

The sample weight was determined at the time of extraction of the dust. Twenty-four hours before the samples were weighed, samples were removed from the freezer and placed in the room in which weighing was performed. Endotoxin and house dust mite allergen Der $p 1$ were extracted from the dust as described by Douwes et al. (7) and van Strien et al. (8) in the laboratory of the Institute for Risk Assessment Sciences, Utrecht, the Netherlands. Bacterial endotoxin levels were assayed with a quantitative kinetic chromogenic Limnulus amoebocyte lysate (LAL) method according to the instructions of the manufacturer (Bio Whittaker, Walkersville, MD, USA) as described previously (7). The house dust mite allergen Der $p 1$ was detected by using reagents for a sandwich EIA, supplied by Indoor Biotechnologies (Cardiff, UK) and according to the manufacturer's instruction.

\section{STATISTICAL ANALYSIS}

Indoor endotoxin levels were expressed as endotoxin units per square meter of surface $\left(\mathrm{EU} / \mathrm{m}^{2}\right.$, 'loads'). Indoor Der $p 1$ levels were expressed as nanograms per square meter of surface $\left(\mathrm{ng} / \mathrm{m}^{2}\right.$, 'loads'). Samples with undetectable $(<20 \mathrm{mg})$ dust $(n=21)$, endotoxin $(n=8)$ or Der $p 1(n=56)$ levels were given a value of $2 / 3$ of the detection limit value of the tests. Since amounts of dust were very low we could not quantify endotoxin and Der $p 1$ concentrations. Except for Der $p 1$ loads, levels were log10-normally distributed. Therefore, data are presented as geometric means (10 to the power of the average of log10-transformed concentrations, GM) and geometric standard deviations (10 to the power of the standard deviation of log10-transformed concentrations, GSD).

First, differences in total dust weights, endotoxin and $\operatorname{Der} p 1$ loads between anthroposophic and conventional families were tested using Student's $t$ tests with log10-transformed concentrations. Der $p 1$ loads were examined by nonparametric Mann-Whitney $U$ tests because of nonnormality. Second, determinants of total dust weights, endotoxin and Der $p 1$ loads were identified by variable selection. Home and cleaning characteristics (defined as in Table I) for which an effect had been hypothesised a priori, and that were significantly $(P<$ $0.10)$ associated with log 10-transformed loads were included in this analysis. Finally, a linear regression model of the association between anthroposophic lifestyle and endotoxin or Der $p 1$ loads was fitted, taking into account the determinants that had been selected in the previous analyses. Results are presented as geometric mean ratio (GMR) with corresponding $95 \%$ confidence 
intervals ( $95 \% \mathrm{CI}$ ). GMR (10 to the power of beta) is the factor by which the geometric mean amounts of the dependent variable differs between the category of interest and the reference category of the determinant.

\section{Results}

Asthma and atopic manifestations in mothers, fathers or older siblings did not differ between anthroposophic and conventional families, except for atopic mothers (more prevalent in the anthroposophic families) (Table I). Anthroposophic families more often lived in older homes (built before 1960) than conventional lifestyle families. Anthroposophic families also used naturally based cleaning products more often. Furthermore, children of anthroposophic families were more likely to sleep on used mattresses.

Total dust weights on floors were highly correlated with endotoxin (Pearson's $\mathrm{r}=0.875, P<0.001$ ) and moderately with Der $p 1$ loads (Pearson's $r$ $=0.614, P<0.001$ ) on floors. Total dust weights on mattresses were also highly correlated with endotoxin (Pearson's $r=0.722, P<0.001$ ) and moderately with Der $p 1$ loads (Pearson's $r=0.581, P<0.001$ ).

Anthroposophic families had higher total dust weights, and endotoxin and Der $p 1$ loads, both on the living room floor and the child's mattress, compared to conventional families (a factor 7.9 difference in geometric mean amounts of living room floor dust $[P<0.001]$ and a factor 1.7 difference for mattresses $[P=$ 0.067]; a factor 9.0 difference in geometric mean loads of living room floor endotoxin $[P<0.001]$ and a factor 3.1 for mattresses $[P=0.008]$; a factor 4.1 difference in geometric mean loads of living room floor Der $p 1[P=0.049]$ and a factor 3.4 difference for mattresses $[P=0.001]$, unadjusted analysis) (Table II).

The association between anthroposophic lifestyle and total dust weights, endotoxin and Der $p 1$ content per $\mathrm{m}^{2}$ floor was evaluated adjusting for determinants that were selected by variable selection by stepwise (backward) multiple linear regression analysis. Log10-transformed gram of dust on floors was explained by lifestyle (GMR $=5.12 ; 95 \% \mathrm{CI}: 2.10-12.59)$, floor covering (GMR = $3.86 ; 95 \% \mathrm{CI}: 1.49-10.05)$, and vacuum cleaning (GMR $=0.39 ; 95 \% \mathrm{CI}: 0.16-$ 0.96). For mattresses, log10-transformed gram of dust was not explained by any of the selected variables. Endotoxin loads on floors were explained by total gram of dust on floors (GMR $=9.51 ; 95 \% \mathrm{CI}: 6.68-13.50)$ and type of floor covering $(\mathrm{GMR}=2.07 ; 95 \% \mathrm{CI}: 1.11-3.88)$. Endotoxin loads on mattresses were explained by total gram of dust on mattresses (GMR $=14.45 ; 95 \% \mathrm{CI}: 6.22-31.62$ ) and age of the mattress (GMR $=1.94 ; 95 \% \mathrm{CI}: 1.00-3.79)$. Der $p 1$ loads on floors were explained by total gram of dust on floors (GMR $=3.59 ; 95 \% \mathrm{CI}: 1.96-6.58)$ and type of floor covering (GMR $=5.41 ; 95 \% \mathrm{CI}: 1.83-15.84)$. Der $p 1$ loads on mattresses were explained by total higher total dust weight (GMR $=17.78 ; 95 \%$ CI: $5.44-50.12$ ) and age of the mattress (GMR $=4,17 ; 95 \% \mathrm{CI}: 1.62-10.66)$. 


\section{Table I}

Asthma and atopic manifestations and home characteristics of conventional and anthroposophic lifestyle families $(n=50)$

\begin{tabular}{|c|c|c|}
\hline \multirow[t]{2}{*}{ Measure } & $\begin{array}{l}\text { Conventional } \\
\text { lifestyle families }\end{array}$ & $\begin{array}{l}\text { Anthroposophic } \\
\text { lifestyle families }\end{array}$ \\
\hline & $N=24$ & $\mathrm{~N}=26$ \\
\hline \multicolumn{3}{|l|}{ Asthma mother } \\
\hline Yes vs. no & $3 / 18$ & $2 / 22$ \\
\hline \multicolumn{3}{|l|}{ Asthma father } \\
\hline Yes vs. no & $3 / 18$ & $3 / 20$ \\
\hline \multicolumn{3}{|l|}{ Asthma older siblings } \\
\hline Yes vs. no & $2 / 12$ & $4 / 16$ \\
\hline \multicolumn{3}{|c|}{ Atopic manifestations mother } \\
\hline Yes vs. no & $8 / 13$ & $16 / 7^{* *}$ \\
\hline \multicolumn{3}{|c|}{ Atopic manifestations father } \\
\hline Yes vs. no & $7 / 17$ & $11 / 11$ \\
\hline \multicolumn{3}{|c|}{ Atopic manifestations older siblings } \\
\hline Yes vs. no & $5 / 8$ & 9/11 \\
\hline \multicolumn{3}{|l|}{ House built before 1960} \\
\hline Yes vs. no & $3 / 21$ & $12 / 14^{*}$ \\
\hline \multicolumn{3}{|c|}{ Floor covering of sample area living room } \\
\hline Smooth vs. carpeted & $19 / 5$ & $15 / 11$ \\
\hline \multicolumn{3}{|c|}{ Floor covering in the child's bedroom } \\
\hline Smooth vs. carpeted & $18 / 6$ & $17 / 9$ \\
\hline \multicolumn{3}{|c|}{ Used mattress in the child's bed } \\
\hline Yes vs. no & $12 / 12$ & $22 / 4^{* *}$ \\
\hline \multicolumn{3}{|c|}{ Mattress with top plastic sheeting } \\
\hline Yes vs. no & $5 / 19$ & $1 / 25$ \\
\hline \multicolumn{3}{|c|}{ Presence of furred pets in the home } \\
\hline Yes vs. no & $8 / 16$ & $8 / 18$ \\
\hline \multicolumn{3}{|c|}{ Vacuum cleaning twice a week or less } \\
\hline Yes vs. no & $13 / 11$ & $18 / 8$ \\
\hline \multicolumn{3}{|c|}{ Damp or mouldy stains on indoor surfaces reported by occupants } \\
\hline Yes vs. no & $0 / 24$ & $1 / 25$ \\
\hline \multicolumn{3}{|c|}{ Use of naturally based cleaning products a } \\
\hline Yes vs. no & $0 / 24$ & $17 / 9^{*}$ \\
\hline
\end{tabular}


higher amounts of house dust on floors, like for example more use of dusty natural materials like sheepskin for decorating the house or else. One may argue that the higher amount of total dust in anthroposophic families simply reflects less cleaning because of a potential lower prevalence of atopic manifestations in these families. However, we found no differences between the anthroposophic and conventional families with regard to asthma and atopic manifestations in parents and older siblings (except for a maternal history of atopic manifestations), and a family history of atopy or asthma was not associated with total amount of dust.

Besides higher loads of endotoxin, we also found higher loads of Der $p 1$ in the homes of anthroposophic lifestyle families. This result follows the finding that children of farmers were not only exposed to considerably higher levels of endotoxin than their non-farming peers, but also to significantly higher levels of house dust mite $(3,15)$.

In conclusion, an anthroposophic lifestyle seems to expose to more dust on floors compared to conventional lifestyle families. We recommend that, in a search for anthroposophic features responsible for the protective effect of anthroposophy on the development of atopy, exposure to house dust components should be taken into account.

\section{Acknowledgments}

We thank all parents who participated in this study and also like to thank the Institute for Risk Assessment Sciences, Utrecht, the Netherlands, for funding of analysis of dust samples. 


\section{References}

1. ISAAC Steering Committee. The International Study of Asthma and Allergies in Childhood (ISAAC) Steering Committee. Worldwide variation in prevalence of symptoms of asthma, allergic rhinoconjunctivitis, and atopic eczema. Lancet, 351:1225-32; 1998.

2. Braun-Fahrlander, C.; Gassner, M.; Grize, L.; Neu, U.; Sennhauser, F.H; Varonier, H.S.; Vuille, J.C.; Wuthrich, B. Prevalence of hay fever and allergic sensitisation in farmer's children and their peers living in the same rural community. Clin Exp Allergy 29:28-34; 1999.

3. Riedler, J.; Braun-Fahrlander, C.; Eder, W.; Schreuer, M.; Waser, M.; Maisch, S.; Carr, D.; Schierl, R.; Nowak, D.; von Mutius, E. Exposure to farming in early life and development of asthma and allergy: a cross-sectional survey. Lancet 358:1129-33; 2001.

4. Alm, J.S.; Swartz, J.; Lilja, G.; Scheynius, A.; Pershagen, G. Atopy in children of families with an anthroposophic lifestyle. Lancet 353:1485-1488; 1999.

5. Kummeling, I.; Thijs, C.; Penders, J.; Snijders, B.E.P.; Stelma, F.; Reimerink, J.; Koopmans, M.; Dagnelie, P.C.; Huber, M., Jansen, C.J.F.; de Bie, R.A.; van den Brandt, P.A. Etiology of atopy in infancy: the KOALA Birth Cohort Study. Pediatr Allergy Immunol. 16:679-84; 2005.

6. Bastiaanssen, J.M.; de Bie, R.A.; Bastiaenen, C.H.; Heuts, A.; Kroese, M.E.; Essed, G.G. et al. Etiology and prognosis of pregnancy-related pelvic girdle pain; design of a longitudinal study. BMC Public Health 5:1-8; 2005.

7. Douwes, J.; Versloot, P.; Hollander, A.; Heederik, D.; Doekes, G. Influence of various dust sampling and extraction methods on the measurement of airborne endotoxin. Appl Environ Microbiol. 61:1763-69; 1995.

8. Van Strien, R.T.; Koopman, L.P.; Kerkhof, M.; Oldenwening, M.; de Jongste, J.C.; Gerritsen, J.; Heijens, H.J.; Aalberse, R.C.; Smit, H.A.; Brunekreef, B. Mattress encasings and mite allergen levels in the Prevention and Incidence of Asthma and Mite Allergy study. Clin Exp Allergy 33:490-95; 2003.

9. Rizzo, M.C.; Naspitz, C.K.; Fernandez Caldas, E.; Lockey, R.F.; Mimica, I.; Sole, D. Endotoxin exposure and symptoms in asthmatic children. Pediatr Allergy Immunol. 8:121-26; 1997.

10. Gehring, U.; Brunekreef, B.; Fahlbusch, B.; Wichmann, H.E.; Heinrich, J. Are house dust mite allergen levels influenced by cold winter weather? Allergy 60:1079-82; 2005.

11. Van Strien, R.T.; Verhoeff, A.P.; van Wijnen, J.H.; Doekes, G.; de Meer, G.E.; Brunekreef, B. Der p I concentrations in mattress surface and floor dust collected from infants' bedrooms. Clin Exp Allergy 25:1184-89; 1995.

12. Wouters, I.M.; Douwes, J.; Doekes, G.; Thorne, P.S.; Brunekreef, B.; Heederik, D.J. Increased levels of markers of microbial exposure in homes with indoor storage of organic household waste. Appl Environ Microbiol. 66:627-31; 2000.

13. Schram-Bijkerk, D.; Doekes, G.; Boeve, M.; Douwes, J.; Riedler, J.; Ublagger, E.; von Mutius, E.; Budde, J.; Pershagen, G.; van Hage, M.; Wickman, M.; Braun-Fahrlander, C.; Waser, M.; Brunekreef, B. Nonlinear relations between house dust mite allergen levels and mite sensitisation in farm and nonfarm children. Allergy 61:640-47; 2006.

14. Luczynska, C.M. Identification and quantification of mite allergens. Allergy 53: 54$57 ; 1998$. 
15. Braun-Fahrlander, C.; Riedler, J.; Herz, U.; Eder, W.; Waser, M.; Grize, L.; Maisch, S.; Carr, D.; Gerlach, F.; Bufe, A.; Lauener, R.P.; Schierl, R.; Renz, H.; Nowak, D.; von Mutius, E. Environmental exposure to endotoxin and its relation to asthma in school-age children. N Engl J Med. 347:869-77; 2002. 


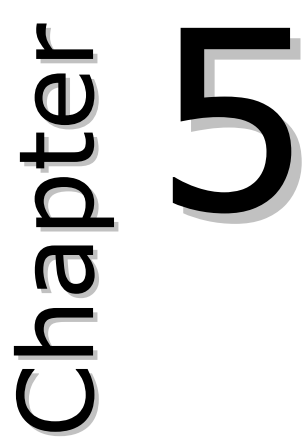

DPPT-Hib vaccinations and risk of eczema and recurrent wheeze in the first year of life

Kummeling I, Thijs C, Stelma F, Huber M, van den Brandt PA, Dagnelie PC

PEDIATRICS 2007 (IN PRESS) 


\section{Abstract}

\section{OBJECTIVE}

Among potential etiological factors for atopic manifestations, infant vaccinations have recently been discussed. We evaluated in a prospective design whether infants who were unvaccinated or vaccinated according to incomplete vaccination schedules in the first six months of age were at decreased risk of eczema and recurrent wheeze in the first year of life.

\section{METHODS}

Information on vaccinations against diphtheria, pertussis, poliomyelitis, tetanus (DPPT), and Haemophilus influenzae type B vaccine (Hib) and eczema and recurrent wheeze was collected by repeated questionnaires in 2764 families participating in the KOALA Birth Cohort Study, the Netherlands. A standard vaccination schedule referred to 3 DPPT-Hib vaccinations in the first 6 months with the first given in months 1-3, an incomplete vaccination schedule was defined as any other vaccination schedule. Exclusion criteria were prematurity (gestational age < 37 weeks) and congenital abnormalities related to immunity (such as Down syndrome). Multiple logistic regression models were fitted to adjust for confounding factors.

\section{RESULTS}

During the first year of life, the incidence of eczema was 23\% (584 of 2537 infants) and of recurrent wheeze $8 \%$ (203 of 2402 infants). At age six months, 1969 of 2545 infants $(78 \%)$ had been vaccinated according to a standard schedule, 393 (15\%) according to an incomplete schedule and $182(7 \%)$ never. Compared to infants with standard vaccination schedules, infants with incomplete schedules did not differ significantly in eczema risk (adjusted odds ratio (ORadj) $=1.24,95 \%$ confidence interval $(\mathrm{CI}): 0.95-1.62$ ) or recurrent wheeze (ORadj=1.38, 95\% CI: 0.93-2.06). This was also true for infants who had never been vaccinated (eczema: $\mathrm{ORadj}=1.30,95 \% \mathrm{CI}: 0.85-2.00$; recurrent wheeze: ORadj=0.76, 95\% CI: 0.32-1.82).

\section{CONCLUSION}

This study shows that the risk of eczema or recurrent wheeze at age one year does not differ between infants with different vaccination status at age six months. 


\section{Introduction}

Atopic eczema is the most common atopic disease in infancy, affecting up to one-third of children in western societies (1). The presence of atopic eczema has been reported to be associated with an increased risk of wheeze and asthma later in life (2).

Among potential etiological factors, vaccinations have recently been discussed. Two mechanisms have been proposed by which vaccinations could affect the development of atopic disease: they may have direct allergy-inducing immune effects, or prevent possible protective effects of natural infections $(3,4)$. Epidemiological evidence for an association between vaccinations and atopy development is inconsistent (4-26). Some caution is needed since some studies were hampered by small numbers of unvaccinated children and some others were cross-sectional, in which, by design, the possibility of reverse causation exists. Also, the possibility of confounding by contraindication is a concern in interpreting results. Motives for not vaccinating are likely to be health-related, which may result in confounding-by-contraindication if these health-related problems are associated with atopic disease, but are not usually described in these studies (27).

The prospective KOALA Birth Cohort Study in the Netherlands includes a large proportion of infants who are completely unvaccinated $(n=182 ; 7 \%)$ at age six months because their parents opted for deviating from the recommended vaccination schedule. KOALA is (in Dutch) an acronym for Child, Parent and health: Lifestyle and Genetic constitution. The present report prospectively evaluates whether infants who were unvaccinated or vaccinated according to an incomplete vaccination schedule in the first six months of age were at decreased risk of eczema or recurrent wheeze in the first year of life compared to infants who were completely vaccinated. We also present parental motives for deviating from the standard vaccinations schedule.

\section{Methods}

\section{STUDY POPULATION}

The KOALA Birth Cohort Study started in October 2000 (28). Participants were recruited from two sources. First, healthy pregnant women at 34 weeks of gestation participating in a cohort study on Pregnancy-related Pelvic Girdle pain (PPGP study) (29), were asked to participate in the KOALA study ('conventional subcohort'). These women had been recruited through midwife practices at 12-16 weeks of gestation (and were therefore not selected on the basis of pelvic pain symptoms). Second, pregnant women with so-called 'alternative' lifestyles were recruited through several specific recruitment channels, i.e. anthroposophic doctors and midwifes, anthroposophic under-five clinics, Steiner Schools, posters and flyers in organic food shops and magazines for special interest groups (e.g. homeopathy, anthroposophy, anti-vaccine) ('alternative subcohort'). Anthroposophy is a human oriented spiritual philosophy grounded by Rudolf Steiner with specific theories and practices on health, education, art, architecture, and "bio-dynamic" agriculture. A total of 2834 participants were included in the KOALA study, of whom 2343 through the PPGP study and 491 through the specific 
recruitment channels. Exclusion criteria in the present study were prematurity (gestational age < 37 weeks) and congenital abnormalities related to immunity (such as Down syndrome). The study was approved by the Medical Ethical Committee of University Maastricht/Academic Hospital Maastricht. All participants had signed informed consent and completed the first questionnaire at the third trimester of pregnancy.

\section{EXPOSURE AND FOLLOW-UP}

In the Netherlands, during the time of the study, infants in their first six months were vaccinated against diphtheria, pertussis (with whole cell pertussis vaccine), poliomyelitis, tetanus and Haemophilus influenzae type B (DPPT-Hib) at 2, 3, and 4 months of age. More specifically, before March 2003 this concerned a combined DPPT vaccination and a separate Hib vaccination given simultaneously. From March 2003 onwards, a combined DPPT-Hib vaccination was given. In this study, the combined diphtheria-pertussis-tetanus-polio vaccination with a separate Hib vaccination (as used before March 2003) was considered as one DPPT-Hib vaccination at the same time and is called 'DTTP-Hib'. A minority of Dutch parents opt for deviating from the standard vaccination schedule and, for example, omit the pertussis component from the DPPT vaccine or postpone the first vaccinations to a later age; some even refrain from all vaccinations.

Vaccinations in the first six months of life were assessed by questionnaire when the infants were 7 months of age. The questions were phrased as follows: 'Until now, has your child received the standard vaccinations?' (namely DTTP-Hib vaccinations at 2,3 and 4 months). Answering options were: 1 . yes; 2 . no, my infant received vaccinations but according to another vaccination schedule; 3 . no, my infant received no vaccinations. Then, the age of the first vaccination was asked for. We divided infants in three groups: vaccinated according to a standard schedule (standard DPPT-Hib vaccinations, the first vaccination given in month 13 ), vaccinated according to an incomplete schedule (any other schedule), or never vaccinated until the age six months. Infants were regarded as vaccinated if they had been vaccinated at least once. We verified the parental reported history of vaccinations in a random sample of 300 subjects from the alternative subcohort by retrieving their vaccination records at the Dutch Vaccination Administration Office (DVAO). Using these records, a medical student who was blinded for the parentally reported vaccination data determined by which vaccination schedule the infants had been vaccinated. $73 \%$ of infants could be found in the records of the DVAO, and the parental reported history was similar to the information in the medical records in $89 \%$ of these cases (notably all 178 infants who were not vaccinated according to the parental report were not vaccinated according to the vaccination records either; and 86/94 (91\%) cases who were standard vaccinated according to parents were confirmed by the vaccination records).

Eczema development in the first year was assessed by questionnaire. At age 7 and 12 months, parents were asked whether their child had ever had an itchy rash that was coming and going in the past months. If this question was answered affirmatively at least once, infants were classified as having developed eczema in the first year of life. Infants for whom only diaper rash, rash around the eyes and/or scalp scaling was reported were not regarded as having developed eczema. Wheeze was also asked for in the 7 and 12 months 
postpartum questionnaires. At age 7 and 12 months, parents were asked whether their child ever had showed symptoms of wheeze and how many attacks in the past months. 'Recurrent wheeze' was defined as reported presence of wheezing with at least 4 attacks ever in the first year.

\section{STATISTICAL ANALYSIS}

Missing data in the questionnaires were treated as missing in the analyses and are presented as 'unknown' in the tables. Multiple logistic regression analyses were used to adjust for potential confounders, by simultaneously including the following covariates in the regression models (all for the first six months of life and defined as in Table I): sex; one or more self-reported doctor's diagnoses of parental or older siblings' atopic manifestations such as asthma, pet or house dust mite allergy, hay fever, eczema, and/or food allergy; number of older siblings; breastfeeding duration and exclusivety; attending daycare facilities; furred pets; exposure to environmental tobacco smoke (ETS); antibiotics use of mother during lactation; oral antibiotic use of infant.

Since some previous studies indicated that associations between exposures and atopic outcomes were limited to groups with increased inherited propensity for developing atopic disease $(30,31)$, we first tested the possibility of interaction between vaccination status and parental or sibling's history of atopy. Since none of these interaction terms were statistically significant they were eliminated from the regression models. Separate analyses of the conventional vs. alternative subcohort or boys vs. girls showed that the key findings were similar within these groups. Therefore we combined all infants in the final analyses, adjusting for 'subcohort' and sex. Results are presented as unadjusted and adjusted odds ratios (ORs) with corresponding 95\% confidence intervals (CI).

\section{Results}

In the present study, three children were excluded because of Down syndrome and 67 for prematurity (gestational age $<37$ weeks), resulting in 2764 participants. Of these, follow-up data on at least one health outcome until age 1 year were available for $90 \%(n=2496)$, which was $89 \% \quad(n=2036)$ of the conventional and $96 \%(n=460)$ of the alternative subcohort. Nearly all parents $(96 \%)$ were born in the Netherlands.

About half of infants had non-atopic parents; approximately $40 \%$ had one or more non-atopic older sibling and $16 \%$ had one or more atopic older sibling (Table I). Most traditional risk factors were equally present in both subcohorts but in the alternative subcohort, antibiotic exposure through medication was less present than in the conventional subcohort. 


\section{Table I}

Characteristics of the study population for the total cohort $(n=2764)$

\begin{tabular}{|c|c|c|}
\hline \multirow[t]{2}{*}{ Characteristic } & \multicolumn{2}{|c|}{ Total cohort } \\
\hline & $\mathrm{N}$ & $\%$ * \\
\hline Male & 1410 & $51 \%$ \\
\hline \multicolumn{3}{|l|}{ Parental history of atopic manifestations } \\
\hline None & 1339 & $48 \%$ \\
\hline Father & 519 & $19 \%$ \\
\hline Mother & 604 & $22 \%$ \\
\hline Both & 302 & $11 \%$ \\
\hline \multicolumn{3}{|l|}{ Sibling history of atopic manifestations } \\
\hline No older siblings & 1155 & $44 \%$ \\
\hline One older sibling - not atopic & 833 & $31 \%$ \\
\hline One older sibling - atopic & 261 & $10 \%$ \\
\hline$\geq 2$ older siblings - not atopic & 235 & $9 \%$ \\
\hline$\geq 2$ older siblings - one or both atopic & 159 & $6 \%$ \\
\hline Unknown & 121 & \\
\hline \multicolumn{3}{|l|}{ Breastfeeding at age 6 months } \\
\hline Yes, months 1-4 exclusive $\mathrm{BF}^{\dagger}$ & 622 & $25 \%$ \\
\hline Yes, months 1-4 non-exclusive $\mathrm{BF}^{\dagger}$ & 441 & $17 \%$ \\
\hline No, months 1-4 exclusive $\mathrm{BF}^{\dagger}$ & 62 & $3 \%$ \\
\hline No, months $1-4$ non-exclusive & 996 & $39 \%$ \\
\hline Never breastfeeding & 410 & $16 \%$ \\
\hline Unknown & 233 & \\
\hline \multicolumn{3}{|l|}{ Day care in first six months } \\
\hline Yes & 831 & $32 \%$ \\
\hline No & 1724 & $68 \%$ \\
\hline Unknown & 209 & \\
\hline \multicolumn{3}{|l|}{ Furred pets in first six months } \\
\hline Yes & 1168 & $45 \%$ \\
\hline No & 1387 & $55 \%$ \\
\hline Unknown & 209 & \\
\hline \multicolumn{3}{|l|}{ Exposure to ETS + in first six months } \\
\hline Yes & 294 & $12 \%$ \\
\hline No & 2197 & $88 \%$ \\
\hline Unknown & 273 & \\
\hline \multicolumn{3}{|c|}{ Antibiotic exposure through breastfeeding in first six months } \\
\hline Yes & 262 & $10 \%$ \\
\hline No & 2161 & $90 \%$ \\
\hline Unknown & 341 & \\
\hline \multicolumn{3}{|c|}{ Antibiotic exposure through oral medication in first six months } \\
\hline Yes & 489 & $20 \%$ \\
\hline No & 1973 & $80 \%$ \\
\hline Unknown & 302 & \\
\hline \multicolumn{3}{|l|}{ Vaccinations in first six months } \\
\hline Standard vaccination schedule & 1969 & $78 \%$ \\
\hline Incomplete vaccination schedule $\ddagger$ & 393 & $15 \%$ \\
\hline Never vaccinated & 182 & $7 \%$ \\
\hline Unknown & 220 & \\
\hline
\end{tabular}


Table I continued

\begin{tabular}{lll}
\hline Eczema in first year & & \\
No & 1953 & $77 \%$ \\
Yes & 584 & $23 \%$ \\
Unknown & 227 & \\
\hline Recurrent wheeze in first year & 2199 & $92 \%$ \\
No & 203 & $8 \%$ \\
Yes & 362 & \\
Unknown & & \\
\hline Excluding missings & & \\
+ BF breastfeeding, ETS environmental tobacco smoke & \\
$*$ Delayed schedule or alternative composition of vaccine & &
\end{tabular}

By the age of six months, 1969 (78\%) of 2545 infants had been vaccinated according to a standard schedule, 393 (15\%) according to an incomplete schedule and $182(7 \%)$ had never been vaccinated. Only $46 \%$ of the alternative compared to $84 \%$ of the conventional subcohort was vaccinated according to the standard schedule. In total, 584 (23\%) of 2537 infants were classified as having had eczema in the first year of life (this was $24 \%$ in the conventional and $20 \%$ in the alternative subcohort). Of these 584 infants with eczema, $483(83 \%)$ had no reported recurrent wheeze; 55 (9\%) had also reported recurrent wheeze and for 46 infants information on recurrent wheeze was unavailable. Recurrent wheeze was reported in 203 (8\%) of 2402 infants (this was $9 \%$ in the conventional and $5 \%$ in the alternative subcohort). Of these 203 infants with recurrent wheeze, 143 (70\%) had no eczema; 55 (27\%) had also reported eczema and for 5 infants information on eczema was unavailable. Of all infants with recurrent wheeze, $67 \%$ had used specific wheeze or asthma medication before age 12 months (beta 2-adrenergic or steroid inhalant therapy).

Compared to infants vaccinated according to the standard schedule, infants who were vaccinated according to incomplete schedules at age six months did not differ significantly in eczema risk (adjusted $\mathrm{OR}=1.24,95 \% \mathrm{CI}: 0.95-1.62$ ) (Table II). This was also true for infants who had never been vaccinated at age six months compared to infants vaccinated according to the standard schedule (adjusted $\mathrm{OR}=1.30,95 \% \mathrm{CI}: 0.85-2.00$ ). The risk of recurrent wheeze did not differ significantly in infants with incomplete vaccination schedules compared to infants with standard schedules (adjusted OR=1.28, 95\% CI: 0.93-2.06). Again, this was also true for infants who had never been vaccinated (adjusted $O R=0.76$, 95\% CI: 0.32-1.82).

To exclude potential reverse causation in the association between vaccinations and eczema or wheeze, we restricted our analyses to infants at risk of a first episode of eczema or recurrent wheeze after age 6 months (by excluding infants who had eczema $(n=447)$ or recurrent wheeze $(n=107)$ onset in the same period as vaccinations had been given, namely the first 6 months). The odds ratio's for eczema did not change much compared to those in Table II (adjusted OR for incomplete vaccination schedules $=1,52,95 \% \mathrm{CI}: 0.95-2.43$; adjusted OR for no vaccinations $=1.35,95 \% \mathrm{CI}: 0.58-3.13$ ). 


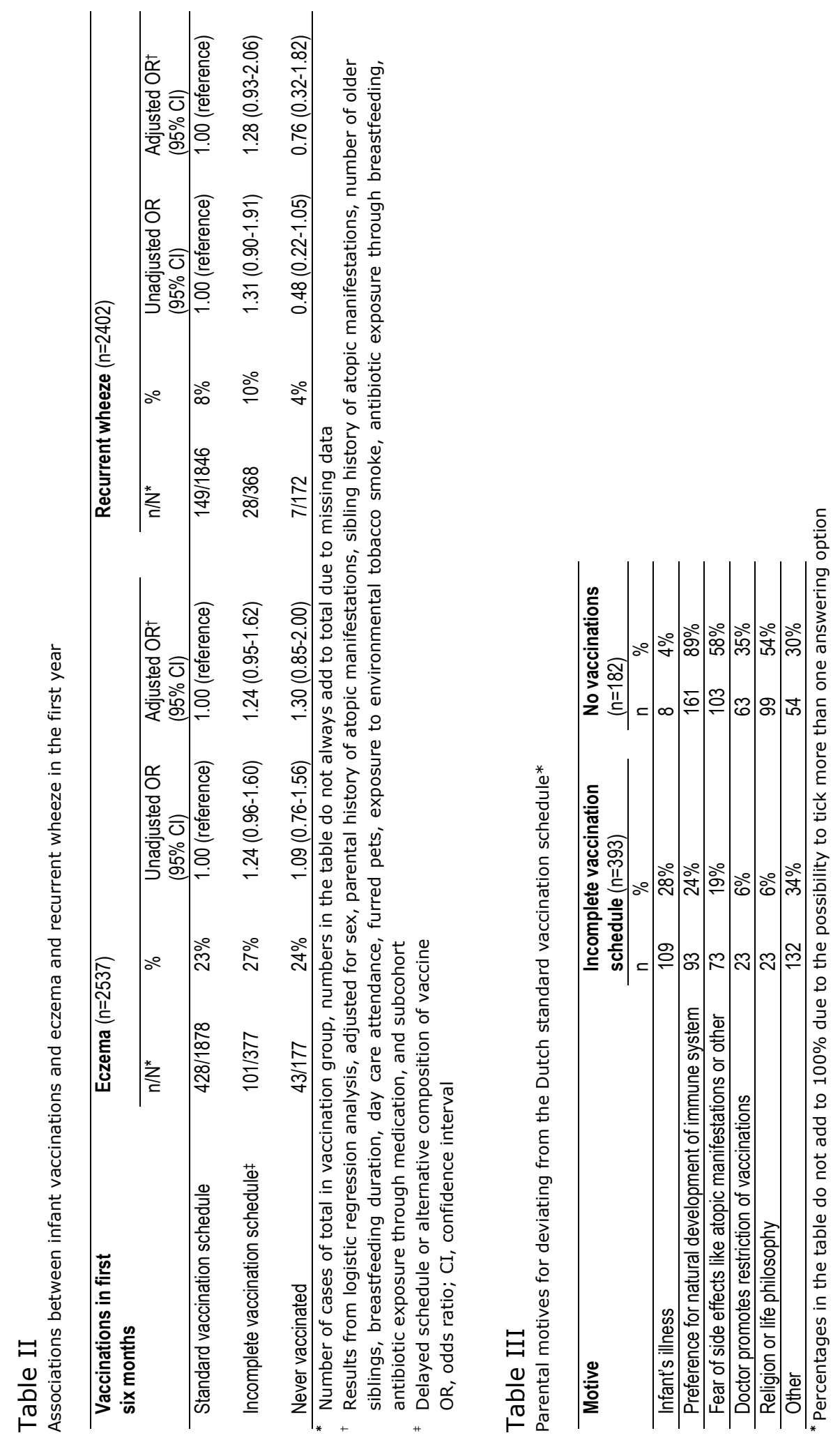


The same was true for the association between recurrent wheeze and never been vaccinated (adjusted OR for no vaccinations $=0.98,95 \% \mathrm{CI}: 0.34-2.87$ ); but when done for incomplete vaccination schedule, the OR moved slightly towards the 1 (adjusted OR for incomplete vaccination schedules $=0.96,95 \% \mathrm{CI}$ : 0.51-1.80). Illness of the infant was only rarely the motive to refrain from all vaccinations in the first six months; this decision was more often based on beliefs with regard to a more natural development of the immune system, fear of side effects and/or religion or life philosophy (Table III).

\section{Discussion}

In this prospective study in a cohort with a relatively large proportion of unvaccinated infants we showed that compared to infants vaccinated according to the standard schedule, infants with incomplete schedules or who were never vaccinated against diphtheria, pertussis, poliomyelitis, tetanus and Hib (DPPT-Hib) at age six months had no different risk of eczema and wheeze in the first year of life. Our study has the advantage of being population-based, with relatively short intervals between subsequent follow-up questionnaires, which decrease the possibility of recall bias. The standard vaccination schedule in the Netherlands is not very complicated and vaccination history may be reliably obtained using questionnaires. Nevertheless, we compared a subset of the parental responses to the information contained in medical records and found that nearly all vaccination data based on medical records to be reflected by the parental responses. We are fairly confident about the validity when parents report that the infant was not vaccinated. First, parents have most often well-expressed beliefs for not vaccinating; and second, the validation by the vaccination records showed $100 \%$ agreement. By contrast, if parents reported that the infant was standard vaccinated, this was not always confirmed by the vaccination records. The vaccination records depend on reporting of each vaccination by the infant welfare centre, and we cannot rule out that vaccinations were incompletely reported to the vaccination administration; but since the validation was performed in the alternative subcohort where underreporting may be more prevalent than in the conventional subcohort, we think that misclassification is of minor effect on the results.

Follow-up rates were high, which would have limited potential bias with regard to baseline characteristics or outcomes. We showed that parents mainly choose to deviate from the standard vaccination schedule because of certain (philosophical) beliefs. This stresses that, at least in our study, motives to refrain from vaccinations are unlikely to be health-related, which limits the possibility of confounding-by-contraindication or reverse causation. 'Fear of side effects like atopic manifestations' was often the reason to refrain from all vaccinations, and one may argue that this is a potential risk of confounding-by-contraindication. This would, however, only be the case if 'fear of side effects' was associated with an increased risk of eczema or wheeze by a family history of atopic manifestations, which was included as a potential confounder in all our analyses. We previously showed that some prudent lifestyle characteristics, among others vaccinations, differed between atopic and non-atopic families, depending on whether atopic manifestations were present in parents or older siblings (32). 
Therefore, we considered a parental and siblings' history of atopic manifestations as separate potential confounders in all analyses. 'Infant's illness' was often a motive for alternative vaccination schedules but rarely for no vaccination, which also indicates that potential reverse causation is limited.

Atopic outcomes like infant eczema and wheeze may be fairly unspecific for infants aged 1 years (33) and therefore weak indicators of atopic development such as asthma in children. Children with physician confirmed wheeze have been reported to have significantly poorer lung function compared to those with only parentally reported wheeze that was medically unconfirmed (34). In individuals with an atopic constitution, the underlying mechanism of developing eczema is often dominated by an IgE-antibody-associated reaction to specific allergens, justifying the term 'atopic eczema'. Specific IgE or total serum IgE levels are, however, only weakly associated with atopic symptoms like eczema and wheeze (35). Therefore, we evaluated clinical symptoms and used the term eczema instead of atopic eczema. Our definitions of eczema and recurrent wheeze were based on questions adapted from the International Study of Asthma and Allergies in Childhood (ISAAC) questionnaires and included generally accepted characteristics, like a chronically relapsing course and an itchy rash (eczema) or recurrent symptoms (wheeze). The fact that the majority of wheeze complaints had been acknowledged by medical doctors (67\% of infants with reported recurrent wheeze had been using wheeze or asthma medication) may strengthen the validity of our measure. Second, parents who object to vaccinations could also have a different way of labelling atopic complaints. Differences in reporting eczema or wheeze symptoms could also have occurred between the conventional and alternative subcohort.

Our findings confirm the findings of some other authors, although observed in older children. DTP vaccinated children were not more than nonvaccinated children afflicted with atopic disease at age 5 years (23); wheezing illnesses up to 18 months (22) and 42 months (12); hay fever (25); asthma, atopic manifestations and wheeze in children < 5 years of age (13); risk of asthma up to age 6 years $(14,21)$; asthma, wheeze and atopy up to age six (24) and asthma or eczema up to age 11 years (16). A case-control study including 7-8 year old Dutch and German children showed no association between pertussis vaccination and respiratory symptoms (26). In these children, pertussis vaccine was co-administered with vaccination against DPT, but pertussis-unvaccinated children were not necessarily completely unvaccinated.

In contrast, authors of a Dutch retrospective study reported pertussis vaccination to be associated with lower risk of eczema in six year old children (17). In this study, 39 of 44 infants classified as not vaccinated for pertussis, had no vaccination at all and 'pertussis-vaccinated' infants were also DPT vaccinated. Therefore, the comparison made in this study would appear to reflect DPPTvaccinated children vs. completely unvaccinated children. A cross-sectional survey in children aged 3-18 years (15) showed ever eczema and current wheeze to be lower in partially vaccinated and completely unvaccinated children. However, due to its cross-sectional design, the results of this study should be interpreted with causation because of the possibility of reverse causation. In contrast, increased prevalence of eczema in DPPT vaccinated children aged 0-5 years was found in a prospective cohort study in New Zealand with only 23 completely unvaccinated children (8). The authors of this study acknowledged that they had not been able 
to adjust simultaneously for all potential confounders because of the small numbers involved.

In conclusion, the present study shows that the risk of eczema or recurrent wheeze at age one year does not differ between infants with different vaccination status at age six months.

\section{Acknowledgments}

We thank Mrs Petra Oomen (Dutch Vaccination Administration Office) for retrieval of vaccination records, and Peter Luyten (medical student) for checking vaccination data; Edmond Schoorel MD, for giving valuable advice; and also like to thank all parents and infants who participated in this study. 


\section{References}

1. The International Study of Asthma and Allergies in Childhood (ISAAC) Steering Committee. Worldwide variation in prevalence of symptoms of asthma, allergic rhinoconjunctivitis, and atopic eczema: ISAAC. Lancet. 1998;351:1225-32.

2. Illi $S$, von Mutius $E$, Lau $S$, et al. The natural course of atopic dermatitis from birth to age 7 years and the association with asthma. J Allergy Clin Immunol. 2004;113:92531.

3. Aaby $\mathrm{P}$, Shaheen So, Heyes $\mathrm{CB}$, et al. Early BCG vaccination and reduction in atopy in Guinea-Bissau. Clin Exp Allergy. 2000;30:644-50.

4. Anderson HR, Poloniecki JD, Strachan DP, et al. Immunization and symptoms of atopic disease in children: results from the International Study of Asthma and Allergies in Childhood. Am J Public Health. 2001;91:1126-9.

5. Floistrup $\mathrm{H}$, Swartz J, Bergstrom A, et al. Allergic disease and sensitisation in Steiner school children. J Allergy Clin Immunol. 2006;117:59-66.

6. Odent $M$, Culpin E. Effect of immunisation status on asthma prevalence. Lancet. 2003;361:434.

7. Odent MR, Culpin EE, Kimmel T. Pertussis vaccination and asthma: is there a link? JAMA. 1994;272:592-3.

8. Kemp $T$, Pearce $N$, Fitzharris $P$, et al. Is infant immunization a risk factor for childhood asthma or allergy? Epidemiology. 1997;8:678-80.

9. Farooqi IS, Hopkin JM. Early childhood infection and atopic disorder. Thorax. 1998;53:927-32.

10. Nilsson L, Kjellman NI, Bjorksten B. A randomized controlled trial of the effect of pertussis vaccines on atopic disease. Arch Pediatr Adolesc Med. 1998;152:734-8.

11. Nilsson L, Kjellman NI, Bjorksten B. Allergic disease at the age of 7 years after pertussis vaccination in infancy: results from the follow-up of a randomized controlled trial of 3 vaccines. Arch Pediatr Adolesc Med. 2003;157:1184-9.

12. Henderson J, North $\mathrm{K}$, Griffiths $M$, et al. Pertussis vaccination and wheezing illnesses in young children: prospective cohort study. BMJ. 1999;318:1173-6.

13. Hurwitz EL, Morgenstern H. Effects of diphtheria-tetanus-pertussis or tetanus vaccination on allergies and allergy-related respiratory symptoms among children and adolescents in the United States. J Manipulative Physiol Ther. 2000;23:81-90.

14. DeStefano F, Gu D, Kramarz $P$, et al. Childhood vaccinations and risk of asthma. Pediatr Infect Dis J. 2002;21:498-504.

15. Enriquez $\mathrm{R}$, Addington $\mathrm{W}$, Davis $\mathrm{F}$, et al. The relationship between vaccine refusal and self-report of atopic disease in children. J Allergy Clin Immunol. 2005;115:737-44.

16. McKeever TM, Lewis SA, Smith $C$, et al. Vaccination and allergic disease: a birth cohort study. Am J Public Health. 2004;94:985-9.

17. Bernsen RM, de Jongste JC, van der Wouden JC. Lower risk of atopic disorders in whole cell pertussis-vaccinated children. Eur Respir J. 2003;22:962-4.

18. Gruber C, Nilsson L, Bjorksten B. Do early childhood immunizations influence the development of atopy and do they cause allergic reactions? Pediatr Allergy Immunol. 2001;12:296-311.

19. Koppen S, De Groot R, Neijens $H J$, et al. No epidemiological evidence for infant vaccinations to cause allergic disease. Vaccine. 2004;22:3375-85.

20. Rottem M, Shoenfeld Y. Vaccination and allergy. Curr Opin Otolaryngol Head Neck Surg. 2004;12:223-31. 
21. Maher JE, Mullooly JP, Drew L, et al. Infant vaccinations and childhood asthma among full-term infants. Pharmacoepidemiol Drug Safety. 2004;13:1-9.

22. Mullooly JP, Pearson J, Drew L, et al. Wheezing lower respiratory disease and vaccination of full-term infants. Pharmacoepidemiol Drug Safety. 2002;11:21-30.

23. Gruber C, Illi S, Lau S, et al. Transient suppression of atopy in early childhood is associated with high vaccination coverage. Pediatrics. 2003;111:282-8.

24. Maitra A, Sherriff A, Griffiths $M$, et al. Pertussis vaccination in infancy and asthma or allergy in later childhood: birth cohort study. BMJ. 2004;328:925-6.

25. Bremner SA, Carey IM, DeWilde $S$, et al. Timing of routine immunisations and subsequent hay fever risk. Arch Dis Child. 2005;90:567-73

26. Mommers M, Weishoff Houben M, Swaen GM, et al. Infant immunization and the occurrence of atopic disease in Dutch and German children: a nested case-control study. Pediatr Pulmonol. 2004;38:329-34.

27. Bernsen RM, van der Wouden JC. Re: no epidemiological evidence for infant vaccinations to cause allergic disease. Vaccine. 2005;23:1427.

28. Kummeling I, Thijs C, Penders J, et al. Etiology of atopy in infancy: the KOALA Birth Cohort Study. Pediatr Allergy Immunol. 2005;16:679-684.

29. Bastiaanssen JM, de Bie RA, Bastiaenen $\mathrm{CH}$, et al. Etiology and prognosis of pregnancy-related pelvic girdle pain; design of a longitudinal study. BMC Public Health. 2005;5:1-8.

30. Remes ST, Castro Rodriguez JA, Holberg CJ, et al. Dog exposure in infancy decreases the subsequent risk of frequent wheeze but not of atopy. J Allergy Clin Immunol. 2001;108:509-15.

31. Wright AL, Sherrill $\mathrm{D}$, Holberg $\mathrm{CJ}$, et al. Breast-feeding, maternal IgE, and total serum IgE in childhood. J Allergy Clin Immunol. 1999;104:589-94.

32. Kummeling I, Thijs C, Stelma F, et al. Do parents with an atopic family history adopt a 'prudent' lifestyle for their infant? (KOALA Study). Clin Exp Allergy. 2006;36:48994.

33. Koopman LP, Brunekreef B, de Jongste JC, et al. Definition of respiratory symptoms and disease in early childhood in large prospective birth cohort studies that predict the development of asthma. Pediatr Allergy Immunol. 2001;12:118-24.

34. Lowe L, Murray CS, Martin L, et al. Reported versus confirmed wheeze and lung function in early life. Arch Dis Child. 2004; 89:540-3.

35. Kusel MM, Holt PG, de Klerk N, et al. Support for 2 variants of eczema. J Allergy Clin Immunol. 2005;116:1067-72. 
- 72 - 


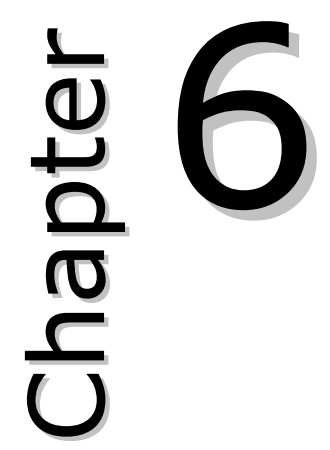

Early life exposure to antibiotics and the subsequent development of eczema, wheeze and atopic sensitisation in the first two years of life

Kummeling I, Stelma F, Dagnelie PC, Snijders BEP, Penders J, Huber $M$, van Ree $R$, van den Brandt PA, Thijs $C$

PEDIATRICS 2007; 119: e225-e231 


\section{Abstract}

\section{OBJECTIVE}

Antibiotic exposure in early life may be associated with atopic disease development either by interfering with bacterial commensal flora or by modifying the course of bacterial infections. We evaluated early life exposure to antibiotics and the subsequent development of eczema, wheeze and atopic sensitisation in infancy.

\section{METHODS}

Information on antibiotic use in the first six months, and eczema and wheeze until age two was collected by repeated questionnaires in 2764 families participating in the KOALA Birth Cohort Study, the Netherlands. Antibiotics exposure was evaluated both as maternal antibiotic use during breastfeeding and infant oral medication. Venous blood samples taken from 815 infants at age 2 years were analyzed for total and specific immunoglobulin $E$ against common food and inhalant allergens using a radioallergosorbent test. Multivariate logistic regression analysis was used to adjust for confounding factors.

\section{RESULTS}

During the first 2 years, eczema was present in $32 \%$ of all infants, recurrent wheeze in $11 \%$, and prolonged wheezing in 5\%. At age 2 years, $27 \%$ of children were sensitised against at least one allergen. At age 6 months, $11 \%$ had been exposed to antibiotics through breast milk and $20 \%$ directly through medication. The risk of recurrent wheeze (adjusted odds ratio (adjOR) $=2.65,95 \%$ confidence interval (CI): 1.95-3.60) and prolonged wheeze (adjOR=2.32, 95\% CI: 1.55-3.48) was higher in infants directly exposed to antibiotics through medication, also after excluding from the analyses children who wheezed in the same period as antibiotic had been used (avoiding reverse causation). Antibiotic use through breastfeeding was associated with recurrent wheeze (adjOR $=1.55,95 \% \mathrm{CI}: 1.02-2.37$ ), but prolonged wheeze was not (adjOR=1.12, 95\% CI: 0.62-2.02). Eczema and sensitisation were not associated with antibiotic exposure.

\section{CONCLUSION}

We demonstrated that early antibiotic use was associated with the manifestation of wheeze, but not eczema or atopic sensitisation, during the first two years of life. Different biological mechanisms may underlie the etiology of wheeze compared to eczema or sensitisation. Antibiotic exposure through breastfeeding was associated with the risk of recurrent wheeze, but this needs further confirmation. 


\section{Introduction}

The prevalence of atopic manifestations, which include eczema, food allergy, hay fever (and other airway allergies) and asthma, have increased worldwide, especially in children $(1,2)$. Symptoms are most common in Western countries, but also increase in developing countries as they become more westernised. Currently one-third of the children in western societies show symptoms (3).

Many western lifestyle and medical care characteristics have changed over the years and might be of interest in relation to atopy. For example, the increased paediatric atopy in developed countries closely followed time trends in increased use of antibiotics among young children. Antibiotics particularly interfere with the bacterial commensal flora and disturb the intestinal microbiota composition (4-6). Consequently, antibiotic exposure in early life may be associated with atopic disease development either by interfering with bacterial commensal flora or by modifying the course of bacterial infections.

Indeed positive associations between antibiotic use and childhood atopic manifestations and asthma has been reported (7-14). The majority of these results came from cross-sectional studies and in many $(7,8,10-12,14)$, the question of 'reverse causation' remained unresolved: Did antibiotic intake precede symptoms or were antibiotics prescribed in response to symptoms of wheezy bronchitis? Also, evaluation of exposure to antibiotics through breastfeeding and subsequent development of atopy is lacking. Antibiotic use is fairly common among breastfeeding mothers (15), in particular penicillins for the treatment of mastitis. Both have been detected in breast milk in small quantities, as reviewed by Chung et al. (16). Maternal use of antibiotics is relevant with regard to transfer to the breastfed infant.

In a large prospective birth cohort study in the Netherlands, we prospectively evaluated the association between early life antibiotic exposure, both through maternal antibiotic use during breastfeeding and through infant oral medication, and the subsequent development of eczema, wheeze and atopic sensitisation in the first two years of life.

\section{Methods}

\section{STUDY SUBJECTS}

A detailed description of the design of our cohort has been published previously (17). In summary, the KOALA Birth Cohort Study started in October 2000. Participants were recruited from two sources. First, healthy pregnant women were recruited from an ongoing prospective cohort study on Pregnancyrelated Pelvic Girdle pain (PPGP study) (18). Participants of the PPGP study were recruited via midwife clinics at 14-16 weeks of gestation. At 34 weeks of gestation PPGP subjects were asked to participate in the KOALA Study ('conventional subcohort'). Second, to increase the number of participants with lifestyle choices that have a low prevalence in the general population, pregnant women with socalled 'alternative' lifestyles were recruited through several specific recruitment channels, i.e. anthroposophic doctors and midwifes, anthroposophic under-five clinics, Steiner Schools, posters and flyers in organic food shops and magazines 
for special interest groups (e.g. homeopathy, anthroposophy, anti-vaccine) ('alternative subcohort'). These women were also enrolled at 14-18 weeks of gestation. A total of 2834 participants were included in the KOALA study, of whom 2343 through the PPGP study and 491 through the specific recruitment channels. The study was approved by the Medical Ethical Committee of University Maastricht/Academic Hospital Maastricht. All participants had signed informed consent and completed the first questionnaire at the third trimester of pregnancy. Most parents (96\%) were white Dutch.

Exclusion criteria in the present study were prematurity (gestational age < 37 weeks) and congenital abnormalities related to immunity (such as Down syndrome). Three children were excluded for Down syndrome and 67 for prematurity, resulting in 2764 participants. Of these, follow-up data on at least one health outcome were available for $93.4 \%(n=2598)$, which was $93.5 \%$ $(n=2135)$ of the conventional and $96.3 \%(n=463)$ of the alternative subcohort.

From January 2004, additional funding was obtained and parents being part of the second half of the cohort $(n=1301)$ were also asked to consent to collecting venous blood from their infant at age two years (for the determination of total and allergen-specific Immuoglobulin E (IgE)-levels). Of these, 815 (65\%) signed informed consent and were visited at home for blood sampling.

\section{EXPOSURE AND FOLLOW-UP}

All parents were sent detailed questionnaires when the infants were 3, 7, 12 and 24 months of age. Antibiotic use in the first 6 months postpartum was assessed by questionnaires. Mothers were asked whether they had used antibiotics during lactation and whether they had completed the course. Antibiotic exposure through breast milk was classified positively if a mother completed a course of antibiotic treatment during lactation. Parents were also asked whether their child had used antibiotics and if yes, for how many days. Direct oral antibiotic exposure was defined as positive when the child had ever been given oral antibiotics for more than 3 consecutive days. No distinction was made between different antibiotics or multiple courses of antibiotics vs. a single course in the questionnaire.

Eczema and wheeze occurrence were assessed by questionnaires. At age 7, 12 and 24 months, parents were asked whether their child had ever had an itchy rash that was coming and going in the past months. If this question was answered affirmatively at least once, infants were classified as having developed eczema in the first two years of life. Infants for whom only diaper rash, rash around the eyes and/or scalp scaling was reported, were not regarded as having developed eczema. Wheeze was also asked in the 7, 12 and 24 months postpartum questionnaires. At age 7, 12 and 24 months, parents were asked whether their child ever had showed symptoms of wheeze and how many attacks in the past months. 'Recurrent wheeze' was defined as reported presence of wheezing with at least 4 attacks ever in the first two years. 'Prolonged wheeze' was classified as ever been awake due to wheezing in both the first and second year. 
Variables considered for inclusion in the multivariate analysis were participant's characteristics such as the infant's sex, parental and older siblings' atopic history and number of older siblings. Positive parental atopic history was defined as one or more self-reported doctor's diagnoses of asthma, pet or house dust mite allergy, hay fever, and eczema (none, father, mother, both). Sibship size and siblings history of atopy (parental reports of doctor's diagnosed asthma, pet or house dust mite allergy, hay fever, eczema and/or food allergy) were combined (no older siblings, one older sibling-not atopic, one older sibling-atopic, two ore more older siblings-not atopic, two ore more older siblings-at least one atopic). Other factors included place and mode of delivery (natural delivery at home, natural delivery in hospital, artificial delivery in hospital (for example delivery by vacuum or forceps extraction) or caesarean section in hospital), breastfeeding at six months of age (breastfeeding at age 6 months which was exclusive at months 1-4; breastfeeding at age 6 months which was non-exclusive at months 1-4; no breastfeeding at age 6 months but exclusive breastfeeding at months 1-4; no breastfeeding at age 6 months but non-exclusive breastfeeding at months 1-4; never breastfeeding), attending daycare facilities in the first six months (yes/no), any furred furred pets in the first six months (yes/no), exposure to environmental tobacco smoke (ETS) in the first six months (yes/no) and experiencing a period of fever (body temperature $>38^{\circ} \mathrm{C}$ ) during the first six months (yes/no). Parents were asked whether their child had been vaccinated according to the standard scheme, an 'alternative vaccination scheme' or not at all. In the Netherlands during the time of the study, infants in their first six months were standard vaccinated against diphtheria, tetanus, pertussis (with whole cell pertussis vaccine), poliomyelitis and Haemophilus influenzae type B vaccine ( $\mathrm{Hib})$ at 2,3 , and 4 months of age. An 'alternative vaccination scheme' was defined as: delayed vaccinations or alternative vaccine composition (for example, omitting the pertussis component from the diphtheria-pertussis-tetanuspolio vaccine).

\section{ASSESSMENT OF SENSITISATION}

Total Immunoglobulin $\mathrm{E}$ ( $\mathrm{IgE}$ ) antibodies were measured by Radio Immuno Assay (RIA) in serum samples as described earlier $(19,20)$. Results were expressed as international units $\mathrm{IgE}$ per $\mathrm{ml}(\mathrm{IU} / \mathrm{ml})$; one international unit is 2.4 $\mathrm{ng}$ IgE. For values < $150 \mathrm{IU} / \mathrm{ml}$ a sandwich RIA was used (19), for values $>150$ IU/ml a competitive RIA (20). Serum level of hen's egg-, cow's milk-, peanut-, birch-, grass pollen-, cat-, dog-, and mite-specific IgE was determined by radioallergosorbent test (RAST) as described previously (20). Calculation was performed by means of a standard curve that was obtained by RAST with a dilution series of a chimeric monoclonal IgE antibody against the major house dust mite allergen Der $p 2$ and Sepharose-coupled recombinant Der p 2 (21). The detection limit for total and specific IgE was $<0.50 \mathrm{IU} / \mathrm{ml}$ and $<0.13 \mathrm{IU} / \mathrm{ml}$, respectively. We defined atopic sensitisation as a RAST value $>0.3 \mathrm{IU} / \mathrm{ml}$ for one or more allergens, and high atopic sensitisation when the value was higher than $0.7 \mathrm{IU} / \mathrm{ml}$. 


\section{STATISTICAL ANALYSIS}

The relationship between antibiotic exposure and atopic manifestations was evaluated in participants with complete information on at least one of the atopic manifestations. Missing data in the questionnaires were treated as missing in the analyses and are presented as 'unknown' in the tables. Unadjusted associations between antibiotic exposure and atopic outcomes were examined using logistic regression. Multivariate logistic regression models were used to control for potential confounders (sex, parental history of atopic manifestations, sibling history of atopic manifestations, number of older siblings, place and mode of delivery, breastfeeding, day care attendance, furred pets, exposure to environmental tobacco smoke, vaccinations, subcohort), by including them in the regression models simultaneously. Differences in geometric mean total IgE levels were evaluated by means of linear regression analyses controlling for the same confounders. Analyses for determination of the effect of antibiotics through breast milk were controlled for the potential confounding effect of antibiotic exposure through oral medication and vice versa. Some previous studies reported associations between exposures and atopic outcomes to be limited to groups with different inherited propensity for developing atopic disease $(22,23)$. In the multivariate analysis, therefore, we first tested the possibility of interaction between antibiotic use and parental history of atopy. Since none of these interaction terms were statistically significant, they were eliminated from the regression models. Separate analyses of the conventional vs. alternative subcohort or boys vs. girls showed that the key findings were similar within these groups. Therefore we combined all infants in the final analyses, adjusting for 'subcohort' and sex. Results are presented as unadjusted and adjusted odds ratios (ORs) with corresponding 95\% confidence intervals (CI).

\section{Results}

\section{STUDY SUBJECTS}

About half of infants had non-atopic parents; approximately $40 \%$ had one or more non-atopic older sibling and $16 \%$ had one or more atopic older sibling (Table I). Most traditional risk factors were equally present in both subcohorts but in the alternative subcohort, antibiotic exposure through medication was less present than in the conventional subcohort. Prevalence of baseline characteristics and eczema and wheeze manifestations did not differ between infants with and without blood samples.

By the age of six months, $262(11 \%)$ of 2423 infants had been exposed to antibiotics through breastfeeding, and 489 (20\%) of 2462 infants through oral medication.

\section{ECZEMA, WHEEZE AND SENSITISATION BY ANTIBIOTIC EXPOSURE}

In total, 817 (32\%) of 2583 infants were classified as having had eczema in the first 2 years of life (this was $32 \%$ in the conventional and $30 \%$ in the alternative subcohort). Of these 817 infants with eczema, 101 (12\%) had also reported recurrent wheeze and $62(6 \%)$ had also reported prolonged wheeze. The incidence of recurrent wheeze was $265(11 \%)$ of 2342 infants (12\% in the 
conventional and $6 \%$ in the alternative subcohort). Of these 265 infants with recurrent wheeze, 93 (35\%) had also reported prolonged wheeze and $101(38 \%)$ had also reported eczema. In total, for 137 (5\%) of 2546 infants parents reported prolonged wheezing $(6 \%$ in the conventional and $4 \%$ in the alternative subcohort). Of these 137 infants with prolonged wheeze, 93 (28\%) had also reported recurrent wheeze and $62(45 \%)$ had also reported eczema. Of infants with reported wheeze in the first two years, $70 \%$ had used beta 2 -adrenergic or steroid inhalant therapy at least once. Of infants with blood samples, $223(27 \%)$ were sensitised against at least one allergen at age 2 years ( $29 \%$ in the conventional and $24 \%$ in the alternative subcohort).

The associations for antibiotic exposure through breastfeeding and through medication were independent from each other (as both were included in the logistic regression models simultaneously). Antibiotic exposure either through breastfeeding or directly through medication was not associated with eczema (Table II). However, antibiotic exposure through breastfeeding was associated with a higher risk of recurrent wheeze (adjusted $\mathrm{OR}=1.55,95 \% \mathrm{CI}: 1.02-2.37$ ). This was not found for prolonged wheeze (adjusted $\mathrm{OR}=1.12$, 95\% CI: $0.62-$ 2.02). Antibiotic exposure through medication was associated with an elevated risk of recurrent wheeze (adjusted $\mathrm{OR}=2.65,95 \% \mathrm{CI}: 1.95-3.60$ ) and prolonged wheeze (adjusted OR=2.32, 95\% CI: 1.55-3.48).

There was no association between antibiotic exposure through breastfeeding and atopic sensitisation nor between oral antibiotic medication and atopic sensitisation (Table II). This result remained unchanged when using a lower cut-off point for sensitisation (specific $\mathrm{IgE}>0.13 \mathrm{IU} / \mathrm{ml}$ ) or when sensitisation to 2 or more allergens was considered as the outcome (not shown). Geometric mean of total serum IgE level at age 2 years was not different between infants with and without antibiotic exposure either through breastfeeding $(\beta=0.002, P=0.99)$ or medication $(\beta=0.048, P=0.80)$.

To exclude potential reverse causation in the association between antibiotic exposure and wheeze, we excluded from the analyses children who wheezed in the first half year of life $(n=203$ for recurrent wheeze; $n=436$ for prolonged wheeze). The odds ratio's for wheezing did not change much compared to those in Table II (adjusted OR for recurrent wheezing $=2.18,95 \% \mathrm{CI}: 1.46$ 3.25; adjusted OR for prolonged wheezing=2.39, 95\% CI: 1.50-3.81).

If we restricted our analysis to infants who had been breastfed the association between antibiotic exposure through breastfeeding and recurrent wheeze remained unchanged (adjusted $\mathrm{OR}=1.54,95 \% \mathrm{CI}: 1.01-2.36$ ). For all outcomes, we tested the possibility of interaction between antibiotic exposure and a parental history of atopic manifestations in the multivariate analyses. None of the tests-for-interaction showed a statistically significant interaction (P-value always equal or greater than 0.10). 
Table I

Characteristics of infants in the present study $(n=2764)$

\begin{tabular}{|c|c|c|}
\hline \multirow[t]{2}{*}{ Characteristic } & \multicolumn{2}{|c|}{ Total cohort } \\
\hline & $\mathbf{N}$ & $\%^{*}$ \\
\hline Male & 1410 & $51 \%$ \\
\hline \multicolumn{3}{|l|}{ Parental history of atopic manifestations } \\
\hline None & 1339 & $48 \%$ \\
\hline Father & 519 & $19 \%$ \\
\hline Mother & 604 & $22 \%$ \\
\hline Both & 302 & $11 \%$ \\
\hline \multicolumn{3}{|l|}{ Sibling history of atopic manifestations } \\
\hline No older siblings & 1155 & $44 \%$ \\
\hline One older sibling - not atopic & 833 & $31 \%$ \\
\hline One older sibling - atopic & 261 & $10 \%$ \\
\hline$\geq 2$ older siblings - not atopic & 235 & $9 \%$ \\
\hline$\geq 2$ older siblings - one or both atopic & 159 & $6 \%$ \\
\hline Unknown & 121 & \\
\hline \multicolumn{3}{|l|}{ Place and mode of delivery } \\
\hline Natural delivery at home & 1179 & $46 \%$ \\
\hline Natural delivery in hospital & 891 & $34 \%$ \\
\hline Artificial delivery in hospital & 217 & $8 \%$ \\
\hline Caesarean section in hospital & 296 & $12 \%$ \\
\hline Unknown & 181 & \\
\hline \multicolumn{3}{|l|}{ Breastfeeding at age 6 months } \\
\hline Yes, months 1-4 exclusive $\mathrm{BF}^{\dagger}$ & 622 & $25 \%$ \\
\hline Yes, months 1-4 non-exclusive $\mathrm{BF}^{\dagger}$ & 441 & $17 \%$ \\
\hline No, months $1-4$ exclusive BF† & 62 & $3 \%$ \\
\hline No, months $1-4$ non-exclusive & 996 & $39 \%$ \\
\hline Never breastfeeding & 410 & $16 \%$ \\
\hline Unknown & 233 & \\
\hline \multicolumn{3}{|l|}{ Day care in first six months } \\
\hline Yes & 831 & $32 \%$ \\
\hline No & 1724 & $68 \%$ \\
\hline Unknown & 209 & \\
\hline \multicolumn{3}{|l|}{ Furred pets in first six months } \\
\hline Yes & 1168 & $45 \%$ \\
\hline No & 1387 & $55 \%$ \\
\hline Unknown & 209 & \\
\hline \multicolumn{3}{|l|}{ Exposure to ETS ${ }^{\dagger}$ in first six months } \\
\hline Yes & 294 & $12 \%$ \\
\hline No & 2197 & $88 \%$ \\
\hline Unknown & 273 & \\
\hline \multicolumn{3}{|l|}{ Vaccinations in first six months } \\
\hline By standard scheme & 1969 & $78 \%$ \\
\hline By alternative scheme $\ddagger$ & 393 & $15 \%$ \\
\hline None & 182 & $7 \%$ \\
\hline Unknown & 220 & \\
\hline
\end{tabular}


Table I continued

\begin{tabular}{|c|c|c|}
\hline \multicolumn{3}{|c|}{ Antibiotic exposure through breastfeeding in first six months } \\
\hline Yes & 262 & \\
\hline No & 2161 & $10 \%$ \\
\hline Unknown & 341 & $90 \%$ \\
\hline \multicolumn{3}{|c|}{ Antibiotic exposure through oral medication in first six months } \\
\hline Yes & 489 & \\
\hline No & 1973 & $20 \%$ \\
\hline Unknown & 302 & $80 \%$ \\
\hline \multicolumn{3}{|c|}{ Eczema in first two years } \\
\hline Yes & 817 & $32 \%$ \\
\hline No & 1766 & $68 \%$ \\
\hline Unknown & 181 & \\
\hline \multicolumn{3}{|c|}{ Recurrent wheeze in first two years } \\
\hline Yes & 265 & $11 \%$ \\
\hline No & 2077 & $89 \%$ \\
\hline Unknown & 422 & \\
\hline \multicolumn{3}{|c|}{ Prolonged wheeze in first two years } \\
\hline Yes & 137 & $5 \%$ \\
\hline No & 2409 & $95 \%$ \\
\hline Unknown & 218 & \\
\hline \multicolumn{3}{|c|}{ Atopic sensitisation at age $2 \S$} \\
\hline Yes & 223 & $27 \%$ \\
\hline No & 592 & $73 \%$ \\
\hline \multicolumn{3}{|c|}{ Specific lgE against: } \\
\hline Hen's egg & 48 & $6 \%$ \\
\hline Cow's milk & 153 & $19 \%$ \\
\hline Peanut & 42 & $5 \%$ \\
\hline Birch & 7 & $1 \%$ \\
\hline Grass pollen & 13 & $2 \%$ \\
\hline Cat & 25 & $3 \%$ \\
\hline Dog & 15 & $2 \%$ \\
\hline Mite & 52 & $6 \%$ \\
\hline \multicolumn{3}{|c|}{ * Excluding missings } \\
\hline \multirow{2}{*}{\multicolumn{3}{|c|}{$\begin{array}{l}\text { BF breastfeeding, ETS environmental tobacco smoke } \\
\text { delayed scheme or alternative composition of vaccine }\end{array}$}} \\
\hline & & \\
\hline \multicolumn{3}{|c|}{$\begin{array}{l}\text { Analyses conducted among infants with blood sample }(n=815) \text {. 'Atopic sensitisation' refers to at } \\
\text { least one allergen-specific IgE } \geq 0.3 \mathrm{IU} / \mathrm{ml}\end{array}$} \\
\hline
\end{tabular}




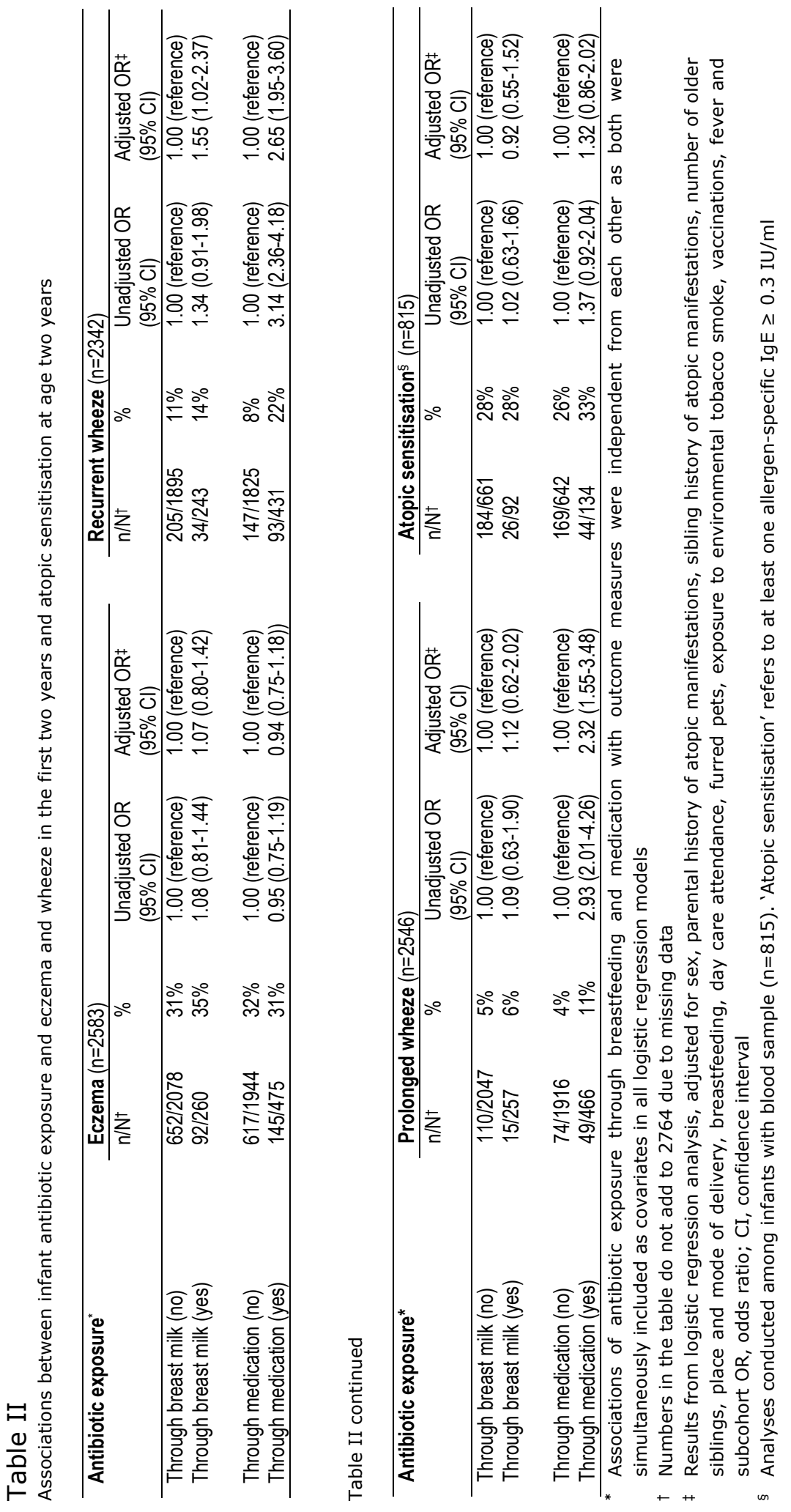




\section{Discussion}

This prospective study shows that early antibiotic exposure, both indirect through breastfeeding and direct through oral medication, is associated with the subsequent development of wheezing in the first two years of life. No association was found between antibiotic exposure and eczema or atopic sensitisation. To our knowledge, this is the first study focusing on the association between antibiotic exposure through breastfeeding and the development of atopy. Our study has the advantage of being population-based, with relatively short intervals between subsequent follow-up questionnaires, which decreases the possibility of recall bias. Follow-up rates were high which limited differential bias with regard to baseline characteristics or outcomes.

Atopic outcomes like infant eczema and wheeze may be fairly unspecific for infants aged 2 years (24) and therefore weak indicators of atopic development such as asthma in children. Children with physician confirmed wheeze have been reported to have significantly poorer lung function compared to those with only parentally reported wheeze that was medically unconfirmed (25). In individuals with an atopic constitution, the underlying mechanism of developing eczema is often dominated by an IgE-antibody-associated reaction to specific allergens, justifying the term 'atopic eczema'. Specific IgE or total serum IgE levels are, however, only weakly associated with atopic symptoms like eczema and wheeze (26). Therefore, we evaluated clinical symptoms and atopic sensitisation as separate outcomes and used the term eczema instead of atopic eczema. Our definition of eczema was based on questions adapted from the International Study of Asthma and Allergies in Childhood (ISAAC) questionnaires and included generally accepted characteristics, like a chronically relapsing course and an itchy rash. Our definition of recurrent wheeze was also based on ISAAC questionnaires. Besides, we identified a second more stringent definition of wheeze ('prolonged'), restricting it to being awake due to wheezing in both the first and second year. In contrast to most population based studies we chose to rely on parents 'reported symptoms' more than 'doctor's diagnosis' when defining outcome variables in order to avoid bias due to the increased likelihood to get a doctor's diagnosis of asthma when parents consult a doctor for the infant's wheezing and get antibiotic medication (at the same or a different occasion). In addition, parents were asked whether medical care was provided to the wheezing infant. This was true for $70 \%$ of wheezy infants, which reinforced us to rely on the parental reports of wheezing.

Lacking information on the antibacterial spectrum (broad vs. narrow), specific indication for which the antibiotics had been prescribed or multiple courses of antibiotics vs. a single course represents a limitation in our study.

Two questions arise from our findings. First, why was antibiotic use associated with wheeze but not eczema and atopic sensitisation? And second, what are the possible mechanisms by which antibiotic exposure increases the risk of wheeze in infancy? We found that wheeze was associated to antibiotic use, but eczema and sensitisation were not, and exposure through breastfeeding was associated only with recurrent wheeze. This finding contradicts that antibiotics have a direct influence on the maturating immune system or effect the development of atopic disease by preventing invasive bacterial infections (if so also eczema and sensitisation would be affected). The exclusive association 
between antibiotic use and the development of wheeze may be due to reverse causation. It is likely that antibiotics are prescribed because of wheezy bronchitis and related conditions, however this is unlikely when considering eczema and atopic sensitisation. To eliminate the possibility of reverse causation, we excluded from the analysis those infants who wheezed in the same period (interval between questionnaires) as antibiotic medication had been used, thereby avoiding that symptoms preceded antibiotic prescription.

However, the association between antibiotic exposure through breastfeeding and wheeze constitutes an argument against reverse causation. Antibiotics administrated to the infant through breastfeeding are prescribed independently of any infant disease as the indication is a maternal infectious episode. Two possible biological mechanisms may explain why wheeze was more susceptible to antibiotic use than the other two outcome measures eczema and sensitisation. Due to a difficult differential diagnosis in general practice between bacterial and viral infections, antibiotics in infancy are often prescribed for viral infections (27). Respiratory Syncytial Virus (RSV) and rhinovirus (RV) infections are strongly associated with infant wheeze in the first years of life (28), and antibiotic use may simply be a marker for viral infections. This may only apply to young infants as the prospective birth cohort study of Celedón et al. did not show an association between antibiotic use in the first year and wheeze in 5 year old children (29).

Also, antibiotics may compromise the commensal flora of the upper airways (30), thereby making way for viral infections, some of which may cause for later wheeze. Simultaneously this explains why antibiotic exposure through breastfeeding is more associated with recurrent wheeze than prolonged wheeze. When the infant is being compromised by maternal antibiotic use, the commensal flora of the upper airways of the infant will recover only after the mother ceases her antibiotic course. The definition of prolonged wheeze symptoms is the presence of wheeze in the first and second year of infant life. It is according to the expectations that there is no association between antibiotic use and prolonged wheeze because it is unlikely that mothers still breastfed in the second year of life.

Our finding that antibiotic exposure was not associated with eczema confirms results from previous cohort studies $(29,31)$, whereas some crosssectional studies showed positive associations (7-10). Cross-sectional studies must be interpreted with caution. They may be subject differential recall bias and recall of antibiotic use may be linked to the reporting of atopic manifestations (reporting bias). Furthermore our study confirms previous results that antibiotic use was not associated with atopic sensitisation at age two years (29).

Taken together, we demonstrated that early antibiotic use was associated with the manifestation of wheeze, but not eczema or atopic sensitisation during the first two years of life. Different biological mechanisms may underlie the etiology of wheeze compared to eczema or sensitisation. The effect of antibiotic use through breastfeeding on wheeze was small $(O R<2)$ and until further research has been performed, we recommend that this finding is replicated in other prospective studies. 


\section{Acknowledgements}

We thank members of the KOALA team for their contribution to data collection, data management and data analysis and also like to thank all parents and infants who participated in this study. 


\section{References}

1. Maziak W, Behrens T, Brasky TM, et al. Are asthma and allergies in children and adolescents increasing? Results from ISAAC phase I and phase III surveys in Munster, Germany. Allergy. 2003;58:572-9.

2. Beasley R, Crane J, Lai CK, et al. Prevalence and etiology of asthma. J Allergy Clin Immunol. 2000;105:S466-72.

3. The International Study of Asthma and Allergies in Childhood (ISAAC) Steering Committee. Worldwide variation in prevalence of symptoms of asthma, allergic rhinoconjunctivitis, and atopic eczema: ISAAC. Lancet. 1998;351:1225-32.

4. Levy J. The effects of antibiotic use on gastrointestinal function. Am J Gastroenterol. 2000; 95:S8-10.

5. Brismar B, Edlund C, Nord CE. Impact of cefpodoxime proxetil and amoxicillin on the normal oral and intestinal microflora. Eur J Clin Microbiol Infect Dis. 1993;12:714-9.

6. Bjorksten $B$, Naaber $\mathrm{P}$, Sepp $\mathrm{E}$, et al. The intestinal microflora in allergic Estonian and Swedish 2-year-old children. Clin Exp Allergy. 1999;29:342-6.

7. Floistrup $\mathrm{H}$, Swartz J, Bergstrom A, et al. Allergic disease and sensitisation in Steiner school children. J Allergy Clin Immunol. 2006;117:59-66.

8. Wjst M, Hoelscher B, Frye $C$, et al. Early antibiotic treatment and later asthma. Eur J Med Res. 2001;6:263-71.

9. Droste $\mathrm{JH}$, Wieringa $\mathrm{MH}$, Weyler JJ, et al. Does the use of antibiotics in early childhood increase the risk of asthma and allergic disease? Clin Exp Allergy. 2000;30:1547-53.

10. von Mutius E, Illi S, Hirsch T, et al. Frequency of infections and risk of asthma, atopy and airway hyperresponsiveness in children. Eur Respir J. 1999;14:4-11.

11. Wickens $\mathrm{K}$, Pearce $\mathrm{N}$, Crane J, et al. Antibiotic use in early childhood and the development of asthma. Clin Exp Allergy. 1999;29:766-71.

12. Alm JS, Swartz J, Lilja G, et al. Atopy in children of families with an anthroposophic lifestyle. Lancet. 1999;353:1485-8.

13. Farooqi IS, Hopkin JM. Early childhood infection and atopic disorder. Thorax. 1998;53:927-32.

14. Cohet C, Cheng S, MacDonald C, et al. Infections, medication use, and the prevalence of symptoms of asthma, rhinitis, and eczema in childhood. J Epidemiol Community Health. 2004;58:852-7.

15. Mathew JL. Effect of maternal antibiotics on breast feeding infants. Postgrad Med J. 2004;80:196-200.

16. Chung AM, Reed MD, Blumer JL. Antibiotics and breast-feeding: a critical review of the literature. Paediatr Drugs. 2002;4:817-37.

17. Kummeling I, Thijs C, Penders J, et al. Etiology of atopy in infancy: the KOALA Birth Cohort Study. Pediatr Allergy Immunol. 2005;16(8):679-684.

18. Bastiaanssen JM, de Bie RA, Bastiaenen $\mathrm{CH}$, et al. Etiology and prognosis of pregnancy-related pelvic girdle pain; design of a longitudinal study. BMC Public Health. 2005;5:1-8.

19. Stallman PJ, Aalberse RC. Estimation of basophil-bound IgE by quantitative immunofluorescence microscopy. Int Arch Allergy Appl Immunol. 1977;54:9-18.

20. Akkerdaas $\mathrm{JH}$, Wensing $\mathrm{M}$, Asero $\mathrm{R}$, et al. IgE binding to pepsin-digested food extracts. Int Arch Allergy Immunol. 2005;138:203-8. 
21. Schuurman J, Perdok GJ, Lourens TE, et al. Production of a mouse/human chimeric IgE monoclonal antibody to the house dust mite allergen Der p 2 and its use for the absolute quantification of allergen-specific IgE. J Allergy Clin Immunol. 1997;99:54550 .

22. Remes ST, Castro Rodriguez JA, Holberg CJ, et al. Dog exposure in infancy decreases the subsequent risk of frequent wheeze but not of atopy. J Allergy Clin Immunol. 2001;108:509-15.

23. Wright AL, Sherrill D, Holberg CJ, et al. Breast-feeding, maternal IgE, and total serum IgE in childhood. J Allergy Clin Immunol. 1999;104:589-94.

24. Koopman LP, Brunekreef B, de Jongste JC, et al. Definition of respiratory symptoms and disease in early childhood in large prospective birth cohort studies that predict the development of asthma. Pediatr Allergy Immunol. 2001;12:118-24.

25. Lowe L, Murray CS, Martin L, et al. Reported versus confirmed wheeze and lung function in early life. Arch Dis Child. 2004; 89:540-3.

26. Kusel MM, Holt PG, de Klerk N, et al. Support for 2 variants of eczema. J Allergy Clin Immunol. 2005;116:1067-72.

27. Nyquist AC, Gonzales R, Steiner JF, et al. Antibiotic prescribing for children with colds, upper respiratory tract infections, and bronchitis. JAMA. 1998;279:875-7.

28. Everard ML. The relationship between respiratory syncytial virus infections and the development of wheezing and asthma in children. Curr Opin Allergy Clin Immunol. 2006;6:56-61.

29. Celedon JC, Litonjua AA, Ryan L, et al. Lack of association between antibiotic use in the first year of life and asthma, allergic rhinitis, or eczema at age 5 years. Am J Respir Crit Care Med. 2002;166:72-5.

30. Van Eldere J. The role of bacteria as a local defence mechanism in the ear, nose and throat. Acta Otorhinolaryngol Belg. 2000;54:243-7.

31. McKeever TM, Lewis SA, Smith C, et al. Early exposure to infections and antibiotics and the incidence of allergic disease: a birth cohort study with the West Midlands General Practice Research Database. J Allergy Clin Immunol. 2002;109:43-50. 


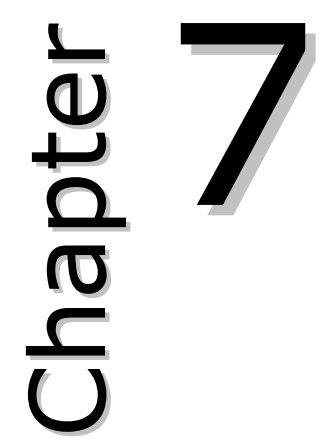

Consumption of organic foods and risk of atopic disease in the first two years of life

Kummeling I, Thijs C, Huber M, van de Vijver LPL, Snijders BEP, Penders J, Stelma F, van Ree R, van den Brandt PA, Dagnelie PC

SUBMITTED FOR PUBLICATION 


\section{Abstract}

\section{OBJECTIVE}

We prospectively investigated if early life organic food consumption was protective against developing atopic manifestations in the first two years of life.

\section{METHODS}

The Dutch birth cohort study $(n=2765)$ measured organic food consumption, eczema and wheeze in infants until age two by repeated questionnaires. Diet was defined as conventional ( $<50 \%$ organic), moderately organic (50-90\% organic) and strictly organic ( $>90 \%$ organic). Venous blood samples taken from 815 infants at age two years were analyzed for total and specific IgE. Multivariate logistic regression models were fitted to control for potential confounding factors.

\section{RESULTS}

Eczema was present in $32 \%$ of infants, recurrent wheeze in $11 \%$, and prolonged wheezing in $5 \%$. At age 2 years, $27 \%$ of children were sensitised against at least one allergen. Ten percent had consumed a moderately organic diet and $6 \%$ a strictly organic diet. Consumption of organic dairy was associated with lower eczema risk but organic meat, fruit, vegetables or eggs and the proportion of organic products within the total diet were all not associated with the development of eczema, wheeze or atopic sensitisation.

\section{CONCLUSION}

In the first two years of life, strict consumption of organic dairy foods is associated with a reduced risk of eczema. This association was remarkably robust to extensive adjustment, for instance for use of raw or farm milk. Further studies to substantiate these results using more detailed and quantitative information are warranted. 


\section{Introduction}

The prevalence of atopic manifestations, including eczema, food allergy, hay fever (and other airway allergies) and asthma, has increased worldwide, especially in children $(1,2)$. Symptoms are most common in Western countries, but also increase in developing countries as they become more westernised. Currently one-third of the children in western societies show symptoms (3).

Many western lifestyle characteristics have changed over the years and might be of relevance in relation to atopy, for example food production and processing. A rapidly growing group of consumers in our society prefers to buy organically grown and processed products, which are perceived as healthier and safer (4-6). However, there are virtually no studies of any size that have evaluated effects of organic vs. conventionally grown foods on human health (7). Food or agricultural production certified as 'organic' is a system that excludes the use of synthetic inputs, such as synthetic fertilizers and pesticides, preventive veterinary drugs, genetically modified seeds and breeds, most preservatives, additives and irradiation (http://www.ifoam.org/sub/faq.html).

More than 100 studies have been performed comparing the nutrient content of conventionally and organically grown products, as thoroughly reviewed by several authors (7-12). Despite these studies, conclusive evidence that supports or refutes the perception of a higher nutritional value of organic foods is currently not available in the scientific literature. Some insights can be gained by investigating the nutritional components of food; however the ultimate test of the nutritional value of organic food is its ability to support health. Only one recent study is known that investigated this topic in humans (13). This cross-sectional study performed in 5 European countries showed no difference in atopic outcomes in 5-13 year old children divided in three groups: a diet based on 1) conventional, 2) biodynamic 3) or a mixture of conventional, biodynamic, and organic foods. Since the infants in the latter group consumed foods from a mixture of production methods, the isolated effect of organic foods could not be assessed in this study. Obviously, there is an urgent need for studies investigating the presumed health benefit of organically produced foods.

This paper describes the first prospective study to evaluate the role of organic food consumption on human health. In a large birth cohort study in the Netherlands, we tested the hypothesis that early life organic food consumption is protective against the development of atopic manifestations in the first two years of life.

\section{Methods}

\section{STUDY SUBJECTS}

A detailed description of the study design has previously been published (14). In summary, the KOALA Birth Cohort Study started in October 2000. KOALA is (in Dutch) an acronym for Child, Parent and health: Lifestyle and Genetic constitution. Participants were recruited from two sources. First, healthy pregnant women were recruited from an ongoing prospective cohort study on Pregnancyrelated Pelvic Girdle Pain (PPGP study) (15). Participants of the PPGP study were recruited via midwife clinics at 14-16 weeks of gestation. At 34 weeks of gestation 
PPGP subjects were asked to participate in the KOALA Study ('conventional subcohort'). Second, to increase the number of participants with alternative lifestyle choices that have a low prevalence in the general population, pregnant women with so-called 'alternative' lifestyles were recruited through several specific recruitment channels, i.e. anthroposophic doctors and midwifes, anthroposophic under-five clinics, Steiner Schools, posters and flyers in organic food shops and magazines for special interest groups (e.g. homeopathy, anthroposophy, organic foods) ('alternative subcohort'). These women were enrolled at 14-18 weeks of gestation. A total of 2834 participants were included in the KOALA study, of whom 2343 through the PPGP study and 491 through the specific 'alternative' recruitment channels. The study was approved by the Medical Ethical Committee of University Maastricht/Academic Hospital Maastricht. All participants signed informed consent and completed the first questionnaire at the third trimester of pregnancy. Nearly all parents (96\%) were born in the Netherlands.

Exclusion criteria in the present study were prematurity (gestational age < 37 weeks) and immunity related congenital abnormalities (such as Down syndrome). Three children were excluded for Down syndrome and 67 for prematurity, resulting in 2764 participants. Of these, follow-up data on at least one health outcome were available for $93.4 \%(n=2598)$, which was $93.5 \%$ $(n=2135)$ of the conventional and $96.3 \%(n=463)$ of the alternative subcohort.

All parents were sent detailed questionnaires when the infants were 3, 7, 12 and 24 months of age. From January 2004, additional funding was obtained and parents being part of the second half of the cohort $(n=1301)$ were also asked to consent to collecting of venous blood of their infant at age two years for the determination of total and allergen-specific IgE-levels. Of these, 815 (65\%) signed informed consent and were visited at home for blood sampling.

\section{EXPOSURE AND FOLLOW-UP}

Organic food consumption was measured at age two years, by the parent reported diet of the infant in the second year of life. Parents were asked whether their infant had consumed one or more products out of seven food groups: 1) meat, 2) eggs, 3) vegetables, 4) fruit, 5) dairy, 6) bread, and 7) dry products such as pasta, rice, beans and wheat. If yes, parents were asked whether these products were conventionally or organically produced. Three diet categories were defined, 'conventional' (organic in $<50 \%$ of occasions that the food group is eaten), 'moderately organic' (organic in $50 \%-90 \%$ of occasions) or 'strictly organic' (organic in $>90 \%$ of occasions). The proportion of organic products within the total diet was calculated as follows: for each of the seven food groups a score was given depending on the percentage organic ('conventional', score=0; 'moderately organic', score 0.7 (mean of $0.5-0.9$ ) and 'strictly organic', score=1). The scores were added up and divided by the number of food groups from which products had been eaten. After multiplying by 100 a score between $0 \%-100 \%$ was achieved. Organic food consumption is more frequent among people with alternative lifestyle practices than in the Dutch general population. Therefore, we calculated cut off points for 3 equal groups within our alternative subcohort only, which were 21.0 and 71.0. Then for the whole cohort, we defined a conventional diet as a score below 21.0, a moderately organic food diet as a score between 
21.0 and 71.0 and a diet strictly based on organic products as a score above 71.0. Production method of the foods consumed in the second year of life was considered to reflect the production method of foods consumed in the entire first two years of life.

Organic food consumption was measured in pregnant mothers at 34 weeks of gestation. For pregnant women we repeated the above-described procedure, using the same food products (ever consumed during pregnancy) and cut-off points to be able to compare the diets of the mothers with that of the infants. The information on the mother's diet was used as a proxy for infants at age two years when information was missing due to incomplete questionnaires $(n=453 ; 16 \%)$ since production method of foods consumed by mothers was strongly correlated with food production method of foods consumed by infants (Pearson's $\mathrm{R}=0.85 ; P<0.001$ ).

Eczema and wheeze occurrence were assessed by questionnaires. At age 7, 12 and 24 months, parents were asked whether their child had ever had an itchy rash that was coming and going in the past months. If this question was answered affirmatively at least once, infants were classified as having developed eczema in the first two years of life. Infants for whom only diaper rash, rash around the eyes and/or scalp scaling was reported were not regarded as having developed eczema. At age 7, 12 and 24 months, parents were asked whether their child ever had showed symptoms of wheeze and how many attacks in the past months. 'Recurrent wheeze' was defined as reported presence of wheezing with at least 4 attacks ever in the first two years. 'Prolonged wheeze' was classified as ever been awake due to wheezing in both the first and second year.

Other 'traditional' variables considered for inclusion in the multivariate analysis were participants' characteristics such as the infants' sex, parental and older siblings' atopic history and number of older siblings. Positive parental atopic history was defined as one or more self-reported doctor's diagnoses of asthma, pet or house dust mite allergy, hay fever, and eczema (none, father, mother, both). Sibship size and parental reports of siblings history of atopy were combined (no older siblings, one older sibling-not atopic, one older sibling-atopic, two or more older siblings-not atopic, two or more older siblings-at least one atopic). Lifestyle characteristics in the first six months included breastfeeding (breastfeeding at age 6 months which was exclusive at months 1-4; breastfeeding at age 6 months which was non-exclusive at months $1-4$; no breastfeeding at age 6 months but exclusive breastfeeding at months $1-4$; no breastfeeding at age 6 months but non-exclusive breastfeeding at months 1-4; never breastfeeding), attending daycare facilities in the first six months (yes/no), any furred furred pets in the first six months (yes/no), exposure to environmental tobacco smoke (ETS) (yes/no), vaccination schedule (standard schedule, alternative schedule, none), oral use of antibiotics (yes/no), antibiotic exposure through breast milk (yes/no) and a vegetarian diet (yes/no).

\section{ASSESSMENT OF SENSITISATION}

Total Immunoglobulin E (IgE) antibodies were measured by Radio Immuno Assay (RIA) in serum samples as described earlier $(16,17)$. Results were expressed as international units IgE per $\mathrm{ml}(\mathrm{IU} / \mathrm{ml})$; one international unit is 2.4 $\mathrm{ng}$ IgE. For values < $150 \mathrm{IU} / \mathrm{ml}$ a sandwich RIA was used (16), for values $>150$ 
IU/ml a competitive RIA (16). Serum levels of specific IgE against hen's egg, cow's milk, peanut, birch pollen, grass pollen, cat, dog, and house dust mite were determined by the radioallergosorbent test (RAST) as described previously (17). Calculation was performed by means of a standard curve that was obtained by RAST with a dilution series of a chimeric monoclonal IgE antibody against the major house dust mite allergen Der $p 2$ and Sepharose-coupled recombinant Der p 2 (18). The detection limit for total and specific IgE was $<0.50 \mathrm{IU} / \mathrm{ml}$ and $<0.13$ $\mathrm{IU} / \mathrm{ml}$, respectively. We defined atopic sensitisation as a RAST value $>0.3 \mathrm{IU} / \mathrm{ml}$ for one or more allergens.

\section{STATISTICAL ANALYSIS}

The relationship between organic food consumption and atopic manifestations was evaluated in participants with complete information on at least one of the atopic manifestations.

Unadjusted associations between organic food consumption and atopic outcomes were examined using logistic regression. Multivariate logistic regression models were fitted to control for potential confounders (sex, parental history of atopic manifestations, sibling history of atopic manifestations, number of older siblings, breastfeeding, day care attendance, furred pets, exposure to environmental tobacco smoke, vaccinations, antibiotic use through breastfeeding or through oral medication, vegetarian diet), by simultaneously including them in the regression models. Missing data in the questionnaires were treated as missing in the analyses and are presented as 'unknown' in the tables. Differences in geometric mean total IgE levels were evaluated by linear regression analyses, controlling for the same confounders. Some previous studies reported associations between exposures and atopic outcomes to be limited to groups with different inherited propensity for developing atopic disease $(19,20)$. In the multivariate analysis, therefore, we first tested the possibility of interaction between organic food consumption and parental history of atopy. Since none of these interaction terms were statistically significant at alpha $=0.05$, they were eliminated from the regression models. Since separate analyses of the conventional vs. alternative subcohort and boys vs. girls showed that the key findings were similar within these groups, in the final models all infants were combined. Results are presented as unadjusted and adjusted odds ratios (ORs) with corresponding $95 \%$ confidence intervals (CI).

\section{Results}

\section{STUDY SUBJECTS}

About half of the infants had non-atopic parents; approximately $40 \%$ had one or more non-atopic older sibling and $16 \%$ had one or more atopic older sibling (Table I). In organic consuming families, there was a higher frequency of longer and exclusive breastfeeding, alternative vaccination schedules and low antibiotic use compared to families with conventional diets. In contrast, exposition to environmental tobacco smoke (ETS) was lower in organic consuming families. Baseline characteristics and prevalence of eczema and wheeze manifestations did not differ between infants with and without blood samplings, but the frequency of 
organic food consumption was slightly higher among infants with blood sampling (data not shown). In the first two years of life, 2306 (84\%) of 2764 infants had consumed a diet based on conventional food products; $283(10 \%)$ consumed a moderately organic diet; and $175(6 \%)$ consumed a strictly organic diet (Table I). During pregnancy, 2369 (86\%) of 2764 mothers consumed a diet based on conventional foods; 255 (9\%) consumed a moderately organic diet, and $150(5 \%)$ consumed a strictly organic diet.

\section{ECZEMA, WHEEZE AND SENSITISATION BY ORGANIC FOOD CONSUMPTION}

In total, 817 (32\%) of 2583 infants were classified as having had eczema in the first 2 years of life (this was $32 \%$ in the conventional and $30 \%$ in the alternative subcohort). Of these 817 infants with eczema, 101 (12\%) had also reported recurrent wheeze and $62(6 \%)$ had also reported prolonged wheeze.

The incidence of recurrent wheeze was 265 (11\%) of 2342 infants (12\% in the conventional and $6 \%$ in the alternative subcohort). Of these 265 infants with recurrent wheeze, 93 (35\%) had also reported prolonged wheeze and 101 (38\%) had also reported eczema. In total, for 137 (5\%) of 2546 infants parents reported prolonged wheezing (6\% in the conventional and $4 \%$ in the alternative subcohort). Of these 137 infants with prolonged wheeze, 93 (28\%) had also reported recurrent wheeze and $62(45 \%)$ had also reported eczema. Of infants with reported wheeze in the first two years, $70 \%$ had used beta 2 -adrenergic or steroid inhalant therapy at least once. Of infants with blood sampling $(n=815)$, $223(27 \%)$ were sensitised against at least one allergen at age 2 years.

Percentages for specific sensitisation in infants with blood sampling were $6 \%$ for hen's egg, $19 \%$ for cow's milk, $5 \%$ for peanut, $1 \%$ for birch, $2 \%$ for grass pollen, $3 \%$ for cat, $2 \%$ for dog and $6 \%$ for mite allergens.

Although a trend for an association between organic food consumption and lower eczema risk was observed, this did not reach statistical significance (Table II). No statistically significant associations were observed between organic food consumption and recurrent wheeze, prolonged wheeze and atopic sensitisation; the latter remained unchanged when using a lower cut-off point for sensitisation (specific IgE $<0.13 \mathrm{IU} / \mathrm{ml}$ ). Geometric mean total serum IgE level at age 2 years was not associated with organic food consumption. We repeated the analyses using information on maternal diet during pregnancy instead of the infants' diet to assure that exposure preceded symptoms. The adjusted odds ratios changed very little compared to those presented in Table II and were for eczema 0.90 (0.64-1.24) and $0.76(0.48-1.19)$; for recurrent wheeze 0.52 (0.27$1.01)$ and 0.90 (41-1.96) and for prolonged wheeze $0.81(0.38-1.72)$ and 0.85 (0.30-2.41) for moderately and strictly organic diets, respectively. 


\section{Table I}

Characteristics of infants in the present study for the total cohort and stratified by category of organic food use

\begin{tabular}{|c|c|c|c|c|c|}
\hline \multirow[t]{2}{*}{ Characteristic } & $\begin{array}{l}\text { Total } \\
\text { cohort }\end{array}$ & $\begin{array}{l}\text { Total } \\
\text { cohort }\end{array}$ & $\begin{array}{l}\text { Conven- } \\
\text { tional }\end{array}$ & $\begin{array}{l}\text { Moderaely } \\
\text { organic }\end{array}$ & $\begin{array}{l}\text { Strictly } \\
\text { organic }\end{array}$ \\
\hline & $\mathrm{N}=2764$ & $\%^{*}$ & $\begin{array}{l}\mathrm{N}=2306 \\
\%^{*}\end{array}$ & $\begin{array}{l}\mathrm{N}=283 \\
\%^{*}\end{array}$ & $\begin{array}{l}\mathrm{N}=175 \\
\%^{*}\end{array}$ \\
\hline Male & 1410 & $51 \%$ & $51 \%$ & $48 \%$ & $55 \%$ \\
\hline \multicolumn{6}{|l|}{ Parental history of atopic manifestations } \\
\hline None & 1339 & $48 \%$ & $48 \%$ & $51 \%$ & $53 \%$ \\
\hline Father & 519 & $19 \%$ & $19 \%$ & $14 \%$ & $22 \%$ \\
\hline Mother & 604 & $22 \%$ & $22 \%$ & $24 \%$ & $15 \%$ \\
\hline Both & 302 & $11 \%$ & $11 \%$ & $11 \%$ & $10 \%$ \\
\hline \multicolumn{6}{|l|}{ Sibling history of atopic manifestations } \\
\hline No older siblings & 1155 & $44 \%$ & $45 \%$ & $35 \%$ & $33 \%$ \\
\hline One older sibling - not atopic & 833 & $31 \%$ & $31 \%$ & $32 \%$ & $36 \%$ \\
\hline One older sibling - atopic & 261 & $10 \%$ & $10 \%$ & $11 \%$ & $10 \%$ \\
\hline$\geq 2$ older siblings - not atopic & 235 & $9 \%$ & $8 \%$ & $12 \%$ & $15 \%$ \\
\hline$\geq 2$ older siblings - one or both atopic & 159 & $6 \%$ & $6 \%$ & $10 \%$ & $6 \%$ \\
\hline Unknown & 121 & & & & \\
\hline \multicolumn{6}{|l|}{ Breastfeeding at age 6 months } \\
\hline Yes, months $1-4$ exclusive $\mathrm{BF}^{\dagger}$ & 622 & $25 \%$ & $19 \%$ & $47 \%$ & $62 \%$ \\
\hline Yes, months $1-4$ non-exclusive BF† & 441 & $17 \%$ & $16 \%$ & $22 \%$ & $22 \%$ \\
\hline No, months $1-4$ exclusive BFt & 62 & $3 \%$ & $2 \%$ & $5 \%$ & $1 \%$ \\
\hline No, months $1-4$ non-exclusive & 996 & $39 \%$ & $44 \%$ & $21 \%$ & $15 \%$ \\
\hline Never breastfeeding & 410 & $16 \%$ & $19 \%$ & $5 \%$ & $0 \%$ \\
\hline Unknown & 233 & & & & \\
\hline \multicolumn{6}{|l|}{ Day care in first six months } \\
\hline Yes & 831 & $32 \%$ & $33 \%$ & $34 \%$ & $20 \%$ \\
\hline No & 1724 & $68 \%$ & $67 \%$ & $66 \%$ & $80 \%$ \\
\hline Unknown & 209 & & & & \\
\hline \multicolumn{6}{|l|}{ Furred pets in first six months } \\
\hline Yes & 1168 & $45 \%$ & $45 \%$ & $47 \%$ & $48 \%$ \\
\hline No & 1387 & $55 \%$ & $55 \%$ & $53 \%$ & $52 \%$ \\
\hline Unknown & 209 & & & & \\
\hline \multicolumn{6}{|l|}{ Exposure to ETS ${ }^{+}$in first six months } \\
\hline Yes & 294 & $12 \%$ & $14 \%$ & $4 \%$ & $1 \%$ \\
\hline No & 2197 & $88 \%$ & $86 \%$ & $96 \%$ & $99 \%$ \\
\hline Unknown & 273 & & & & \\
\hline \multicolumn{6}{|l|}{ Vaccinations in first six months } \\
\hline By standard scheme & 1969 & $78 \%$ & $84 \%$ & $54 \%$ & $27 \%$ \\
\hline By incomplete schemeł & 393 & $15 \%$ & $14 \%$ & $25 \%$ & $21 \%$ \\
\hline None & 182 & $7 \%$ & $2 \%$ & $21 \%$ & $52 \%$ \\
\hline Unknown & 220 & & & & \\
\hline \multicolumn{6}{|l|}{$\begin{array}{l}\text { Antibiotic exposure through breastfeeding } \\
\text { in first six months }\end{array}$} \\
\hline Yes & 262 & $10 \%$ & $11 \%$ & $8 \%$ & $7 \%$ \\
\hline No & 2161 & $90 \%$ & $89 \%$ & $92 \%$ & $93 \%$ \\
\hline Unknown & 341 & & & & \\
\hline \multicolumn{6}{|l|}{$\begin{array}{l}\text { Antibiotic exposure through oral } \\
\text { medication in first six months }\end{array}$} \\
\hline Yes & 489 & $20 \%$ & $21 \%$ & $16 \%$ & $10 \%$ \\
\hline No & 1973 & $80 \%$ & $79 \%$ & $84 \%$ & $90 \%$ \\
\hline Unknown & 302 & & & & \\
\hline
\end{tabular}


Table I continued

\begin{tabular}{|c|c|c|c|c|c|}
\hline \multicolumn{6}{|c|}{ Eczema in first two years } \\
\hline Yes & 817 & $32 \%$ & $32 \%$ & $33 \%$ & $29 \%$ \\
\hline No & 1766 & $68 \%$ & $68 \%$ & $67 \%$ & $71 \%$ \\
\hline Unknown & 181 & & & & \\
\hline \multicolumn{6}{|c|}{ Recurrent wheeze in first two years } \\
\hline Yes & 265 & $11 \%$ & $12 \%$ & $7 \%$ & $8 \%$ \\
\hline No & 2077 & $89 \%$ & $88 \%$ & $93 \%$ & $92 \%$ \\
\hline Unknown & 422 & & & & \\
\hline \multicolumn{6}{|c|}{ Prolonged wheeze in first two years } \\
\hline Yes & 137 & $5 \%$ & $6 \%$ & $5 \%$ & $5 \%$ \\
\hline No & 2409 & $95 \%$ & $94 \%$ & $95 \%$ & $95 \%$ \\
\hline Unknown & 218 & & & & \\
\hline \multicolumn{6}{|c|}{ Atopic sensitisation at age $2 \S$} \\
\hline Yes & 223 & $27 \%$ & $28 \%$ & $23 \%$ & $29 \%$ \\
\hline No & 592 & $73 \%$ & $72 \%$ & $77 \%$ & $71 \%$ \\
\hline \multirow{2}{*}{\multicolumn{6}{|c|}{ * Percentage sum up vertically to $100 \%$, excluding missings. }} \\
\hline & & & & & \\
\hline \multicolumn{6}{|c|}{${ }^{\ddagger}$ Delayed scheme or alternative composition of vaccine. } \\
\hline \multicolumn{6}{|c|}{$\begin{array}{l}\S \text { Analyses conducted among infants with blood sample }(n=815) \text {. 'Atopic sensitisation' refers to } \\
\text { least one allergen-specific IgE } \geq 0.3 \mathrm{IU} / \mathrm{ml} \text { against hen's egg, cow's milk, peanut, birch pollen, }\end{array}$} \\
\hline
\end{tabular}

We evaluated the isolated effects of dairy, meat, fruit, vegetables, or eggs (Table III). Consuming organic dairy was associated with a reduced risk of eczema and the odds ratio for strictly organic dairy hardly changed if we restricted the analysis to 1 ) infants who had been consuming dairy (excluding infants who never consumed dairy, $n=226$, adjusted OR $0.69(0.48-1.01) ; 2$ ) infants who had never consumed raw/farm milk (excluding infants $(n=52)$ who ever consumed raw/farm milk in the first year, adjusted OR 0.63 (0.43-0.93); or 3) when using information on the mothers' diet during pregnancy instead of children's diet (adjusted OR 0.67 (0.46-0.98), even when mothers who avoided dairy $(n=40)$ were excluded from the analysis (adjusted OR 0.67 (0.46-0.99). No other statistically significant associations were observed.

To further explore the association between the specific food groups and atopic manifestations, we evaluated the isolated effects of dairy, meat, fruit, vegetables, or eggs (Table III). Consuming organic dairy was associated with a reduced risk of eczema: adjusted OR 0.90 (0.58-1.40) and 0.64 (0.44-0.93) for moderately and strictly organic dairy, respectively. The odds ratio for organic dairy and eczema hardly changed if we restricted the analysis to 1 ) infants who had been consuming dairy (excluding infants who never consumed dairy, $n=226$, adjusted OR $0.69(0.48-1.01) ; 2)$ infants who had never consumed raw/farm milk (excluding infants $(n=52)$ who ever consumed raw/farm milk in the first year, adjusted OR $0.63(0.43-0.93)$; or 3$)$ when using information on the mothers' diet during pregnancy instead of children's diet (adjusted OR 0.67 (0.46-0.98), even when mothers who avoided dairy $(n=40)$ were excluded from the analysis (adjusted OR 0.67 (0.46-0.99). 


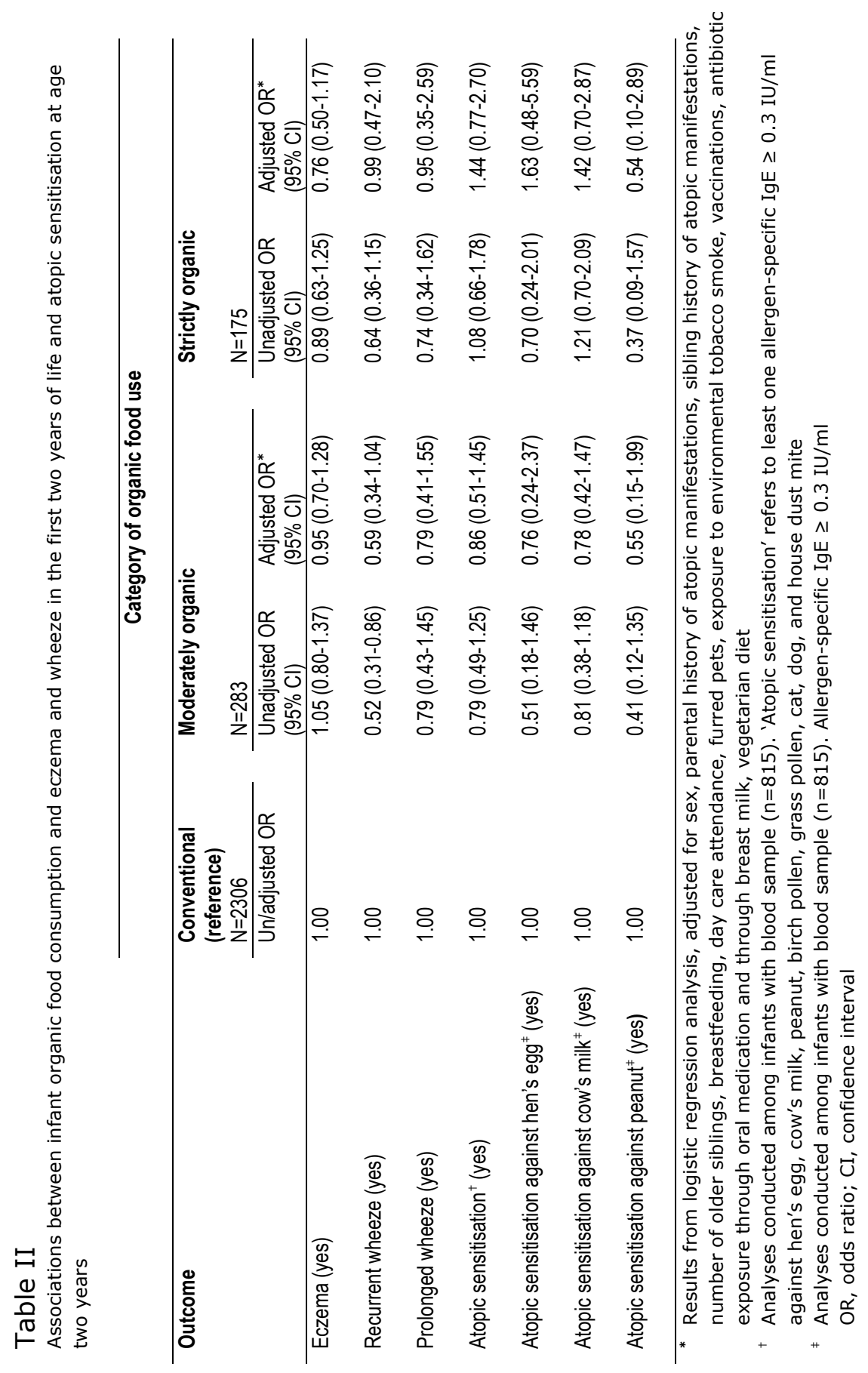




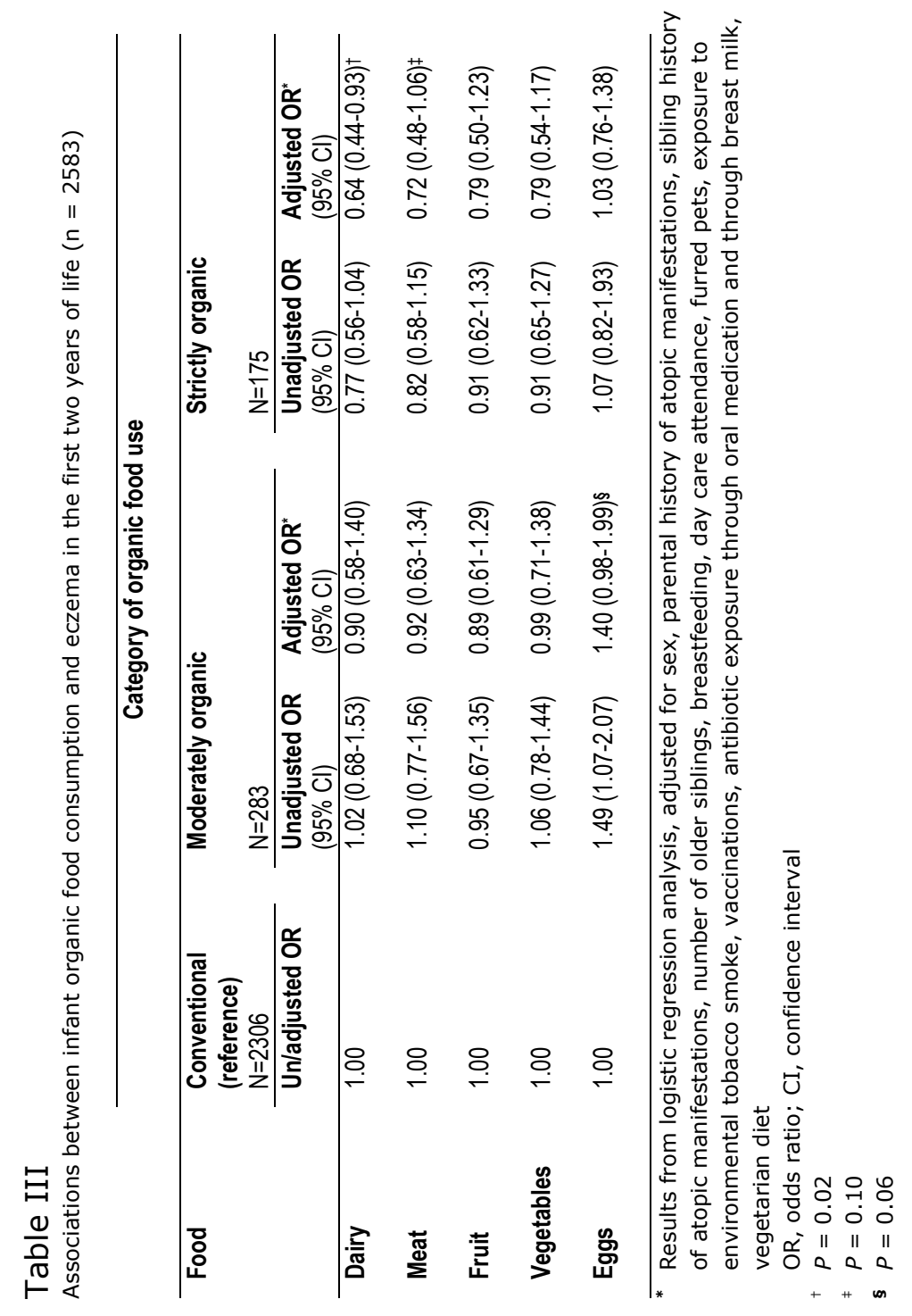




\section{Discussion}

We showed that the overall proportion of organic products within the total diet was not statistically significant associated with the development of eczema and prolonged wheeze in the first two years of life or with atopic sensitisation at age two years. However, we found an independent association between consuming strictly organic dairy and a reduced risk of eczema.

To the best of our knowledge, this is the first prospective cohort study focusing on the health effects of consuming organic food products. So far, only one recent cross-sectional study on this topic is known (13). This study performed in 5 European countries showed no difference in atopic outcomes in 5-13 year old children divided in three groups: a diet based on 1) conventional, 2) biodynamic 3) or a mixture of conventional, biodynamic, and organic foods. Since the infants in the latter group consumed foods from a mixture of production methods, the isolated effect of organic foods could not be assessed.

Strengths of our study are the fact that it is population-based, with a large number of infants involved, as well as the large contrast in the use of conventional and organic products due to the specific recruitment of participants with alternative lifestyles. Moreover, the relatively short intervals between subsequent follow-up questionnaires decreased the possibility of recall bias. Follow-up rates were high which limited differential bias with regard to baseline characteristics or outcomes. Since children from conventionally eating mothers might be given organic foods because of the symptoms they had early in life, we also used information on organic food consumption in pregnant mothers instead, and were thus able to exclude the possibility of bias in the associations found for infants. Furthermore, the fact that we extensively adjusted for potential confounders such as vaccinations, use of antibiotics, breastfeeding duration and exclusivity makes it highly unlikely that the observed associations would be caused by an association between organic dieting and other healthy lifestyle characteristics.

Several methodological aspects merit consideration. First, atopic outcomes like infant eczema and wheeze may be fairly unspecific for infants aged 2 years (21), and therefore subject to misclassification. Although not likely, we cannot completely disregard the possibility that parents who choose organic foods may report atopic symptoms differently from other parents as they may be more health conscious. This would however tend to lead to overreporting rather than underreporting in organic eating families, and therefore further strengthens our results. Second, atopic outcomes like infant eczema and wheeze may be fairly unspecific for infants aged 2 years and therefore weak indicators of atopic development such as asthma in children. Children with physician confirmed wheeze have been reported to have significantly poorer lung function compared to those with only parentally reported wheeze that was medically unconfirmed (22). In individuals with an atopic constitution, the underlying mechanism of developing eczema is often dominated by an IgE-antibody-associated reaction to specific allergens, justifying the term 'atopic eczema'. Specific IgE or total serum IgE levels are, however, only weakly associated with atopic symptoms like eczema and wheeze (23). Therefore, we evaluated clinical symptoms and atopic sensitisation as separate outcomes and used the term eczema instead of atopic eczema. Our definition of eczema was based on questions adapted from the 
International Study of Asthma and Allergies in Childhood (ISAAC) questionnaires and included generally accepted characteristics, like a chronically relapsing course and an itchy rash. Our definition of recurrent wheeze was also based on ISAAC questionnaires. Besides, we identified a second more stringent definition of wheeze ('prolonged'), restricting it to infants who repeatedly woke up in the night due to wheezing in both the first and second year. In addition, parents were asked whether medical care was provided to the wheezing infant. This was true for $70 \%$ of wheezy infants, which reinforced us to rely on the parental reports of wheezing. Finally, though we found a beneficial effect of the consumption of organic dairy on the development of eczema, we cannot exclude the possibility that organic dairy as a part of an organic diet plays a protective role.

The mechanism by which organic dairy consumption protects against development of eczema is unknown. Dietary studies have indicated that raw (unpasteurised) or farm milk was associated with a protective effect against development of atopic manifestations, independent of farming status (24-26). This would raise the question whether families eating organic dairy might consume raw milk more often relative to families consuming conventional produce. However, when we repeated our analyses with exclusion of raw/farm milk consumers, the protective effect of organic dairy consumption remained unchanged.

Various components of organic dairy could be involved in the beneficial association between strictly organic dairy consumption and eczema in infants in the present study. One of the most pronounced dietary changes that has paralleled the increased prevalence of atopic diseases over the past decades is the altered consumption of polyunsaturated fatty acids (PUFA), especially elevated consumption of pro-inflammatory n-6 PUFA (especially linoleic acid in margarines and vegetable oils for cooking) and lower intake of $n-3$ (omega 3) PUFA (especially alfalinolenic acid from green vegetables and fish oils from fatty fish) (27). It has been hypothesised that derivates of long chain PUFA are involved in the regulation of inflammatory processes and immune cell functional responses through eicosanoid production (28). In addition, n-3 fatty acids in maternal milk have been shown to influence the risk of non-atopic eczema and asthma in infants, but not the risk of atopic sensitisation $(29,30)$. Therefore, the possible protecting effect of $\mathrm{n}-3$ fatty acids does probably not involve IgE-mediated immunity, but rather anti-inflammatory properties or maintenance of the skin barrier. This is consistent with our finding of an association between organic dairy use and eczema but not atopic sensitisation. It has been shown in a variety of studies (31-33) that the levels of conjugated linoleic acid (CLA) and n-3 PUFA in cow's milk from organic producers in Europe, including the Netherlands (34), are significantly higher than in the milk from conventional producers. Also, we recently found breast milk of organic dairy consuming mothers to contain higher levels of CLA and trans-vaccenic acid (TVA) compared to mothers consuming conventional dairy (Rist et al., unpublished data, 2006). In the Netherlands, the main sources of CLA are of dairy origin (35). The health effects of CLA on human newborns are still unknown, but there is promising evidence from studies with human adults. For example, CLA supplementation in young healthy men affected the immune function in terms of increased plasma $\operatorname{IgA}$, IgM, and the antiinflammatory cytokine IL-10, and decreased levels of IgE and the proinflammatory cytokine TGF- $\beta$ (36). However, our findings (the association of 
organic dairy use and eczema but not atopic sensitisation) do not indicate that an immunological mechanism is involved. Organic dairy can also contain gramnegative bacteria and their endotoxin. It was shown that raw milk contained more endotoxin than pasteurised milk (37), consequently leading to the hypothesis that the protective factor associated with the consumption that organic dairy, like farm milk, could be associated with ingestion of non-infectious microbial components, with resultant changes to the commensal gut flora. Since our study did not contain enough infants using raw milk, we were not able to study this group separately and check whether results for organic dairy consumption and raw milk were similar. However, the results suggest the possibility that raw milk and organic dairy products share some factor(s) protective against atopic disease.

Dietary studies have indicated that margarine intake was linked to an increased risk (38-40) and butter consumption and use of full cream milk to a decreased risk of atopic diseases (40-43). This leads to the question whether families eating organic dairy also consume higher levels of milk fat because of the deliberate choice for full fat dairy products. However, the information collected in the present study does not allow us to discriminate whether the dairy consumed contained full cream milk or semi-skim milk, or concerned margarine vs. butter.

In summary, the present prospective birth cohort study suggests that the consumption of organic dairy foods, within the context of an organic diet, may protect against the development of eczema. Further studies to substantiate these results using more detailed and quantitative information are warranted. Also, information on the nutritional composition of organic dairy in the development of eczema, separately from atopic disease would be valuable.

\section{Acknowledgements}

We thank members of the KOALA team for their contribution to data collection, data management and data analysis and also like to thank all parents and infants who participated in this study. 


\section{References}

1. Maziak W, Behrens T, Brasky TM, et al. Are asthma and allergies in children and adolescents increasing? Results from ISAAC phase I and phase III surveys in Munster, Germany. Allergy. 2003;58:572-9.

2. Beasley R, Crane J, Lai CK, et al. Prevalence and etiology of asthma. J Allergy Clin Immunol. 2000;105:S466-72.

3. The International Study of Asthma and Allergies in Childhood (ISAAC) Steering Committee. Worldwide variation in prevalence of symptoms of asthma, allergic rhinoconjunctivitis, and atopic eczema: ISAAC. Lancet. 1998;351:1225-32.

4. Magnusson MK, Arvola A, Hursti UK, et al. Choice of organic foods is related to perceived consequences for human health and to environmentally friendly behaviour. Appetite. 2003; 40:109-17.

5. Lockie S, Lyons K, Lawrence G, et al. Choosing organics: a path analysis of factors underlying the selection of organic food among Australian consumers. Appetite. 2004;43:1346.

6. Williams PR, Hammitt JK. Perceived risks of conventional and organic produce: pesticides, pathogens, and natural toxins. Risk Anal. 2001;21:319-30.

7. Williams CM. Nutritional quality of organic food: shades of grey or shades of green? Proc Nutr Soc. 2002;61:19-24.

8. Bourn D, Prescott J. A comparison of the nutritional value, sensory qualities, and food safety of organically and conventionally produced foods. Crit Rev Food Sci Nutr. 2002;42:1-34.

9. Magkos F, Arvaniti F, Zampelas A. Organic food: nutritious food or food for thought? A review of the evidence. Int J Food Sci Nutr. 2003;54:357-71.

10. Magkos F, Arvaniti F, Zampelas A. Organic food: buying more safety or just peace of mind? A critical review of the literature. Crit Rev Food Sci Nutr. 2006;46:23-56.

11. Woese $\mathrm{K}$, Lange $\mathrm{D}$, Boess $\mathrm{C}$, Bögl KW. A comparision of organically and conventionally grown foods - Results of a review of the relevant literature. J Sci Food Agriculture. 1997; 74: 281-293.

12. Worthington $V$. Nutritional quality of organic versus conventional fruits, vegatables and grains. J Alter Compl Med. 2001;7:161-173.

13. Floistrup $\mathrm{H}$, Swartz J, Bergstrom A, et al. Allergic disease and sensitisation in Steiner school children. J Allergy Clin Immunol. 2006;117:59-66.

14. Kummeling I, Thijs C, Penders J, et al. Etiology of atopy in infancy: the KOALA Birth Cohort Study. Pediatr Allergy Immunol. 2005;16:679-684.

15. Bastiaanssen JM, de Bie RA, Bastiaenen $\mathrm{CH}$, et al. Etiology and prognosis of pregnancy-related pelvic girdle pain; design of a longitudinal study. BMC Public Health. 2005;5:1-8.

16. Stallman PJ, Aalberse RC. Estimation of basophil-bound IgE by quantitative immunofluorescence microscopy. Int Arch Allergy Appl Immunol. 1977;54:9-18.

17. Akkerdaas $\mathrm{JH}$, Wensing $\mathrm{M}$, Asero $\mathrm{R}$, et al. IgE binding to pepsin-digested food extracts. Int Arch Allergy Immunol. 2005;138:203-8.

18. Schuurman J, Perdok GJ, Lourens TE, et al. Production of a mouse/human chimeric IgE monoclonal antibody to the house dust mite allergen Der $\mathrm{p} 2$ and its use for the absolute quantification of allergen-specific IgE. J Allergy Clin Immunol. 1997;99:54550 . 
19. Remes ST, Castro Rodriguez JA, Holberg CJ, et al. Dog exposure in infancy decreases the subsequent risk of frequent wheeze but not of atopy. J Allergy Clin Immunol. 2001;108:509-15.

20. Wright $A L$, Sherrill $D$, Holberg $C$ J, et al. Breast-feeding, maternal IgE, and total serum IgE in childhood. J Allergy Clin Immunol. 1999;104:589-94.

21. Koopman LP, Brunekreef B, de Jongste JC, et al. Definition of respiratory symptoms and disease in early childhood in large prospective birth cohort studies that predict the development of asthma. Pediatr Allergy Immunol. 2001;12:118-24.

22. Lowe L, Murray CS, Martin L, et al. Reported versus confirmed wheeze and lung function in early life. Arch Dis Child. 2004; 89:540-3.

23. Kusel MM, Holt PG, de Klerk N, et al. Support for 2 variants of eczema. J Allergy Clin Immunol. 2005;116:1067-72.

24. Riedler J, Braun-Fahrländer C, Eder W, et al. Exposure to farming in early life and development of asthma and allergy: a cross-sectional survey. Lancet, 2001;358:1129-33.

25. Wickens $\mathrm{K}$, Lane JM, Fitzharris $\mathrm{P}$, et al. Farm residence and exposures and the risk of allergic diseases in New Zealand children. Allergy. 2002;57:1171-9.

26. Perkin MR, Strachan DP. Which aspects of the farming lifestyle explain the inverse association with childhood allergy? J Allergy Clin Immunol. 2006;117:1374-81.

27. Black PN, Sharpe S. Dietary fat and asthma: is there a connection? Eur Respir J. 1997; 10:6-12.

28. Calder PC. Abnormal fatty acid profiles occur in atopic dermatitis but what do they mean? Clin Exp Allergy. 2006;36:138-141.

29. Wijga $A H$, van Houwelingen AC, Kerkhof $M$, et al. Breast milk fatty acids and allergic disease in preschool children: the Prevention and Incidence of Asthma and Mite Allergy birth cohort study. Allergy Clin Immunol. 2006;117:440-7.

30. Oddy WH, Pal S, Kusel MM, et al. Atopy, eczema and breast milk fatty acids in a highrisk cohort of children followed from birth to $5 \mathrm{yr}$. Pediatr Allergy Immunol. 2006;17:4-10.

31. Jahreis G, Fritsche J, Steinhart $\mathrm{H}$. Conjugated linoleic acid in milk fat: high variation depending on production system. Nutr Res. 1997;17:1479-84.

32. Bergamo $P$, Fedele $E$, Iannibelli $L$, et al. Fat-soluble vitamin contents and fatty acid composition in organic and conventional Italian dairy products. Food Chemistry. 2003;82: 625-31.

33. Dewhurst RJ, Evans RT, Scollan ND, et al. Comparison of grass and legume silages for milk production. 2. In vivo and in sacco evaluations of rumen function. J Dairy Sci. 2003;86:2612-21.

34. Adriaansen-Tennekes R, Bloksma J, Huber MAS, et al. [Organic products and health. Results of milk research.] Biologische producten en gezondheid. Resultaten melkonderzoek (Dutch). 2005 Louis Bolk Intituut, Publication GVV06, Driebergen, the Netherlands.

35. Voorrips LE, Brants HA, Kardinaal AF, et al. Intake of conjugated linoleic acid, fat, and other fatty acids in relation to postmenopausal breast cancer: the Netherlands Cohort Study of Diet and Cancer. Am J Clin Nutr. 2002;76:873-82.

36. Song $\mathrm{HJ}$, Grant I, Rotondo $\mathrm{D}$, et al. Effect of CLA supplementation on immune function in young healthy volunteers. Eur J Clin Nutr. 2005;59:508-17.

37. Suhren G, Hesselbarth $H$, Heeschen W, et al. Evaluation of the lipopolysaccharide (LPS) content as determined by the limulus test in milk and milk products II: raw milk and influences of of technological procedures. Michwissenschaft. 1986;41:156-60. 
38. Sausenthaler S, Kompauer I, Borte M, et al. Margarine and butter consumption, eczema and allergic sensitisation in children. The LISA birth cohort study. Pediatr Allergy Immunol. 2006; 17:85-93.

39. Bolte $\mathrm{G}$, Frye $\mathrm{C}$, Holscher $\mathrm{B}$, et al. Margarine consumption and allergy in children. Am J Respir Crit Care Med. 2001;163:277-9.

40. Dunder T, Kuikka L, Turtinen J, et al. Diet, serum fatty acids, and atopic diseases in childhood. Allergy. 2001;56:425-8.

41. von Mutius E, Weiland, SK, Fritzsch C, et al. Increasing prevalence of hay fever and atopy among children in Leipzig, East Germany. Lancet. 1998;351:862-6.

42. Wijga $\mathrm{AH}$, Smit $\mathrm{HA}$, Kerkhof $\mathrm{M}$, et al. Association of consumption of products containing milk fat with reduced asthma risk in pre-school children: the PIAMA birth cohort study. Thorax. 2003;58:567-72.

43. von Ehrenstein OS, von Mutius E, Illi S, et al. Reduced risk of hay fever and ashtma among children of farmers. Clin Exp Allergy. 2000;30:187-93. 


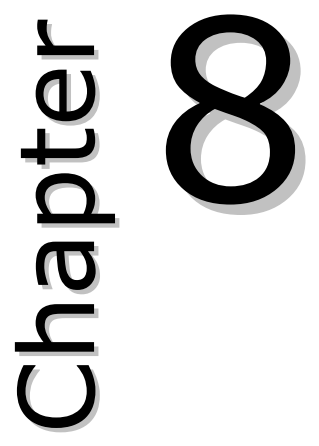

General discussion 


\section{Introduction}

Worldwide, lifestyle and environmental exposures are investigated intensively in attempts to understand the causes for the increasing prevalence of atopic diseases in western societies over the last few decades. In this thesis, we report on research that was part of the KOALA Birth Cohort Study, the Netherlands; a study that aimed to identify factors that influence the clinical manifestations of atopic disease in early infancy. The work in this thesis specifically focuses on the role of alternative lifestyle factors.

In this general discussion we reflect on the results described in this thesis, highlighting novel findings compared to the literature, and put them into a broader perspective.

\section{EPIDEMIOLOGICAL BASIS OF THE STUDIES REPORTED IN THIS THESIS}

In 1999, Alm et al. published a paper describing that an anthroposophic lifestyle protected against atopic disease in 7-8 year old children participating in a Swedish cross-sectional study (1). Several aspects of an anthroposophic lifestyle that could have a protective effect on atopy development were put forward, such as restricted use of vaccinations and antibiotics and organic food consumption.

\section{Study design}

As discussed in the previous chapters, the main limitation of crosssectional studies is that exposures and outcomes are measured simultaneously (2). Consequently, this design does not allow the separation between cause and effect. In order to detect causal relationships in humans, prospective studies are preferable. If feasible, an intervention study would be the best study design since in this type of studies, the exposure is assigned to subjects in random fashion or by chance. Randomisation of subjects ensures that both known and unknown confounders will be equally distributed among the exposed and unexposed groups. An example of such an intervention study is the Prevention and Incidence of Asthma and Mite Allergy study (PIAMA), in which children were randomly allocated to an 'intervention' group, a 'placebo' group, and a second control group, the intervention being application of mite-impermeable mattress covers for the bed of the child and the bed of the parents, and mite-impermeable pillow covers also for the parents (3). However, assignment of exposures related to, in our case, alternative lifestyle choices such as restricted use of vaccinations is not feasible for ethical reasons. Also, parents are likely not willing to being randomised in, for example, vaccination or antibiotic studies, resulting in a limited amount of people interested to participate. Therefore, in these circumstances and for diseases that occur from infancy onwards, a birth cohort study is the best possible design (4). Besides the KOALA study, current birth cohort studies aiming to establish crucial risk factors for asthma and other atopic diseases in childhood are, among others, the BAMSE project (Sweden) (5), LISA study (Germany) (6), and MAS study (Germany) (7). 


\section{Special feature of the KOALA study}

To investigate the relationship between atopic disease and lifestyle choices that have a low prevalence in the general population (e.g. restricted use of antibiotics and vaccinations, organic food consumption) we needed a special recruitment procedure. As described in Chapter 2, compared to other European birth cohort studies, the KOALA study is unique in having specifically enrolled a large group of participants with so-called 'alternative' lifestyle choices $(n=491)$. Pregnant women with alternative lifestyles were invited to participate through several specific recruitment channels, i.e. anthroposophic doctors and midwifes, anthroposophic under-five clinics, Steiner Schools, posters and flyers in organic food shops and magazines for special interest groups (e.g. homeopathy, anthroposophy, anti-vaccine). Besides these 491 families with alternative lifestyles, 2343 conventional families consented to participate, resulting in a considerable size cohort with a relatively large contrast in exposure to special dietary habits (including long duration of breastfeeding, organic foods, and vegetarian diet), alternative vaccination schemes and antibiotic use. Consequently, the great diversity of lifestyle choices within our study population gave us the opportunity to investigate the effect of single, independent, (lifestyle) exposure factors. As described in Chapter 5, 6 and 7, separate analyses of the conventional versus alternative subcohort showed that key findings were quite similar within these groups. Therefore, in all studies described in this thesis, we combined all infants enrolled via both alternative and conventional recruitment channels as one cohort in the final analyses.

Two aspects of special importance in longitudinal observational studies such as the present birth cohort study are confounding-by-indication and reverse causation, both being alternative explanations of the association between exposure and outcome. Below, we will briefly discuss the implications of these two issues for the present thesis.

\section{Confounding-by-indication}

A family history of atopic disease is a traditional confounder in atopy research $(6,7)$. As described in Chapter 3 , parents with a positive family history of atopic disease may adopt lifestyle characteristics that allegedly protect against atopy. This causes differences in exposure to important risk or protective factors in early life between children of atopic and non-atopic families (8). Consequently, the validity of epidemiological research concerning the role of lifestyle factors in relation to atopic disease may be affected: if atopic families adopt a 'prudent' lifestyle, i.e. a lifestyle which allegedly protects against atopic disease, the effect of lifestyle on the development of atopy will be confounded by family history of atopy (confounding-by-indication) (Figure I). 


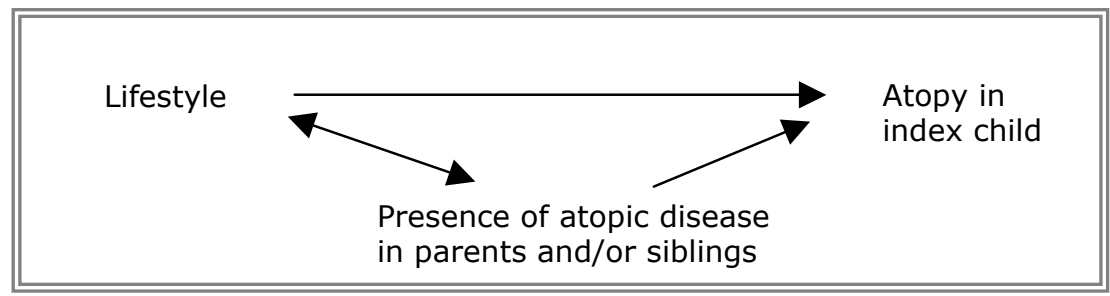

Figure I

Schematic presentation of confounding-by-indication: a family history of atopic disease confounds the observed association between the exposure to a certain lifestyle factor and the presence of atopy

Chapter 3 of this thesis shows that, indeed, some 'prudent' lifestyle characteristics differed between atopic and non-atopic families, depending on whether atopic manifestations were present in parents or older siblings. Based on these findings, we decided to control all data analyses in the subsequent chapters for potential confounding-by-indication due to a family history of atopic manifestations. Of note, the results of these analyses showed that atopy in parents and siblings have to be viewed as separate confounders. Although so far, few researchers have separated the effects of parental and sibling atopic manifestations, we would recommend for future studies to take this difference into account.

\section{Reverse causation}

One aspect for establishing causality is to assess the time relation between an exposure and outcome: does the cause (exposure) precede the effect (outcome)? In this thesis, we have in all cases accounted for the possibility of reverse causation by, after performing overall analyses for all available infants, repeating the same analyses while restricting them to at risk infants only (i.e. by excluding from the analyses children with the atopic manifestation under study in the same period that the exposure was measured). In chapter 5, 6 and 7 we show that the findings described in this thesis were not due to reverse causation.

\section{ALTERNATIVE LIFESTYLE CHOICES}

Alm et al. (1) put forward several aspects of an anthroposophic lifestyle that could have a protective effect on atopy development, such as restricted use of vaccinations and antibiotics and organic food consumption. In the following paragraphs we will discuss if one of these could be confirmed by the KOALA study.

\section{Vaccinations}

Chapter 5 of this thesis shows that the risk of eczema or recurrent wheeze at age one year did not differ between infants with different vaccination status at age six months. Since the majority of infants are vaccinated against diphtheria, pertussis, poliomyelitis, and tetanus (DPPT) in western countries, unvaccinated children in the general population are rare. Because of the specific recruitment strategy described above, the KOALA cohort had a relatively large proportion of unvaccinated infants $(n=182 ; 7 \%)$. 
In a recent systematic review (9), the authors concluded that vaccinations do not cause atopic disease. However, it is possible that confounding-by-indication has biased the results of all studies included in this review: motives for not vaccinating are likely to be health-related, which may result in confounding-by(contra)indication if these health-related problems are associated with atopic disease (10). Unlike other vaccination studies, in the KOALA study, we measured motives of parents to opt for alternative vaccination schemes. We showed that parents in our study had mainly chosen to deviate from the standard vaccination schedule because of certain philosophical principles or beliefs, rather than because of health-related considerations, which limited the possibility of biased findings. Results from another study recently showed that DPPT vaccinations were also not related to atopic disorders in Dutch primary school aged children (11). As this study was conducted in a religious group in the Netherlands, where part of the population refuses vaccinations for religious and mostly not for health-related reasons, the problem of confounding-by-indication was also limited in their study.

These findings appear to support the conclusion in the above-mentioned review, that the DTTP vaccination is indeed not associated with atopic disease. At the time of writing, the KOALA study team is preparing a second, expanded, investigation of the effect of vaccinations on the development of atopic manifestations. In infants followed until two years of age on atopic outcomes and vaccination status, the effect of additional vaccinations such as mumps, measles and rubella (MMR) will be studied.

\section{Antibiotics}

In chapter 6, we report that early antibiotic exposure through oral medication was positively associated with the development of wheezing, but not eczema or atopic sensitisation, in the first two years of life. We can only speculate about the causality of this association. One possibility is that antibiotics are prescribed because of wheezy bronchitis and related conditions (reverse causation). We have attempted to eliminate this possibility by restricting the analysis to infants who had no wheeze at the time of antibiotic use, thereby avoiding that symptoms would precede antibiotic prescription. However, this relied on parent-reported wheeze, so that we cannot rule out the possibility that the child suffered from wheezy bronchitis. Recently, results of a young Swedish birth cohort study showed that neonatal antibiotic treatment increased the risk of wheeze at age 1 year (12). The fact that antibiotic treatment in this study was measured in the neonatal period excluded the possibility of reverse causation (except if the clinical manifestations of wheeze would have begun very early in life which is unlikely). Antibiotics use could simply have been a marker for viral infections since they are often prescribed for infant viral infections (13). Respiratory Syncytial Virus (RSV) and rhinovirus (RV) infections are strongly associated with infant wheeze in the first years of life (14). To our knowledge, our study is the first study focusing on the association between antibiotic exposure through breastfeeding and the development of atopy. We found a positive association between indirect exposure to antibiotics via breastfeeding, and the development of wheezing.

Although our study cannot confirm or refute a causal relationship between antibiotic exposure and wheeze, these results support the hypothesis that earlylife exposure of antibiotics is associated with atopic manifestations, thereby adding 
further evidence to this controversial subject. Additional well-designed prospective studies are needed to corroborate this association and to replicate our findings of the effect of antibiotic use through breastfeeding on wheeze.

\section{Organic food consumption}

The KOALA study also appears to be the first prospective cohort study focusing on the health effects of consuming organic food products. Chapter 7 shows that the overall proportion of organic products within the total infant diet was not statistically significant associated with the development of atopic manifestations. However, we found an independent association between strictly consuming organic dairy and a reduced risk of eczema. This finding needs to be interpreted with some caution since we cannot completely exclude the possibility that organic dairy as a part of an organic diet may play a protective role. The mechanism by which organic dairy consumption protects against development of eczema is unknown and various components could be involved. Two components may be briefly mentioned here: the presence of gram-negative bacteria and their endotoxin and fatty acid composition, especially n-3 fatty acids, in organic dairy. Organic dairy may contain different levels of endotoxin, consequently leading to the hypothesis that the protective factor associated with the consumption that organic dairy could be associated with ingestion of non-infectious microbial components, with a possible role in the development and maintenance of immune tolerance against microbial and food antigens. Recently, $n-3$ fatty acids in maternal milk have been shown to influence the risk of non-atopic eczema and asthma in infants, but not the risk of atopic sensitisation $(15,16)$. The levels of conjugated linoleic acid (CLA) and n-3 polyunsaturated fatty acids (PUFA) in cow's milk from organic producers in Europe, including the Netherlands, were reported to be significantly higher than in the milk from conventional producers (17-20). Also, we recently found breastmilk from mothers consuming organic dairy to contain higher levels of CLA and trans-vaccenic acid (TVA) compared to mothers consuming conventional dairy (Rist et al., unpublished data, 2006). In the Netherlands, the main sources of CLA are of dairy origin (21). Dietary studies have indicated that margarine intake was linked to an increased risk of atopic diseases (22-24), whereas butter consumption and use of full cream milk was associated with a decreased risk of atopic disease (24-27). This would raise the question whether families eating organic dairy also consume higher levels of milk fat because of the deliberate choice for full fat dairy products. However, the information collected in the present study does not allow us to discriminate whether the dairy consumed contained full cream milk or semi-skim milk, or concerned butter versus margarine.

The fact that we extensively adjusted for potential confounders such as vaccinations, use of antibiotics, breastfeeding duration and exclusivity makes it highly unlikely that the observed associations would be caused by confounding. Dietary studies have indicated that raw (unpasteurised) or farm milk was associated with a protective effect against development of atopic manifestations, independent of farming status (28-30). This would raise the question whether families eating organic dairy might consume raw milk more often relative to families consuming conventional produce. However, this explanation seems to be ruled out by the fact that repeated analyses with exclusion of raw/farm milk 
consumers yielded similar results, i.e., the protective effect of organic dairy consumption remained unchanged.

Further studies to substantiate these results using more detailed and quantitative information would appear to be warranted. Also, more information on the nutritional composition of organic dairy in relation to the development of eczema, separately from atopic disease, would be valuable.

\section{House dust}

We wondered whether house dust components like higher levels of endotoxin might be among the factors related to an anthroposophic lifestyle. It was recently hypothesised that higher microbial exposure, especially to bacterial endotoxin, could protect against the development of atopy (31). Endotoxin is a cell wall component of Gram-negative bacteria and is commonly present in normal indoor environments as a constituent of house dust. The findings, presented in Chapter 4, suggested that an anthroposophic lifestyle may expose to more dust on living room floors, and therefore to more endotoxin and Der $p 1$ per $\mathrm{m}^{2}$, compared to conventional lifestyle families. This finding confirmed another study which showed more living room and mattress dust and higher levels of endotoxin when expressed per square meter, but not when expressed per gram of dust, in the homes of anthroposophic compared to conventional families (32). It remains to be elucidated which characteristics associated with an anthroposophic lifestyle determine these higher amounts of house dust on floors, like for example more use of dusty natural materials like sheepskin for decorating the house, or others. Also, whether these higher amounts of house dust are really a causative factor which contributes to the lower prevalence of atopy in infants of families with an anthroposophic lifestyle, will need confirmation in future studies. If this were true, then a possible explanation for this would be that a higher exposure to endotoxin prevents from other atopic manifestations such as house dust mite allergy.

\section{Factors not investigated in this thesis}

Certainly, there are other factors characteristic for alternative lifestyles that may be associated with atopic diseases. As described earlier, the establishment of the intestinal microflora is a major factor driving the maturation of the immune systems in newborns (33), possibly effecting atopic disease development. Alm et al. (34) suggested that the microflora of the gut in infants could be affected by certain lifestyle characteristics associated with anthroposophy. Indeed, both the KOALA study (35) as well as a Swedish study (34) recently showed that certain environmental exposures characteristic of an alternative and/or anthroposophic lifestyle, such as vegetarian food, home delivery, type of infant feeding, and antibiotic use by the infant, were important determinants of the gut microbiotic composition in infants. Whether these differences in the gut microbiotic composition also affect atopic disease development is currently being investigated in the KOALA study. The findings in the current thesis, however, do not indicate the involvement of an IgE mediated immunological mechanism in the observed associations between organic dairy consumption and eczema and between antibiotic use and recurrent wheeze.

Other dietary factors associated with alternative lifestyle habits (i.e. longer breastfeeding duration, the consumption of fermented foods, or a 
vegetarian diet) have not been investigated as independent determinants in the present thesis, but will be the subject of other theses from the KOALA study.

Finally, of particular interest is the possible influence of stress on manifestations of atopic disease (36). Mechanisms linking psychological stress, personality, and emotion to the increased risk of atopy have recently been suggested (37-39). Hormones and neuropeptides released into the circulation when individuals experience stress may also regulate both immune-mediated and neurogenic inflammation (36). So far, there appear to be no studies on differences in psychological responses to environmental stressors between alternative and conventional families. Anthroposophic child rearing advocates restricting or 'filtering' the sensory impressions, such as potentially disturbing, stressful, loud or aggressive influences (i.e. radio and television sounds, colours, environmental smoking, being in crowds, certain materials of clothes and toys), in the physical and non-physical environment of newborns. We recommend that future studies investigate the possible influence of stress on manifestations of atopic disease in infancy.

\section{Concluding remarks}

Which factors can explain the lower prevalence of atopy in infants of families with alternative lifestyles? In this thesis, we showed that differences in vaccination schedules did not lead to a different risk of eczema and wheeze. This may be reassuring for parents who fear possible adverse effects of DTTP vaccinations. The similarity of the risk of developing atopic manifestations in vaccinated and unvaccinated infants also gave no evidence for a direct allergyinducing immune effect of vaccinations or additives used in these vaccines. Infants with differences in antibiotic use had a similar risk of eczema and atopic sensitisation but had a different risk of wheeze (although we cannot confirm or refute a causal relationship yet). At this moment, it is also too early to draw definite conclusions from our findings on antibiotic exposure through breastfeeding and organic food consumption. However, our findings are promising and offer two interesting new subjects to the field of future atopy research that so far have been neglected.

\section{EPILOGUE}

Currently, from a public health perspective, there is an urgent need to formulate strategies leading to a reduction in atopic diseases. Although the genetics of these disorders are being investigated, manipulation of known environmental risk factors would appear to remain the best, or perhaps even only available, option to reduce the prevalence of atopic diseases. However, after decades of research, current literature on risk factors for the development of atopic diseases often still shows contradictory results and conclusions, hampering the formulation of public health strategies.

\section{Outcome definition in future epidemiological research}

Many studies have defined atopic outcomes as symptoms combined with atopic sensitisation (as measured by increased specific Immunoglobulin E (IgE) levels to common environmental allergens or skin prick testing). However, in this 
thesis it was shown that potential determinants of atopic manifestations were either associated with eczema (organic food) or wheeze (antibiotics) and never with atopic sensitisation (vaccinations, antibiotics, and organic foods). Also, although the disease phenotype called eczema has been thought of as principally an atopic disease since its association with atopic sensitisation, findings in the KOALA study show that far from all children with parental reported eczema have raised specific IgE-levels (Figure II).

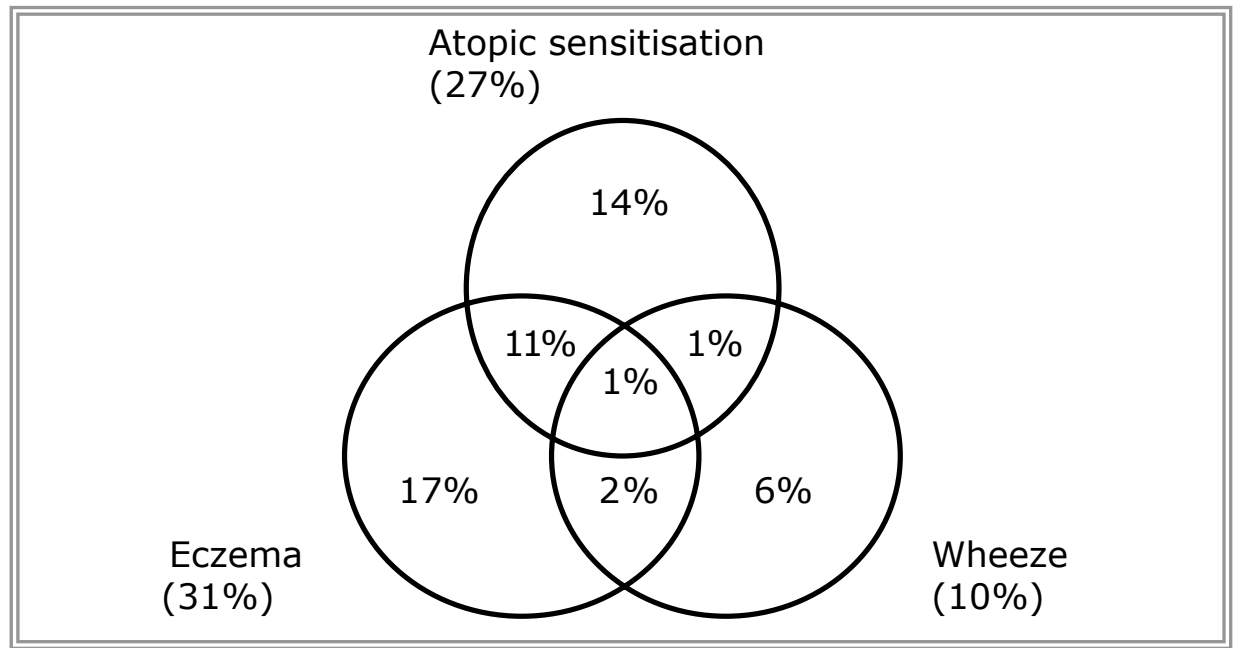

Figure II

Venn diagram showing the proportion of infants with atopic sensitisation at age 2 years (specific serum IgE to hen's egg, cow's milk, peanut, birch, grass pollen, cat, dog and/or house dust mite), parental reported eczema or wheeze during the first 2 years of life or any combination of the three conditions in the KOALA study. Subset areas presented above are not proportional to the actual relative subset size.

These findings contribute to the current controversy as to whether atopic sensitisation is either an essential feature of infant atopic disease, or primarily an epiphenomenon of disease activity (40), or that the disrupted skin, as found in eczema, may be the entrance point of antigen sensitisation (41). None of the studies conducted so far allow conclusions on whether eczema precedes the development of atopic sensitisation or vice versa. The fact that eczema usually develops early in life, whereas allergen-specific antibodies appear later in infancy, seems to point to the last suggestion. Since most eczema patients have a dry skin and a damaged skin barrier, this way of allergen penetration and sensitisation should be an important focus point for future research.

The venn diagram above also illustrates that, in the KOALA cohort, wheeze and eczema seem only weakly associated. Also other birth cohorts (42) found only weak associations between eczema and wheeze. Like the findings described in this thesis, Linneberg et al. (43) showed that the many potential risk factors of atopic disease had differential effects on infant wheeze and eczema, emphasising the suggestion that these phenotypes have a different etiology. We recommend that future atopy research should focus on individual atopic 
manifestations, investigating whether these manifestations are truly 'atopic' (IgE) or not. In addition, it may be noted that interventions aimed at preventing atopic sensitisation as the principal outcome, may not necessarily have the desired effect on reducing clinical manifestations. Finally, if individuals with different atopic manifestations have different risk profiles, then individuals with different risk profiles require different preventive strategies (44).

\section{Multinational collaboration}

Disease definition remains a particular problem in atopy research. Unlike many other fields, clear and uniform diagnostic criteria have long been lacking (45). Therefore, the successful efforts to coordinate multinational collaborative projects on atopic diseases constitute an important achievement (i.e. the European Community Respiratory Health Survey (ECRHS) (46), the International Study of asthma and allergies in children (ISAAC) (47), the Global Allergy and Asthma European Network (GA2LEN) (4) or EuroPrevall (www.europrevall.org)).

The KOALA Birth Cohort Study was neither the first nor the last prospective birth cohort study being initiated when it started in October 2000 . The European Commission acknowledged the importance of conducting birth cohort studies in atopy research by funding the Global Allergy and Asthma European Network (GA ${ }^{2}$ LEN)-work package 'Birth cohorts'. By February 2006, this work package had established a common database of al relevant study characteristics of 18 observational birth cohort studies designed to examine asthma and atopic

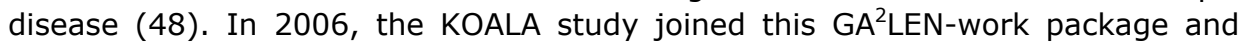
other new birth cohorts are constantly encouraged to participate in the work package.

Multinational collaborative projects ensure research groups working together towards collective goals. This is an important step forward in achieving uniformity in study results and conclusions in future investigations.

\section{Does one size ever fit all?}

Although current epidemiological literature on individual risk factors for the development of atopic diseases shows contradictory results, consistent evidence exists for a protective effect of growing up in a farming (49-55) or anthroposophic family. After a lower prevalence of atopy in anthroposophic families was shown in 1999 (1), this finding was confirmed by a second study group in 2006 (50). Growing up on farms is associated with exposure to endotoxin, helminths, lactobacilli and saprophytic mycobacteria, whilst alternative and anthroposophic lifestyles are related to restricted use of antibiotics and vaccinations and consumption of organic food and naturally fermented vegetables. Therefore, rather then considering a single exposure that may prevent atopy, future epidemiological studies should shift their focus towards different exposures that differ between modern and traditional lifestyles and that may act together in impacting on the development of atopic disease (56). But, it may be less likely to find environments that are harmful or health protective to everybody in general as risk factors may differ between individuals with different susceptibilities. 


\section{References}

1. Alm JS, Swartz J, Lilja G, et al. Atopy in children of families with an anthroposophic lifestyle. Lancet. 1999;353:1485-8.

2. Apter AJ. Early exposure to allergen: Is this the cat's meow, or are we barking up the wrong tree? J Allergy Clin Immunol. 2003;111:938-46.

3. Brunekreef B, Smit J, de Jongste J, et al. The Prevention and Incidence of Asthma and Mite Allergy (PIAMA) birth cohort study: design and first results. Pediatr Allergy Immunol. 2002;13:suppl 55-60.

4. Keil T, Kulig M, Simpson A, et al. European birth cohort studies on asthma and atopic diseases: I. Comparison of study designs - a GA²LEN initiative. Allergy. 2006;61:2218.

5. Wickman M, Kull I, Pershagen G, et al. The BAMSE Project: presentation of a prospective longitudinal birth cohort study. Pediatr Allergy Immunol. 2002;13:suppl 11-3.

6. Gering $\mathrm{U}$, Bolte $\mathrm{G}$, Borte $\mathrm{M}$, et al. Exposure to endotoxin decreases the risk of atopic eczema in infancy: a cohort study. J Allergy Clin Immunol. 2001;108:847-54.

7. Lau S, Illi S, Platts-Mills TA, et al. Longitudinal study on the relationship between cat allergen and endotoxin exposure, sensitisation, cat-specific IgG and development of asthma in childhood - report of the German Multicentre Allergy Study (MAS 90). Allergy. 2005;60:766-73.

8. Schayck CP, Knottnerus JA. Can the 'hygiene hypothesis' be explained by confounding by behaviour? J Clin Epidemiol. 2004;57:435-7.

9. Koppen S, De Groot R, Neijens HJ, et al. No epidemiological evidence for infant vaccinations to cause allergic disease. Vaccine. 2004;22:3375-85.

10. Bernsen RM, van der Wouden JC. Re: no epidemiological evidence for infant vaccinations to cause allergic disease. Vaccine. 2005;23:1427.

11. Bernsen RM, de Jongste JC, Koes BW, et al. The diphtheria tetanus pertussis poliomyelitis vaccination and reported atopic disorders in 8-12 year old infants. Vaccine. 2006;24:2035-42.

12. Erdes L, Alm B, Mollborg P, et al. Neonatal antibiotic treatment as a risk factor for wheezing disorder at age twelve months. Abstract Book European Academy of Allergology and Clinical Immunology (EAACI); Abstract 970:Vienna 2006. ISBN 39810999-0-7.

13. Nyquist AC, Gonzales R, Steiner JF, et al. Antibiotic prescribing for children with colds, upper respiratory tract infections, and bronchitis. JAMA. 1998;279:875-7.

14. Everard ML. The relationship between respiratory syncytial virus infections and the development of wheezing and asthma in children. Curr Opin Allergy Clin Immunol. 2006;6:56-61.

15. Wijga $A H$, van Houwelingen AC, Kerkhof $M$, et al. Breast milk fatty acids and allergic disease in preschool children: the Prevention and Incidence of Asthma and Mite Allergy birth cohort study. Allergy Clin Immunol. 2006;117:440-7.

16. Oddy WH, Pal S, Kusel MM, et al. Atopy, eczema and breast milk fatty acids in a highrisk cohort of children followed from birth to $5 \mathrm{yr}$. Pediatr Allergy Immunol. 2006;17:4-10.

17. Jahreis G, Fritsche J, Steinhart H. Conjugated linoleic acid in milk fat: high variation depending on production system. Nutr Res. 1997;17:1479-84. 
18. Bergamo P, Fedele E, Iannibelli L, et al. Fat-soluble vitamin contents and fatty acid composition in organic and conventional Italian dairy products. Food Chemistry. 2003;82: 625-31.

19. Dewhurst RJ, Evans RT, Scollan ND, et al. Comparison of grass and legume silages for milk production. 2. In vivo and in sacco evaluations of rumen function. J Dairy Sci. 2003;86:2612-21.

20. Adriaansen-Tennekes R, Bloksma J, Huber MAS, et al. [Organic products and health. Results of milk research.] Biologische producten en gezondheid. Resultaten melkonderzoek (Dutch). 2005 Louis Bolk Intituut, Publication GVV06, Driebergen, the Netherlands.

21. Voorrips LE, Brants HA, Kardinaal AF, et al. Intake of conjugated linoleic acid, fat, and other fatty acids in relation to postmenopausal breast cancer: the Netherlands Cohort Study of Diet and Cancer. Am J Clin Nutr. 2002;76:873-82.

22. Sausenthaler S, Kompauer I, Borte M, et al. Margarine and butter consumption, eczema and allergic sensitisation in children. The LISA birth cohort study. Pediatr Allergy Immunol. 2006;17:85-93.

23. Bolte G, Frye C, Holscher B, et al. Margarine consumption and allergy in children. Am J Respir Crit Care Med. 2001;163:277-9.

24. Dunder T, Kuikka L, Turtinen J, et al. Diet, serum fatty acids, and atopic diseases in childhood. Allergy. 2001;56:425-8.

25. von Mutius E, Weiland, SK, Fritzsch C, et al. Increasing prevalence of hay fever and atopy among children in Leipzig, East Germany. Lancet. 1998;351:862-6.

26. Wijga $\mathrm{AH}$, Smit $\mathrm{HA}$, Kerkhof $\mathrm{M}$, et al. Association of consumption of products containing milk fat with reduced asthma risk in pre-school children: the PIAMA birth cohort study. Thorax. 2003;58:567-72.

27. von Ehrenstein OS, von Mutius E, Illi S, et al. Reduced risk of hay fever and ashtma among children of farmers. Clin Exp Allergy. 2000;30:187-93.

28. Riedler J, Braun-Fahrländer C, Eder W, et al. Exposure to farming in early life and development of asthma and allergy: a cross-sectional survey. Lancet, 2001;358:1129-33.

29. Wickens K, Lane JM, Fitzharris P, et al. Farm residence and exposures and the risk of allergic diseases in New Zealand children. Allergy. 2002;57:1171-9.

30. Perkin MR, Strachan DP. Which aspects of the farming lifestyle explain the inverse association with childhood allergy? J Allergy Clin Immunol. 2006;117:1374-81.

31. Riedler J, Braun-Fahrlander C, Eder W, et al. Exposure to farming in early life and development of asthma and allergy: a cross-sectional survey. Lancet. 2001;358:1129-33.

32. Schram D, Doekes G, Boeve M, et al. Bacterial and fungal components in house dust of farm children, Rudolf Steiner school children and reference children - the PARSIFAL Study. Allergy. 2005;60:611-18.

33. Bjorksten B. The intrauterine and postnatal environments. $J$ Allergy Clin Immunol. 1999;104:1119-27.

34. Alm JS, Swartz J, Bjorksten, B. An anthroposophic lifestyle and intestinal microflora in infancy. Pediatr Allergy Immunol. 2002;13:402-11.

35. Penders J, Thijs C, Vink C, et al. Factors influencing the composition of the intestinal microbiota in early infancy. Pediatrics. 2006;118:511-21.

36. Wright R. Stress and atopic disorders. J Allergy Clin Immunol. 2005;116:1301-6.

37. Wright R, Cohen RT, Cohen $\mathrm{S}$. The impact of stress on the development and expression of atopy. Curr Opin Allergy Clin Immunol. 2005;5:23-9. 
38. Segerstrom SC, Miller GE. Psychological stress and the human immune system: a meta-analytic study of 30 years of inquiry. Psychol Bull. 2004;130:601-30.

39. Olgart Hoglund C, Axen J, Kemi C, et al. Changes in immune regulation in response to examination stress in atopic and healthy individuals. Clin Exp Allergy. 2006;36:98292.

40. Flohr C, Johansson SGO, Wahlgren CF, et al. How atopic is atopic dermatitis? J Allergy Clin Immunol. 2004;114:150-8.

41. Simpson EL, Hanifin JM. Atopic dermatitis. Med Clin N Am. 2006;90:149-167.

42. Illi S, von Mutius $E$, Lau $S$, et al. The natural course of atopic dermatitis from birth to age 7 years and the association with asthma. J Allergy Clin Immunol. 2004;113:92531.

43. Linneberg A, Simonsen JB, Petersen J, et al. Differential effects of risk factors on infant wheeze and atopic dermatitis emphasize a different etiology. J Allergy Clin Immunol. 2006;117:184-9.

44. Arshad SH. Primary prevention of asthma and allergy. $J$ Allergy Clin Immunol. 2005;116:3-14.

45. Pershagen G. Challenges in epidemiologic allergy research. Allergy. 1997;52:10451049.

46. Burney PGJ, Luczinska C, Chinn S, Jarvis D. European Community Respiratory Health Survey. Eur Respir J. 1994;7:954-60.

47. Asher $\mathrm{HI}$, Keil U, Anderson $\mathrm{HR}$, et al. International study of asthma and allergies in childhood (ISAAC): rationale and methods. Eur Respir J. 1995;8:483-91.

48. Keil T, Kulig M, Simpson A, et al. European birth cohort studies on asthma and atopic diseases: II. Comparison of outcomes and exposures - a GA2LEN initiative. Allergy. 2006;61:1104-1111.

49. Klintberg B, Berglund N, Lilja G, et al. Fewer allergic respiratory disorders among farmers' children in a closed birth cohort from Sweden. Eur Respir J. 2001;17:1151-7.

50. Alfven T, Braun-Fahrlander C, Brunekreef B, et al. Allergic diseases and atopic sensitisation in children related to farming and anthroposophic lifestyle - the PARSIFAL study. Allergy. 2006;61:414-21.

51. Ernst $P$, Cormier $Y$. Relative scarcity of asthma and atopy among rural adolescents raised on a farm. Am J Respir Crit Care Med. 2000;161:1563-6.

52. Riedler J, Braun Fahrlander C, Eder W, et al. Exposure to farming in early life and development of asthma and allergy: a cross-sectional survey. Lancet. 2001:358;1129-33.

53. Von Ehrenstein OS, von Mutius E, Illi S, et al. Reduced risk of hay fever and asthma among children of farmers. Clin Exp Allergy. 2000;30:187-93.

54. Portegen L, Sigsgaard T, Omland O, et al. Low prevalence of atopy in young Danish farmers and farming students born and raised on a farm. Clin Exp Allergy. 2002;32:247-53.

55. Braun Fahrlander C, Gassner M, Grize L, et al. Prevalence of hay fever and allergic sensitisation in farmer's children and their peers living in the same rural community. SCARPOL team. Swiss Study on Childhood Allergy and Respiratory Symptoms with Respect to Air Pollution. Clin Exp Allergy. 1999;29:28-34.

56. Semic-Jusufagic A, Simpson A, Custovic A. Environmental exposures, genetic predisposition and allergic diseases: one size never fits all. Allergy. 2006;61:397-99. 
- 120 - 


\section{Summary}

Worldwide, lifestyle and environmental exposures are investigated intensively in attempts to understand the causes for the increasing prevalence of atopic diseases in western societies over the last few decades. In this thesis, we report on research that was part of the KOALA Birth Cohort Study, the Netherlands; a study that aimed to identify factors that influence the clinical manifestations of atopic disease in early infancy. Chapter $\mathbf{1}$ introduces the background and aim of the study described in this thesis, namely to specifically focus on the role of alternative lifestyle factors in the early development of atopy.

The underlying mechanisms and causes of atopic disease are thought to be manifold. Although genetic predisposition is a fundamental factor in the susceptibility to the disease, the rate of change in its prevalence has been too rapid to be explained by genetic factors, thus environmental and lifestyle changes are considered responsible. In 1999, a Swedish study group published a paper describing that an anthroposophic lifestyle protected against atopic disease in 7-8 year old children. Several aspects of an anthroposophic lifestyle that could have a protective effect on atopy development were put forward, such as restricted use of vaccinations and antibiotics and organic food consumption, but due to the cross-sectional design of the study, specific protective factors could not be identified. The study of this Swedish group was one important reason for prospectively investigating the role of alternative lifestyle choices in the development of atopic disease.

Three outcomes are addressed: eczema (a chronic inflammatory pruritic skin disease), wheeze (whistling sound produced in the respiratory airways during breathing) and atopic sensitisation (increased specific immunoglobulin E levels ( $\mathrm{IgE}$ ) to common environmental allergens). Eczema and wheeze were measured during the first two years of life and atopic sensitisation was measured at age 2 years. Although the disease phenotypes called eczema and wheeze has been thought of as principally atopic diseases since their reported association with atopic sensitisation, results of the several studies, including the KOALA study, showed that far from all children with parental reported eczema and wheeze had raised specific IgE-levels. Therefore, eczema, wheeze and atopic sensitisation are addressed as separate outcomes in the present thesis.

To investigate the relationship between atopic disease and lifestyle choices that have a low prevalence in the general population (e.g. restricted use of antibiotics and vaccinations, organic food consumption) we needed a special recruitment procedure. Compared to other European birth cohort studies, the KOALA study is unique in having specifically enrolled a large group of participants with so-called 'alternative' lifestyle choices $(n=491)$. Pregnant women with alternative lifestyles were invited to participate through several specific recruitment channels, i.e. anthroposophic doctors and midwifes, anthroposophic under-five clinics, Steiner Schools, posters and flyers in organic food shops and magazines for special interest groups (e.g. homeopathy, anthroposophy, antivaccine). Besides these 491 families with alternative lifestyles, 2343 conventional families consented to participate, resulting in a considerable size cohort with a relatively large contrast in exposure to special dietary habits (including long duration of breastfeeding, organic foods, and vegetarian diet), alternative vaccination schemes and antibiotic use. Consequently, the great diversity of 
lifestyle choices within our study population gave us the opportunity to investigate the effect of single, independent, (lifestyle) exposure factors. The design of the study is elaborated in Chapter 2.

We first investigated whether atopic parents adopt lifestyle characteristics which allegedly protect against atopic disease. If this was true, infants from atopic parents would be characterised by low-risk behaviour and consequently our study might have been biased by confounding-by-indication. Chapter 3 of this thesis shows that a few 'prudent' lifestyle characteristics differed between atopic and non-atopic families, depending on whether atopic manifestations were present in parents or older siblings. Consequently, our study might be biased by confounding-by-indication. Based on these findings, we decided to control all data analyses in the subsequent chapters for potential confounding-by-indication due to atopic manifestations in parents or siblings. Few researchers have separated the effects of parental and sibling atopic manifestations and we recommended for future studies to take this difference into account.

We wondered whether house dust components like higher levels of endotoxin might be among the factors related to an anthroposophic lifestyle since it was recently hypothesised that higher microbial exposure, especially to bacterial endotoxin, could protect against the development of atopy. Endotoxin is a cell wall component of Gram-negative bacteria and is commonly present in normal indoor environments as a constituent of house dust. The findings, presented in Chapter 4, suggested that an anthroposophic lifestyle may expose to more dust on living room floors, and therefore to more endotoxin, per $\mathrm{m}^{2}$, compared to conventional lifestyle families. It remains to be elucidated which characteristics associated with an anthroposophic lifestyle determine these higher amounts of house dust on floors. Also, whether these higher amounts of house dust are really a causative factor which contributes to the lower prevalence of atopy in infants of families with an anthroposophic lifestyle, will need confirmation in future studies. If this were true, then a possible explanation for this would be that a higher exposure to endotoxin prevents from other atopic manifestations such as house dust mite allergy.

Two mechanisms have been proposed by which vaccinations could affect the development of atopic disease: they may either have direct allergy-inducing immune effects, or prevent possible protective effects of natural infection. Chapter $\mathbf{5}$ of this thesis shows that differences in vaccination schedules in the first 6 months of life did not lead to a different risk of eczema and wheeze until age 1 year. This may be reassuring for parents who fear possible adverse effects of DTTP vaccinations. The similarity of the risk of developing atopic manifestations in vaccinated and unvaccinated infants also gave no evidence for a direct allergyinducing immune effect of vaccinations or additives used in these vaccines. We measured motives of parents to opt for alternative vaccination schemes and showed that parents had mainly chosen to deviate from the standard vaccination schedule because of certain philosophical or religious principles or beliefs, rather than because of health-related considerations, which limited the possibility of biased findings.

The increased prevalence of atopy in developed countries closely followed time trends in increased use of antibiotics among young children. Antibiotics particularly interfere with the bacterial commensal flora and disturb the intestinal microbiota composition. Consequently, antibiotic exposure in early life may be 
associated with atopic disease development either by interfering with bacterial commensal flora or by modifying the course of bacterial infections. In Chapter 6, we report that infants with differences in antibiotic use had a similar risk of eczema and atopic sensitisation but intants having used antibiotics had a higher risk of wheeze in comparision with infants with no antibiotics use. We could only speculate about the causality of this association. One possibility is that antibiotics are prescribed because of wheezy bronchitis and related conditions (reverse causation). We have attempted to eliminate this possibility by restricting the analysis to infants who had no wheeze at the time of antibiotic use, thereby avoiding that symptoms would precede antibiotic prescription. However, this relied on parent-reported wheeze, so that we cannot rule out the possibility that the child suffered from wheezy bronchitis. Antibiotic use during lactation was also associated with the development of wheeze but, at this moment, it is also too early to draw definite conclusions from this finding. However, this finding offers an interesting new subject to the field of future atopy research that so far has been neglected.

A rapidly growing group of consumers in our society prefers to buy organically grown and processed products, which are perceived as healthier and safer. However, there are few studies that have evaluated effects of organic vs. conventionally grown foods on human health. Chapter $\mathbf{7}$ shows that the overall proportion of organic products within the total infant diet was not statistically significant associated with the development of atopic manifestations. However, we found an independent association between strictly consuming organic dairy and a reduced risk of eczema. This finding needs to be interpreted with some caution since we cannot completely exclude the possibility that organic dairy as a part of an organic diet may play a protective role. The mechanism by which organic dairy consumption protects against development of eczema is unknown and various components could be involved (i.e. the presence of gram-negative bacteria and their endotoxin and fatty acid composition in organic dairy, association of organic dairy consumption and consumption of higher levels of milk fat). The fact that we extensively adjusted for potential confounders such as vaccinations, use of antibiotics, breastfeeding or farm/raw milk consumption makes it highly unlikely that the observed associations would be caused by confounding. Further studies to substantiate these results using more detailed and quantitative information would appear to be warranted. Also, more information on the nutritional composition of organic dairy in relation to the development of eczema, separately from atopic disease, would be valuable.

In Chapter $\mathbf{8}$ we discuss the findings described in this thesis and make several suggestions for future epidemiological research of atopic disease development. We discussed an important aspect for establishing causality, namely to assess the time relation between an exposure and outcome: does the cause (exposure) precede the effect (outcome)? In this thesis, we have in all cases accounted for the possibility of reverse causation by, after performing overall analyses for all available infants, repeating the same analyses while restricting them to at risk infants only (i.e. by excluding from the analyses children with the atopic manifestation under study in the same period that the exposure was measured). In Chapter 5, 6 and 7 we showed that the findings described in this thesis were not due to reverse causation. 
Besides the factors addressed in this study (indoor domestic environment, low vaccinations uptake, restrictions of antibiotics and organic food consumption), there are other factors characteristic for alternative lifestyles that may be associated with atopic diseases. These will be the subject of other theses from the KOALA study, for example differences in the gut microflora composition (due to certain environmental exposures characteristic of an alternative and/or anthroposophic lifestyle) and longer breastfeeding duration. Of particular interest is the possible influence of stress on manifestations of atopic disease. So far, there appear to be no studies on differences in psychological responses to environmental stressors between alternative and conventional families. We recommended that future studies investigate the possible influence of stress on manifestations of atopic disease in infancy.

Since we showed that potential determinants of atopic manifestations were either associated with eczema (organic food) or wheeze (antibiotics) and never with atopic sensitisation (vaccinations, antibiotics, and organic foods) we recommended that future atopy research should focus on individual clinical manifestations (eczema, wheeze) and biologic parameters of atopic sensitisation (IgE) and investigate whether these manifestations are truly 'atopic' (IgE) or not.

Finally, we make several recommendatations for future international collabortation and the use of uniform disease definition. 


\title{
Samenvatting
}

\author{
Summary in Dutch
}

'Atopische aandoeningen' is een verzamelnaam voor voedsel- en luchtwegallergie, bepaalde vormen van eczeem, en bepaalde vormen van astma. Het vóórkomen deze aandoeningen is de afgelopen decennia sterk toegenomen in westerse landen, vooral onder kinderen. Wereldwijd wordt onderzocht waarom dit zo is en of leefwijze en omgevingskenmerken hierin een rol spelen. Dit proefschrift presenteert onderzoeksresultaten van het KOALA geboortecohortonderzoek, een studie naar factoren die een rol spelen in de ontwikkeling van atopische manifestaties in de vroege levensjaren. KOALA staat voor: Kind, Ouder en gezondheid: Aandacht voor Leefwijze en Aanleg.

Hoofstuk 1 introduceert de achtergrond en het doel van de deelstudie dat beschreven wordt in dit proefschrift, namelijk het onderzoeken van de rol die alternatieve leefwijzen spelen in de vroege ontwikkeling van atopische manifestaties. Men vermoedt dat de onderliggende mechanismen en oorzaken van atopische aandoeningen veelvoudig zijn. Hoewel een erfelijke aanleg een fundamentele factor is in de ontvankelijkheid om de ziekte te ontwikkelen, is de snelheid waarmee het vóórkomen van atopische ziekten is gestegen te snel geweest om geheel te kunnen worden verklaard door genetische factoren. Daarom moeten leefwijze en omgevingskenmerken ook een rol spelen. In 1999 rapporteerde een Zweedse onderzoeksgroep dat 7-8 jarige vrijeschool-leerlingen een lagere kans hadden op het ontwikkelen van atopische manifestaties dan 7-8 jarige kinderen die naar een reguliere school gingen. De onderzoekers concludeerden dat een antroposofische leefwijze beschermend zou kunnen werken tegen de ontwikkeling van atopische manifestaties. In dit onderzoek was het echter nog niet mogelijk om vast te stellen wat oorzaak en gevolg was en om te bepalen welke specifieke factor in het geding was, zoals terughoudendheid ten aanzien van kindervaccinaties, een beperkt gebruik van antibiotica en/of het consumeren van biologische voeding. De resultaten van deze Zweedse groep waren voor ons een belangrijke aanleiding om de rol van alternatieve leefwijzen in de ontwikkeling van atopische manifestaties te onderzoeken. Om meer zekerheid te krijgen over de oorzakelijkheid is een prospectieve onderzoeksopzet nodig, dat wil zeggen de blootstellingen aan de risicofactoren worden gemeten voordat de ziekte ontstaat. Dit vereist dus dat een groep kinderen wordt gevolgd in een zogenaamd cohortonderzoek. Bovendien moet er voldoende variatie in de onderzoekspopulatie zijn om de bijdrage van verschillende risicofactoren te kunnen ontrafelen.

Het design van de studie wordt uiteengezet in Hoofdstuk 2. Om de relatie tussen atopische aandoeningen en leefwijzen die in de algemene populatie minder vaak voorkomen (zoals terughoudendheid ten aanzien van kindervaccinaties, een beperkt gebruik van antibiotica en het consumeren van biologische voeding) goed te kunnen onderzoeken, moesten we een specifieke wervingsprocedure toepassen om deelnemers voor het onderzoek te vinden. In vergelijking met andere Europese geboortecohort-onderzoeken is het KOALAonderzoek uniek voor wat betreft de grote groep deelnemers met alternatieve leefwijzen (namelijk 491). Zwangere vrouwen met een alternatieve leefwijze zijn specifiek geworven via antroposofische huisartsen en verloskundigen, 
antroposofische consultatiebureaus, vrijescholen, posters en flyers in reformwinkels en via tijdschriften voor bepaalde doelgroepen. Naast deze 491 deelnemers met een alternatieve leefwijze hebben we 2343 families met een conventionele leefwijze bereid gevonden om mee te werken. Dit resulteerde in een grote groep mensen met het gewenste, grote contrast in blootstelling aan verschillende voedinggewoonten (biologisch, vegetarisch), kindervaccinaties, antibiotica of de duur van borstvoeding. Door deze grote diversiteit in leefwijze in onze studiepopulatie hadden wij de kans om het onafhankelijke effect van verschillende leefwijzefactoren nader te onderzoeken.

In dit proefschrift zijn drie atopische uitkomsten onderzocht: eczeem (een chronische en jeukende huiduitslag), piepen op de borst (een piepend, fluitend geluid dat geproduceerd wordt in de luchtwegen tijdens het ademhalen) en atopische sensitisatie (allergie, gekenmerkt door Immunoglobuline $E$ (IgE)antistoffen die specifiek zijn gericht tegen bepaalde stoffen (allergenen) in voeding of lucht). Eczeem en piepen op de borst werden meerdere keren gedurende de eerste twee levensjaren vastgesteld, via vragenlijsten die naar de ouders werden gestuurd; atopische sensitisatie werd getest op tweejarige leeftijd door het afnemen van een beetje bloed en een daarop volgende laboratoriumanalyse. Hoewel de ziekteverschijnselen eczeem en piepen op de borst beschouwd worden als atopische ziekten omdat ze vanaf de schoolleeftijd vaak samengaan met atopische sensitisatie, hebben de resultaten van verschillende onderzoeksgroepen, waaronder de onze, laten zien dat deze samenhang op jongere leeftijd zwak is. Daarom zijn eczeem, piepen op de borst en atopische sensitisatie in dit proefschrift als aparte uitkomsten bepaald.

Allereerst hebben we onderzocht of ouders met een familiegeschiedenis van atopische klachten kiezen voor bepaalde leefwijzen waarvan bekend is dat ze misschien beschermen tegen atopie (laag-risicogedrag). Als dit het geval is, dan worden kinderen van ouders met een familiegeschiedenis van atopische klachten gekenmerkt door laag-risicogedrag van hun ouders. Als gevolg daarvan zouden onze resultaten vertekend worden door een verschijnsel dat in de epidemiologie 'confounding-by-indication' heet. 'Confounding' is een epidemiologische term die aangeeft dat een gevonden verband tussen twee variabelen (deels) verklaard wordt door een derde variabele (dit kan zijn om een bepaald effect te bereiken (indicatie) of te vermijden (contraindicatie)). Hoofdstuk 3 laat zien dat er enkele leefwijzekenmerken waren die verschilden tussen atopische en niet-atopische families, en dat dit afhankelijk was van of de klachten voorkwamen in een van de ouders zelf of in een broertje/zusje van het kind in onze studie. Ouders met een familiegeschiedenis van atopische klachten stelden hun kind minder vaak bloot aan een rokerige omgeving of aan huisdieren dan ouders zonder atopische klachten. Ouders van atopische kinderen zijn minder snel bereid om een volgend kind te laten vaccineren volgens het Rijksvaccinatieprogramma en kiezen vaker voor een alternatief vaccinatieschema. Vanwege deze resultaten hebben we besloten om alle statistische analyses beschreven in de volgende hoofdstukken van het proefschrift te corrigeren voor potentiele confounding-by-indication als gevolg van een familiegeschiedenis van atopische klachten in ouders of broertjes/zusjes. Weinig andere onderzoekers hebben hun analyses apart gecorrigeerd voor atopische klachten in ouders en broertjes/zusjes, en we hebben toekomstige onderzoekers aangeraden om dat te doen. 
We vroegen ons af of bepaalde componenten in huisstof, namelijk endotoxine en huisstofmijtallergeen, meer aanwezig waren in de huizen van antroposofische gezinnen. Recentelijk is gesuggeerd dat een hogere microbiele blootstelling, met name aan bacterieel endotoxine, zou kunnen beschermen tegen de ontwikkeling van atopische aandoeningen. Endotoxine is een celwandcomponent van Gram-negatieve bacteriën en is gewoonlijk binnenshuis aanwezig als onderdeel van het huisstof. De resultaten, die gepresenteerd zijn in Hoofdstuk 4, suggereren dat in de huizen van antroposofische families, in vergelijking met die van conventionele families, meer huisstof op de woonkamervloer ligt, en dat er daarom ook meer endotoxine per vierkante meter gemeten werd. Er werden geen verschillen gevonden in hoeveelheid huisstof dat was gemeten op de matrassen van de kinderen. Het moet nog worden onderzocht welke karakteristieken van een antroposofische leefwijze precies zorgen voor die hogere gehaltes van stof op de vloer. Tevens moet nader onderzocht worden of deze huisstofkenmerken inderdaad een (causale) rol spelen die bijdragen aan een lagere prevalentie van atopie in antroposofische kinderen. Als dat zo is, dan zou een mogelijke verklaring hiervoor zijn dat dat de hoge blootstelling aan endotoxine in huisstof tegengaat dat kinderen allergisch worden voor huisstofmijtallergeen in huisstof (en ook voor andere allergieën).

Er zijn twee mechanismen voorgesteld middels welke vaccinaties een effect zouden kunnen hebben op de ontwikkeling van atopie: ze kunnen ofwel een direkt atopie-inducerend immuuneffect hebben, of ze benemen het kind de mogelijke positieve effecten van een natuurlijke infectie op het immuunsysteem. Hoofdstuk 5 laat echter zien dat kinderen die in de eerste zes maanden ingeënt waren volgens een alternatief vaccinatieschema, of zelfs helemaal niet waren ingeënt, in het eerste levensjaar een gelijke kans hadden op het ontwikkelen van eczeem of piepen op de borst als kinderen die ingeënt waren via het Rijksvaccinatieprogramma. We hebben gevraagd wat de redenen van ouders waren om af te wijken van het Rijksvaccinatieprogramma. Dit toonde aan dat ouders die met name voor kozen vanuit filosofische of religieuze beweegredenen, en niet zo zeer vanwege gezondheidsgerelateerde redenen. Dit beperkte de mogelijkheid dat onze resultaten vertekend waren door confounding-bycontraindication (een beslissing om het vaccineren uit te stellen of weg te laten in verband met ziekte in het kind). Onze resultaten kunnen geruststellend zijn voor ouders die vrezen dat vaccinaties een negatieve invloed hebben op het ontstaan van atopische aandoeningen. Het gelijke risico op het ontstaan van atopische manifestaties in gevaccineerde en ongevaccineerde kinderen verschafte ook geen bewijs voor een mogelijk direkt atopie-inducerend immuuneffect van vaccinaties of de immuunversterkende hulpstoffen (adjuvantia) die gebruikt worden in vaccinaties.

De toegenomen prevalentie van atopische aandoeningen in westerse landen liep parallel aan de toename van antibioticagebruik onder kinderen. Antibiotica verstoren de samenstelling van de darmflora. Daarom zou antibioticagebruik op zeer jonge leeftijd geassocieerd kunnen zijn met atopische ziekten, enerzijds door het verstoren van de bacteriële darmflora of anderzijds door het modificeren van bacteriële infecties. In hoofdstuk 6 laten we zien dat kinderen die in de eerste zes levensmaanden antibiotica kregen een gelijke kans hadden op eczeem of atopische sensitisatie in de eerste twee jaar als kinderen die in de eerste zes maanden geen antibiotica hadden gekregen. Het krijgen van 
antibiotica was echter wel geassocieerd met een hogere kans om klachten van piepen op de borst te ontwikkelen. Eén mogelijke verklaring voor onze bevinding is dat antibiotica worden voorgeschreven vanwege het piepen op de borst zélf (dit verschijnsel heet in de epidemiologie reverse causation ('omgekeerde oorzakelijkheid')). We hebben gepoogd om deze mogelijkheid te elimineren door de statistische analyses te beperken tot kinderen die geen piepen op de borst hadden tijdens de periode waarin we het antibiotica gebruik maten (de eerste zes levensmaanden). Daardoor hebben we voorkomen dat in de analyses de symptomen van piepen op de borst vooraf gingen aan het gebruik van de antibiotica. Onze studie maakt echter gebruik van door de ouders zelfgerapporteerde symptomen van piepen op de borst en we kunnen niet helemaal uitsluiten dat het kind leed aan piepende bronchitis of andere gerelateerde luchtwegklachten. Antibiotica gebruik tijdens lactatie was ook geassocieerd met piepen op de borst maar op dit moment is het nog te vroeg om aan deze bevinding definitieve conclusies te verbinden.

In toenemende mate geven consumenten in onze samenleving de voorkeur aan de biologische varianten van voedingsproducten met als reden dat biologische voeding gezonder en veiliger zou zijn. Er zijn echter bijna geen wetenschappelijke studies verricht die het effect van biologische voeding op de gezondheid van de mens hebben onderzocht. In hoofdstuk 7 laten we zien dat het aandeel van biologische producten in het dieet van een kind in zijn eerste twee levensjaren geen invloed had op het ontstaan van atopische manifestaties. Kinderen die nooit biologische producten consumeerden hadden een gelijke kans op piepen op de borst en atopische sensitisatie als kinderen met een dieet dat voor de helft of zelfs bijna helemaal uit de biologische varianten bestond. Echter, voor eczeem was er wel een aanwijzing dat biologische voeding een beschermend effect kan hebben op het ontstaan van eczeem. Om dit meer in detail te onderzoeken, hebben we gekeken naar het effect van afzonderlijke voedingsproducten (zuivel, vlees, fruit, groente en eieren). We vonden een lager risico op eczeem in de eerste twee levensjaren voor kinderen die geheel biologische zuivel consumeerden in vergelijking met kinderen die conventionele zuivel, of zuivel consumeerden die soms biologisch was en soms conventioneel. Deze bevinding moet voorzichtig geïnterpreteerd worden omdat we niet geheel kunnen uitsluiten dat het gaat om biologische zuivel die geconsumeerd wordt als onderdeel van een biologisch dieet. Verschillende componenten in de biologische voeding kunnen een rol spelen (bijvoorbeeld endotoxine in zuivel, de verzuursamenstelling van biologische zuivel, of een mogelijk verband tussen het consumeren van biologische zuivel en consumptie van volvette zuivelproducten). Het feit dat we in onze statistische analyses uitgebreid gecorrigeerd hebben voor mogelijke verstorende leefwijzen (zoals bijvoorbeeld keuzes ten aanzien van vaccinaties, antibiotica gebruik, borstvoeding of rauwe melk consumptie) maakt het minder waarschijnlijk dat onze bevinding verklaard wordt door confounding. Er zijn nieuwe studies nodig om onze resultaten te bevestigen waarin meer gedetailleerde en kwantitatieve gegevens over het dieet van mensen die biologische zuivel consumeren alsmede de samenstelling van biologische zuivel gezameld moet worden.

In hoofdstuk 8 bediscussiëren we de resultaten en doen we enkele voorstellen voor toekomstig epidemiologisch onderzoek. We bediscussiëren nogmaals het aspect 'omgekeerde oorzakelijkheid' en geven aan dat het 
belangrijk is om rekening te houden met de tijdsrelatie tussen de blootstelling en de uitkomst: namelijk gaat de oorzaak (de blootstelling) inderdaad vooraf aan het effect (uitkomst)? In dit proefschrift hebben we in alle gevallen geprobeerd om omgekeerde oorzakelijkheid te elimineren, door analyses te herhalen bij kinderen die nog geen klachten hadden in de periode waarin de betreffende leefwijzefactor zijn invloed kon uitoefenen. We concluderen daarom ook dat de resultaten die gepresenteerd zijn in hoofdstuk 5, 6 en 7 niet verklaard konden worden door omgekeerde oorzakelijkheid.

Naast de factoren die in dit proefschrift zijn beschreven (zoals huisstof, vaccinaties, antibiotica en biologische voeding) zijn er nog vele andere mogelijke alternatieve leefwijzefactoren die belangrijk kunnen zijn bij het ontstaan van atopische aandoeningen. Deze onderwerpen worden op dit moment bestudeerd door andere onderzoekers binnen het KOALA-onderzoek, bijvoorbeeld de rol van borstvoeding of verschillen in de samenstelling van de darmflora tussen gezinnen met verschillende leefwijzen. Ook krijgt de mogelijke invloed van stress op het ontstaan van atopische manifestaties aandacht in wetenschappelijk onderzoek. Tot op dit moment zijn er nog geen studies verricht naar mogelijke verschillen in psychologische reacties op omgevingsprikkels tussen individuen met een alternatieve of gangbare leefwijze, en dit is een interessant onderwerp voor toekomstig onderzoek.

Opvallend is dat de onderzochte leefwijzefactoren van atopische manifestaties ofwel geassocieerd waren met eczeem (biologische voeding) ofwel met piepen op de borst (antibiotica), maar in geen van de gevallen met atopische sensitisatie. Daarom bevelen we aan dat toekomstig onderzoek zich richt op de afzonderlijke, individuele manifestaties zoals eczeem en piepen op de borst, en apart daarvan op biologische parameters zoals atopische sensitisatie, zoals wij in deze studie hebben gedaan. Ook zou in deze gevallen bekeken moeten worden of de onderzochte klinische manifestaties altijd echt atopisch zijn (dat wil zeggen gebaseerd zijn op de vorming van specifieke IgE-antistoffen).

Als slotopmerkingen doen we aanbevelingen voor internationale samenwerking en afstemming over definities en meetmethoden. 


\section{Dankwoord}

\section{Acknowledgements in Dutch}

Onderzoek en een proefschrift schrijven doe je niet alleen. Op deze plek wil ik iedereen bedanken die de afgelopen jaren een bijdrage heeft geleverd. Een aantal personen wil ik hierbij in het bijzonder noemen.

Bianca en John, jullie steun, adviezen en onze vele gezellige momenten in de afgelopen 4 jaar waren onmisbaar! Ik heb veel aan jullie te danken.

Carel Thijs, Pieter Dagnelie, Foekje Stelma, en Piet van den Brandt, bedankt voor jullie wetenschappelijke begeleiding, ideeën en opbouwende kritiek. Mijn AiOperiode was leerzaam en ik kijk er met veel plezier op terug! Carel, fijn dat je deur altijd openstond voor vragen en je tijd nam om ze te beantwoorden.

Ook de overige leden van het KOALA team wil ik hartelijk bedanken voor hun bijdrage en prettige samenwerking.

Bedankt Hasibe Aydeniz, Corine Coorens, Petra Cuijpers, Nicole Custers, Chantal Delnoy, Karen Groot, Willeke Hendrikx, Monique Koekkelkoren, Cobie Martens, Monique Mommers, Jos Slangen, Luc Smits, Trix Voogd, Brigitte Winants.

Een woord van dank gaat ook uit naar projectleden, stuurgroepleden, begeleidingscommisieleden en co-auteurs:

Rob de Bie, Bert Brunekreef, Machteld Huber, Margje Jansen, Marion Koopmans, Johan Reimerink, Willem Kramers, Mirjam Matze, Ronald van Ree, Huub Savelkoul, Anne Schaafsma, Onno van Schayck, Edmond Schoorel, Lucy van de Vijver, Jan de Vries.

Het was een genoegen om de volgende stagiaires te mogen helpen tijdens hun (afstudeer)onderzoek en ik dank hen hartelijk voor hun bijdrage aan het mijne. Dank jullie wel Carl de Bont, Brenda Elzer, Joyce Gorissen, Peter Luyten, Eljanne Wardenier.

De bijdrage van vele andere betrokkenen aan mijn werkzaamheden voor het KOALA-onderzoek heb ik zeer op prijs gesteld.

Bedankt Janneke Bastiaanssen, Carolien Bastiaenen, thank you Professor Peter Burney, Ria Francke, Christel van Gool, Gonnie Klabbers, Ton van Moergastel, Annemie Mondant, Harry van Montfort, Petra Oomen, Nathalie Slangen, Ruud Schmeitz, Connie de Zwart - en overige ex-collega's op de afdeling Epidemiologie.

Yvonne Jaegers zet ik in het zonnetje vanwege haar hulp bij het lay-outen van dit proefschrift. 
Een aantal sponsors hebben mijn werk financieel mogelijk gemaakt en worden op deze plaats nogmaals hartelijk bedankt.

Iona Stichting, Profileringsfonds (azM/UM), Raphael Stichting, Stichting ter Bevordering van de Heilpedagogie, Stichting Phoenix, Stichting Triodos Foundation.

Aan de werving van deelnemers hebben een groot aantal instellingen en organisaties mee gewerkt en zonder hen zou ik geen 'alternatieve deelnemers' hebben gehad. Hartelijk dank:

Antroposofische consultatiebureaus, antroposofische huisartspraktijken, antroposofische kinderopvangcentra, Avalon, biologische voedingswinkeliers, De Kleine Aarde, De Natuur uw Arts, Dynamisch Perspectief, Educare, Homeopathie, Jonas, Motief, Noor Prent-Tromp, Overgevoeligheden, Smaakmakend, Stichting Antroposofisch Medisch Onderzoek, Stichting Voedsel Allergie, Verloskundigen en gynaecologen in de Bekkenpijnstudie, Vrije Opvoedkunst, Vrije Scholen - en Iris Kummeling voor de mooie tekeningen.

Zonder de 2834 deelnemende families in het KOALA-onderzoek was dit proefschrift nooit geschreven en ik ben hen erkentelijk voor het vele werk dat zij vrijwillig hebben verzet. Ik leef mee met de families waarvan het pasgeboren kindje een minder gunstige gezondheidsontwikkeling doormaakte.

Tot slot wil ik mijn vrienden, paranimfen, (schoon-)familie, ouders en Thamar bedanken voor hun onvoorwaardelijke steun en altijd aanwezige belangstelling voor alles dat ik doe. 


\section{About the author}

Ischa Kummeling (1973) grew up in Raalte, the Netherlands, and passed secondary school (Steiner School Zutphen) in 1993. She started her college education in Health Sciences at Maastricht University in 1994. Research internships as part of this study were spent at the Human Biology department at Maastricht University and in Copenhagen, Denmark (Healthy Cities Project, WHO Regional Office for Europe).

In 1999, she graduated from Maastricht University with a master's degree in Health Sciences, specialising in Human Biology and Health Promotion. After completing a position as a research assistant at Stichting Adhesie in Deventer, she travelled through Eastern Europe, the Middle East and Asia (10 months).

In September 2001, she moved back to Maastricht to work on the present thesis as a PhD student at the department of Epidemiology at the Maastricht University. Meanwhile, from 2003 to 2004 she continued education in Epidemiology and in 2005 received her diploma and registered as an Epidemiologist at the Dutch Epidemiological Society.

Since May 2006, she has been working as research associate at Imperial College London, where she is involved in a large research project on the prevalence, cost, and basis of food allergy across Europe.

\section{De auteur}

Ischa Kummeling (1973) is opgegroeid in Raalte en slaagde voor haar VWO examen op de Vrije School Zutphen in 1993. In 1994 begon ze aan haar studie Gezondheidswetenschappen aan de Universiteit Maastricht (UM). Haar wetenschapsstages heeft zij verricht op de afdeling Humane Biologie van de UM en in Kopenhagen, Denemarken, bij de Wereldgezondheidsorganisatie (WHO).

In 1999 is ze afgestudeerd aan de UM als Gezondheidswetenschapper, met als specialisaties Biologische Gezondheidkunde en Gezondheidsvoorlichting. Nadat ze een onderzoeksproject had afgerond bij Stichting Adhesie in Deventer is ze 10 maanden gaan reizen door Oost-Europa, het Midden-Oosten en Azië.

In September 2001 begon ze aan haar baan als assistent-in-opleiding op de afdeling Epidemiologie aan de UM waar ze heeft gewerkt aan het onderzoek dat beschreven is in dit proefschrift. Tussen 2003 en 2004 heeft ze haar Epidemiologie diploma behaald en is ze geregistreerd Epidemioloog bij de Nederlandse Vereniging voor Epidemiologie.

Sinds mei 2006 werkt ze als onderzoeker bij Imperial College London in Engeland waar ze betrokken is bij een groot onderzoek dat zich richt op het vóórkomen en de kosten van voedselallergie in Europa. 


\section{List of publications}

\section{FULL ARTICLES}

Kummeling I, Stelma F, PC Dagnelie, Snijders BEP, Penders J, Huber M, van Ree $R$, van den Brandt PA, Thijs $C$. Early life expsore to antibiotics and the subsequent development of eczema, wheeze and allergic sensitisation in the first two years of life: the KOALA Birth Cohort Study. Pediatrics 2007; 119: e225-e231.

Kummeling I, Thijs C, Stelma F, Huber M, van den Brandt PA, Dagnelie PC. DPPTHib vaccinations and risk of eczema and recurrent wheeze in the first year of life: the KOALA Birth Cohort Study. Pediatrics 2007; 119: [in press].

Kummeling I, Thijs C, Stelma F, Huber M, van den Brandt PA, Dagnelie PC. Do parents with an atopic family history adopt a 'prudent' lifestyle for their infant? (KOALA Study). Clin Exp Allergy 2006; 36: 489-494.

Kummeling I, Thijs C, Penders J, Snijders BE, Stelma F, Reimerink J, Koopmans M, Dagnelie PC, Huber M, Jansen MC, de Bie R, van den Brandt PA. Etiology of atopy in infancy: the KOALA Birth Cohort Study. Pediatr Allergy Immunol 2005; 16: $679-684$.

Rist L, Mueller A, Barthel C, Snijders B, Jansen J, Simoes-Wust AP, Huber M, Kummeling I, von Mandach $U$, Steinhart $H$, Thijs $C$. Influence of organic diet on the amount of conjugated linoleic acids in breast milk of lactating women in the Netherlands. Br J Nutr 2007; [in press].

Snijders BEP, Thijs C, Kummeling I, Penders J, van den Brandt PA. Breastfeeding and eczema in the first year of life in the KOALA Birth Cohort Study, a risk-period specific analysis. Pediatrics 2007; 119: e137-e141.

Snijders BEP, Damoiseaux J, Penders J, Kummeling I, Stelma F, van Ree R, van den Brandt PA, Thijs C. Cytokines and soluble CD14 in breast milk in relation with atopic manifestations in mother and infant (KOALA study). Clin Exp Allergy 2006; $36,1609-15$.

Penders J, Thijs C, Vink C, Stelma FF, Snijders B, Kummeling I, van den Brandt PA, Stobberingh EE. Factors influencing the composition of the intestinal microbiota in early infancy. Pediatrics 2006; 118: 511-521.

Penders J, Thijs C, van den Brandt PA, Kummeling I, Snijders BEP, Stelma F, Adams $H$, van Ree $R$, Stobberingh EE. Gut microbiota composition and development of atopic manifestations in infancy: the KOALA Birth Cohort Study. Gut 2006; 17; [Epub ahead of print]

van Egmond J, Kummeling I, Balkom T.A. Secondary gain as hidden motive for getting psychiatric treatment. Eur Psychiatry 2005; 20: 416-21.

van Egmond J, Kummeling I. A blind spot for secondary gain affecting therapy outcomes. Eur Psychiatry 2002; 17: 46-54. 
Kummeling I, de Bont C, Thijs C, Huber M, Brunekreef B, van den Brandt PA, Stelma F. House dust endotoxin in the homes of families with an anthroposophic lifestyle [submitted].

Kummeling I, Thijs C, Huber M, van de Vijver LPL, Snijders BEP, Penders J, Stelma $F$, van Ree R, van den Brandt PA, Dagnelie PC. Consumption of organic foods and risk of atopic disease in the first two years of life [submitted].

Snijders BEP, Thijs C, Pieter PC, Stelma F, Mommers M, Kummeling I, Penders J, van Ree $R$, van den Brandt PA. Breastfeeding duration and infant atopic manifestations, by maternal allergic status, in the first two years of life (KOALA study) [submitted].

\section{ABSTRACTS}

Kummeling I, Stelma F, Penders J, Dagnelie P, Huber M, van Ree R, van den Brandt $P$, Thijs $C$. Early life receipt of antibiotics is associated with wheeze but not eczema and sensitisation in infancy (KOALA study). Allergy \& Clinical Immunology International 2006; XXV Congress of the European Academy of Allergology and Clinical Immunology: Vienna, Austria 10-14 June 2006. ISBN 39810999-0-7 (abstract 107) [oral presentation].

Kummeling I, Thijs C, Stelma F, Huber M, van den Brandt PA, Dagnelie PC. Does a family history of atopy lead to different lifestyle choices? Allergy \& Clinical Immunology International 2005; World Allergy Congress: Munich, Germany June 26-July 1 2005. ISBN 0-88937-294-2 (abstract 17) [oral presentation].

Kummeling I, Stelma F, Bont de C, Thijs C, Huber M, Brandt van den PA. House dust in the homes of families with an anthroposophic lifestyle. Van Wijk RG et al. XXIII Congress of the European Academy of Allergology and Clinical Immunology: Amsterdam, the Netherlands 12-16 June 2004. ISBN 3-9808961-3-7 (abstract 125) [poster].

Kummeling I, Stelma F, Bont de C, Thijs C, Huber M, Brandt van den PA. House dust in the homes of families with an anthroposophic lifestyle. Werking en Bijwerking, 29ste WEON Symposium (10 en 11 juni 2004), Leiden: Leids Universitair Medisch Centrum, 2004: 154 (abstract), ISBN 90-801879-2-5 [poster].

Kummeling I. Secondary gain and therapy outcome. $28^{\text {th }}$ Annual Conference of the Dutch Psychiatry Association, Maastricht, the Netherlands 29-31 March 2000 [oral presentation].

Snijders BEP, Thijs C, Kummeling I, Penders J, van den Brandt PA. Breastfeeding and eczema in the KOALA birth cohort study. Eur J Epidemiol 2006; 21(suppl): 90 [poster].

Thijs C, Snijders BEP, Kummeling I, Jansen M, Huber M, van Ree R, Muller A, Rist $L$, van den Brandt PA. Low perinatal omega-3 fatty acid supply increases the risk of atopic eczema in the first year of life. Eur J Epidemiol 2006; 21(suppl): 92 [poster]. 